\title{
Argumentation profiles and the manipulation of common ground. The arguments of populist leaders on Twitter
}

\author{
Fabrizio Macagno
}

ArgLab - Instituto de Filosofia da Nova (IFILNOVA), Faculdade de Ciências Sociais e Humanas, Universidade Nova de Lisboa, Avenida de Berna 26, 1069-061 Lisbon, Portugal

\section{A R T I C L E I N F O}

\section{Article history:}

\section{Keywords:}

Pragmatics

Manipulation

Propaganda

Discourse analysis

Fallacies

Argumentation

\begin{abstract}
A B S T R A C T
The detection of hate speech and fake news in political discourse is at the same time a crucial necessity for democratic societies and a challenge for several areas of study. However, most of the studies have focused on what is explicitly stated: false article information, language expressing hatred, derogatory expressions. This paper argues that the explicit dimension of manipulation is only one - and the least problematic - of the risks of political discourse. The language of the unsaid is much more dangerous and incomparably more difficult to detect, hidden in different types of fallacies and inappropriate uses of emotive language. Through coding scheme developed by integrating instruments drawn from argumentation theory and pragmatics, a corpus of argumentative tweets published by 4 politicians (Matteo Salvini, Donald Trump, Jair Bolsonaro, and Joseph Biden) within 6 months from their taking office is analyzed, detecting the types of argument, the fallacies, and the uses and misuses of "emotive words." This coding results in the argumentation profiles of the speakers, which are compared statistically to show their different implicit strategies and deceptive tactics.
\end{abstract}

() 2022 Elsevier B.V. All rights reserved.

\section{Introduction}

The detection of hate speech and fake news in political discourse is at the same time a crucial necessity for democratic societies and a challenge for several areas of study - including linguistics, information technology, forensic sciences, and computing. The focus of these studies has been placed on what is explicitly stated: factual claims (Shu et al., 2017), slurs, or hate speech keywords (Davidson et al., 2017). However, the analysis of both hate speech and fake news faces a twofold problem. On the one hand, explicit derogatory language can be used for non-derogatory purposes (Bianchi, 2014) (such as in quotations or uses of slurs for cursing), and explicit factual claims can be used for purposes different from sharing information (irony, small talk, etc.). On the other hand, hatred and misleading and false information is conveyed often implicitly or through emotive uses of expressions that are not necessarily derogatory (Stevenson, 1944).

The use of slurs or hate words and manipulative lies are only one extreme of the deceptive tactics used in political discourse - indeed the most easily identifiable and thus easily condemnable ones (Blitz, 2018). These strategies are only the tip of the iceberg of the mechanisms of manipulation (Habgood-Coote, 2019), which include many sophistical strategies

E-mail addresses: fabrizio.macagno@fcsh.unl.pt, fabriziomacagno@hotmail.com. 
ranging from classical fallacies (Walton, 1987) to deceptive use of emotive language or redefinitions (Stanley, 2015, chap. 4; Walton, 2007). Many of these manipulative tactics are grounded on the implicit encoding of information (Lombardi Vallauri et al., 2020; Lombardi Vallauri and Masia, 2014), which makes their detection and assessment extremely difficult to perform and, more importantly, justify.

In this paper, the tools developed in argumentation theory and ancient dialectics are combined for outlining the argumentation profiles of the speakers, namely the strategic choices that their texts reveal in terms of types of arguments, deceptive tactics, and emotive language used. This theoretical approach to the analysis of strategic communication will be illustrated through the analysis of a corpus of argumentative tweets published by four politicians (Matteo Salvini, Donald Trump, Jair Bolsonaro, and Joe Biden) within 6 months from their taking office. Their argumentation profiles will be compared to bring to light the differences in terms of types of arguments and manipulatory strategies.

\section{Literature review}

The analysis of political discourse, and in particular political messages conveyed through the so-called "social media," is becoming an increasingly important topic (Allcott and Gentzkow, 2017). The suspension of famous political users from platforms such as Twitter ${ }^{1}$ is only the latest manifestation of a growing worry about the use of online messaging tools for spreading false information, hate messages, incitements to violence, and manipulative arguments.

The detection of "fake news" and "hate speech" (Blitz, 2018; Davidson et al., 2017; Habgood-Coote, 2019; Shu et al., 2017) has attracted most of the research in computational linguistics and information technology. However, this research has addressed only one limited manifestation of one aspect of manipulative speech, namely the explicit expression of false information (Allcott and Gentzkow, 2017, p. 213; Shu et al., 2017, p. 23) or hatred through the most visible and prototypical indicators, such as false titles, the relationship between title and body text (Shu et al., 2017), or the use of slurs (Davidson et al., 2017). The automatic detection of fake news is mostly based on the syntactical structure of the links and the headlines, contextual information (the network in which the news are spread), or some easily detectable textual indicators (Aldwairi and Alwahedi, 2018; Shu et al., 2017). However, one of the greatest vulnerabilities acknowledged in these automatic detection systems is the lack of biunivocal correspondence between expression and meaning (Pisarevskaya, 2017; Rubin et al., 2015; Rubin and Lukoianova, 2015), and more importantly the failure to take into account other dimensions and types of manipulation, analyzed in the rhetorical and dialectical tradition under the label of "fallacies" (even the ones that are essentially related to hate speech, see Habernal et al., 2018). In this picture, the traditional fallacies become extremely relevant for detecting the hidden side of manipulative discourse (Walton, 1987, 1999), namely the information taken for granted by the speakers and not shared by the audience (Lombardi Vallauri et al., 2020; Lombardi Vallauri and Masia, 2014; Macagno, 2018b).

The recent field of argument mining has addressed the same problem of "information ecology" (Shu et al., 2017, p. 22) from a different perspective. The manual and automatic annotation of speech for detecting arguments (Dusmanu et al., 2017; Mochales Palau and Moens, 2009, 2011), fallacies (Habernal et al., 2018), and rhetorical strategies (Duthie et al., 2016) has been developed by combining different fields such as linguistics, argumentation, and IT. One of the challenges of argument mining is to go beyond the simple detection of arguments or argument structures (Mizuta et al., 2006) and capture the types of argument used in a text, represented as argumentation schemes (Walton et al., 2008). From the first attempts to distinguish automatically the most frequent types of argument from a specific corpus of already annotated arguments (Wei Feng and Hirst, 2011), argument mining has developed partially automated systems able to identify some (few) schemes (Green, 2018; Lawrence and Reed, 2016). The detection of potentially problematic schemes (such as the ad hominem) can lead to an assessment of the discourse under analysis (Habernal et al., 2018).

All these trends of research focus on specific, partial dimensions of discourse. However, speakers, and more specifically political actors communicating publicly, use complex strategies for leading the interlocutor to accept a viewpoint. Arguments, intended as means for addressing an actual or potential difference (at the level of opinions, factual judgments, decisions, etc.) (Walton, 1990), are one of the most important tools, and characterize a fundamental aspect of the orator's style (Hansen and Walton, 2013). However, political discourse is defined also by other tactics that are normally labelled as "rhetorical," such as the use of emotions (Macagno and Walton, 2019), fallacies - intended as manipulation of the shared ground or the dialectical contexts (Walton, 1987) - or redefinitions (Schiappa, 2003).

The analysis and assessment of the argumentative structure of discourse faces two interrelated problems. First, the instruments available are theoretically grounded, but extremely difficult to implement. Argumentation schemes and fallacies are normally developed at a theoretical level and investigated through fictional examples. Empirical applications are rare and controversial, due to the lack of clear distinctions between the codes used for annotating the argumentative texts. The lack of reliability is even worse for manipulative tactics, which have been used only for descriptive (qualitative) analyses. Thus, quantitative studies have opted for narrowing the complex analytical frameworks to a very limited

1 https://blog.twitter.com/en_us/topics/company/2020/suspension. 
number of codes, and even creating annotations that capture isolated and not exhaustive aspects of text "persuasiveness" (Anand et al., 2011; Iyer and Sycara, 2019). Second, capturing one dimension of an argumentative text is not sufficient for evaluating its quality and detecting manipulative attempts. The continuum between reasonableness and manipulation can be analyzed only considering all the contextual and pragmatic dimensions of arguments that include the purpose of a move, its co-text and conversational context, and the common ground between the interlocutors (Walton, 1995, 2010). However, even qualitative studies have taken into account the different argumentative dimensions isolatedly (see for instance, Fairclough and Fairclough, 2012).

A promising attempt to provide an integrated view of argumentative texts and their assessment is the idea of argumentation profile. The initial proposal was advanced by Hansen and Walton (2013), who coded the arguments of distinct political candidates in the Ontario provincial elections using argumentation schemes (Walton, 1996), and quantified and compared the results, outlining the speakers' argument preferences. This approach was refined by Rapanta and Walton (2016), who addressed the differences in the production of arguments by students of different cultures, combining the analysis of the types of argument with the fallacies (paralogisms) committed. Both approaches had some fundamental limitation. In the first study, the authors did not consider the manipulative dimension of the speeches or the quality of the arguments. In the second work, both reasonable and weaker arguments were identified, but the types of fallacies coded corresponded only to uncritical uses of argumentation schemes (arguments not backed by the necessary evidence) (Walton, 2010). The classical fallacies, which can reveal deeper levels of manipulation, were not considered in this analysis.

These studies, however, outline a promising path that this paper intends to follow, building on the notion of argumentation profiles to capture the strategies that political leaders use to defend their ideas, and manipulate the public. To this purpose, the existing theoretical instruments (argumentation schemes and fallacies) will be developed as coding schemes, which will be validated for reliability. Tools from corpus linguistics will be used for analyzing the uses of emotive words, providing a multi-dimensional overview of a speaker's argumentative strategies. This profile can reveal the argumentative tactics, tendencies, and manipulations that characterize the discourse of political leaders, including the "populist" ones.

\section{Methodology}

An argumentation profile can be defined as the dialectical and rhetorical strategy that a speaker preferentially uses for defending his or her viewpoint or addressing a possible doubt. An argumentation profile can be determined considering two levels: the descriptive (consisting in the quantification of the different tactics used detectable without involving evaluative considerations), and the evaluative (consisting in the quantification of deceptive tactics) (Macagno, 2019; Rapanta and Walton, 2016). An argumentation profile is defined by the presence and the evaluation of arguments, classically defined as a reason producing belief regarding a matter that is in doubt (Boethius, De Topicis Differentiis, 1173D 22-23 - see Stump, 2004). The frequencies of types of arguments and fallacies capture the dialectical dimension of discourse, namely how a conclusion is supported by "logical" inferences based on accepted premises, and how this support can be manipulated. The rhetorical dimension is captured by the identification and frequency of emotive words and the corresponding emotions (Macagno, 2014), which can account for the emotional responses that a speaker seeks to arouse in an audience.

\subsection{Identification of types of arguments}

The core of the dialectical tradition (see for instance the classical "textbooks," Petrus Hispanus, Summulae Logicales Hispanus, 1990 - and Boethius, De Topicis Differentiis) was constitued by the distinction between different types of arguments, characterized by distinct types of "warrants" or inference rules. In argumentation theory, the types of arguments have been normally analyzed through the concept of argumentation scheme (Macagno and Walton, 2015; Walton et al., 2008), i.e. stereotypical patterns of argument, representing the most generic types of argument as a combination of one or more factual premises, a generalization (a warrant), and a conclusion. These schemes are associated to a set of critical questions, which represent the acceptability conditions of an argument (including the acceptability of the factual premises and the relationship between the latter and the warrant). Should these questions be not fulfilled, the argument cannot be considered as acceptable - or even reasonable - and cannot be used to provide a presumptive reason for accepting the conclusion.

In the literature, more than 60 schemes have been analyzed (Walton et al., 2008). However, most of them are combinations of some more basic schemes. In the Codebook for Argument Analysis (supplementary material), the argumentation schemes have been reduced to 13 types classified in five categories based on their pragmatic purpose (Macagno, 2015; Macagno and Walton, 2015), as shown in the following Table 1. 
Table 1

Argumentation schemes.

\begin{tabular}{|c|c|c|}
\hline Argument category & Argument & Example \\
\hline \multirow[t]{3}{*}{ 1. Practical arguments } & 1. Argument from consequences & $\begin{array}{l}\text { a. If the ban were announced with a one-week notice, the "bad" would } \\
\text { rush into our country during that week. A lot of bad "dudes" out there! }\end{array}$ \\
\hline & 2. Argument from practical reasoning & $\begin{array}{l}\text { b. For criminals, drug dealers, and murderers who bring war to our } \\
\text { home, there is only one solution: EXPULSION. }\end{array}$ \\
\hline & 3. Argument from commitment & $\begin{array}{l}\text { c. The crackdown on illegal criminals is merely the keeping of my } \\
\text { campaign promise. }\end{array}$ \\
\hline \multirow[t]{2}{*}{ 2. Evaluative arguments } & 4. Argument from values & $\begin{array}{l}\text { d. Peaceful protests are a hallmark of our democracy. Even if I don't } \\
\text { always agree, I recognize the rights of people to express their views. }\end{array}$ \\
\hline & 5. Victimization & $\begin{array}{l}\text { e. It is amazing how rude much of the media is to my very hard- } \\
\text { working representatives. Be nice, you will do much better! }\end{array}$ \\
\hline \multirow[t]{3}{*}{$\begin{array}{l}\text { 3. Source-based (external) } \\
\text { arguments }\end{array}$} & $\begin{array}{l}\text { 6. Argument from expert opinion/position to } \\
\text { know }\end{array}$ & $\begin{array}{l}\text { f. FoxNews from multiple sources: "There was electronic surveillance of } \\
\text { Trump, and people close to Trump. This is unprecedented." @FBI }\end{array}$ \\
\hline & 7. Argument from popular opinion & $\begin{array}{l}\text { g. Everyone acknowledges that the fundamentals of the Italian } \\
\text { economy are good and do not correspond to the present spread. }\end{array}$ \\
\hline & 8. Ad hominem argument & $\begin{array}{l}h . \text { The failing @nytimes does major FAKE NEWS China story saying “Mr. } \\
\text { Xi has not spoken to Mr. Trump since Nov.14." }\end{array}$ \\
\hline \multirow[t]{3}{*}{ 4. Discovery arguments } & 9. Argument from cause to effect & $\begin{array}{l}\text { i. If people do not work, they cannot invest in the FUTURE and cannot } \\
\text { have CHILDREN }\end{array}$ \\
\hline & 10. Argument from best explanation & $\begin{array}{l}\text { j. Watched protests yesterday but was under the impression that we } \\
\text { just had an election! Why didn't these people vote? }\end{array}$ \\
\hline & 11. Argument from sign & $\begin{array}{l}\text { k. Stock market hits new high with longest winning streak in decades. } \\
\text { Great level of confidence and optimism - even before tax plan rollout! }\end{array}$ \\
\hline \multirow[t]{2}{*}{ 5. Other } & 12. Argument from analogy/example & $\begin{array}{l}\text { l. Thanks to Trump's tax cuts, the American economy started to grow } \\
\text { again. Step by step, by introducing the flat tax also in Italy, the } \\
\text { production, the work, the consumes, and our country will start to grow } \\
\text { again. }\end{array}$ \\
\hline & 13. Argument from classification & $\begin{array}{l}\text { m. What we witnessed yesterday was not dissent - it was disorder. } \\
\text { They weren't protestors - they were rioters, insurrectionists, and } \\
\text { domestic terrorists. }\end{array}$ \\
\hline
\end{tabular}

The coding scheme, grounded on a theoretical framework shared in argumentation studies, has been assessed for reliability through interrater agreement between two independent coders. The coding of a sample size amounted to $20 \%$ of the argumentative tweets randomly selected within the corpus $(\mathrm{N}=530)$ (see Section 4) (Geisler and Swarts, 2019, chap. 5). The agreement between coders was substantial (Krippendorff's Alpha (categorial) $=0.791 ; \kappa=0.791 \mathrm{p}<.001$ ) (Carletta et al., 1997; Cohen, 1960; Krippendorff, 2011). ${ }^{2}$ The detailed interrater reliability results per category are given below (Table 2 ).

Table 2

Detailed interrater reliability results per category of argument.

\begin{tabular}{llll}
\hline & Percent agreement & Cohen's kappa \\
\hline Argument from consequences & $93.2 \%$ & 0.687 & 0.685 \\
Argument from practical reasoning & $93.8 \%$ & 0.651 & 0.651 \\
Argument from commitment & $97.7 \%$ & 0.694 & 0.87 \\
Argument from values & $96.2 \%$ & 0.757 & 0.694 \\
Ad hominem & $96.8 \%$ & 0.87 & 0.756 \\
Victimization & $98.7 \%$ & 0.887 & 0.87 \\
Argument from popular opinion & $96.4 \%$ & 0.844 \\
Argument from position to know & $98.5 \%$ & 0.556 \\
Argument from sign & $96.6 \%$ & 0.858 & 0.887 \\
Argument from best explanation & $97 \%$ & 0.889 & 0.844 \\
Argument from cause to effect & $99.1 \%$ & 0.946 \\
Argument from analogy & $99.8 \%$ & 0.867 \\
Argument from classification & $99.4 \%$ & 0.858 \\
\hline
\end{tabular}

\footnotetext{
2 Since the sample was randomly selected, the number of arguments per category varied according to the distribution of the corpus - in particular, the Argument from classification and the Argument from analogy had a lower distribution than the other arguments (rough 10). Previous attempts to test the reliability of argumentation schemes have resulted in contradictory outcomes - achieving results ranging from only fair (Dumani et al., 2021; Schneider et al., 2013) to satisfactory (Green, 2015; Visser et al., 2018). However, also these latter two studies present limitations, as the number of schemes was reduced to few specific categories, or the reliability testing procedure involved expert annotators and a very limited number of arguments coded. None of these studies has based the coding on a codebook.
} 
The agreement relative to the specific categories is almost perfect for 8 of the types of arguments, substantial for 4 of them, and fair to substantial for only one category (argument from sign).

\subsection{Evaluation of arguments}

Arguments can be evaluated along a continuum ranging from presumptively acceptable reasons to fallacies, namely discourses that only appear to be (good) arguments (Walton, 2010). An argument can be used manipulatively for pragmatic, logical, or epistemic reasons. From a pragmatic perspective, an argument is used in a context of dialogue to pursue a dialogical goal (Macagno, 2008, 2018a; Walton, 2004; Walton and Macagno, 2016). When an argument is used in a context to pursue a goal different from the one shared by the interlocutors (for example, attacking instead of finding a solution) or addresses a premise or viewpoint that is not the one under discussion, the argument is only an apparent reason (Walton, 1995, 2008). Moreover, an argument is grounded on what the interlocutors take for granted (Stalnaker, 1998) - their implicit, dark-side commitments. However, arguments can rely on premises that are unshared, shifting onto the other party the burden of disproving that they are part of the common ground (Macagno, 2018b; Macagno and Walton, 2014).

The twofold pragmatic dimension of arguments (context of dialogue and common ground) encompasses the logical dimension. In some contexts of dialogue (such as inquiry dialogues or some legal discussions), the conclusion needs to follow from the premises pursuant to deductive or inductive axioms strictly applied. In other contexts, arguments normally conceived as fallacies in logical textbooks (such as affirming the consequent or denying the antecedent) are admitted as reasonable. However, in both circumstances the reasoning needs to follow from warrants that are shared. When this type of manipulation of the common ground occurs, a fallacy is clearly committed.

While the pragmatic criterion distinguishes fallacies from potentially acceptable arguments, the epistemic dimension provides a criterion for recognizing arguments presumptively acceptable from the ones that cannot fulfil their burden of proof. This criterion is grounded on the dialectical principle that when a factual premise is potentially doubtful, it needs to be backed by adequate evidence (Kuhn, 2010, p. 817, 1993), which is commonly represented in argumentation theory through critical questions (Rapanta and Walton, 2016; Walton, 2010). The continuum between manipulative and presumptively acceptable arguments can be represented as follows (Fig. 1).

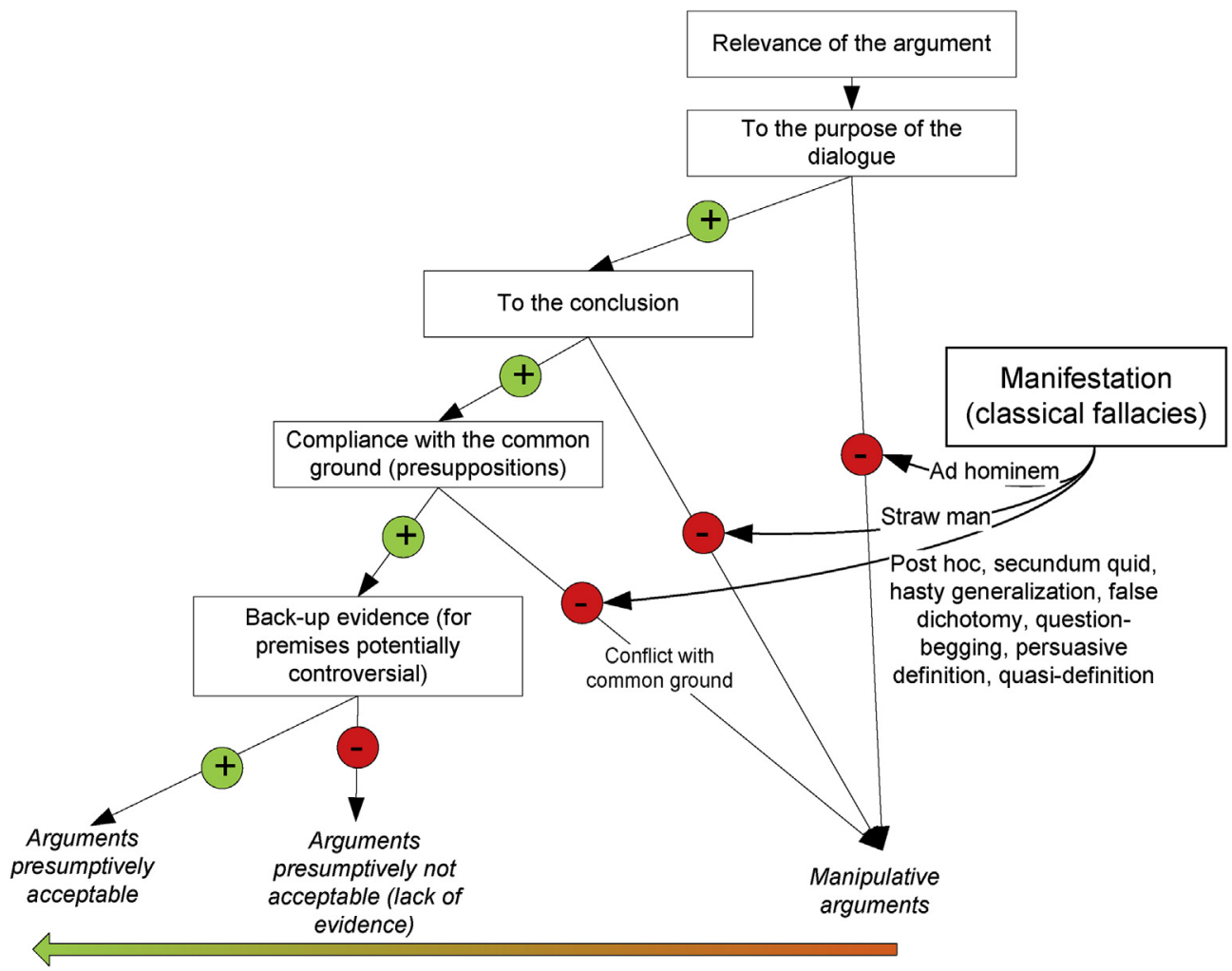

Fig. 1. Acceptability of arguments.

Fallacies are regarded as distinct from unbacked claims as the former represent an intentional manipulation of the distinct dimensions of an argument, i.e., the dialogical, the pragmatic, the logical, and the epistemic one (see the Codebook for Fallacy Analysis in the supplementary material), which ultimately correspond to distinct types of information taken for granted. The 
dialectical tradition (Aristotle, Sophistical Refutations - see Aristotle, 1991) and the modern argumentation theories list a number of fallacies that varies noticeably depending on the perspective adopted. As specified in detail in the aforementioned Codebook, the number of fallacies has been reduced to 9 types by combining a top-down approach, based on the dimensions of an argument, and with a bottom-up one, considering both the literature on the analysis of the quality of written arguments (Rapanta and Walton, 2016; Walton, 2007) and pilot studies (Macagno, 2019; Macagno and Gil, forthcoming).

The 9 types of fallacies mirror three different strategies, each manipulating the common ground in a specific way. The first strategy consists in attacking a viewpoint, which is implicitly distorted and taken for granted as corresponding to the original one. The second strategy includes two types of common ground manipulation. The first consists in taking for granted facts or evaluations through the use of loaded words (such as epithets in topical position, factives, etc.), false dichotomies (presupposing an unaccepted or unacceptable alternative) or ignoring qualifications (taking for granted premises without the necessary qualifications). The second involves taking for granted unacceptable warrants, unshared because unbacked by evidence or because they are simply wrong (post-hoc), or overgeneralized (hasty generalization; slippery slope). Finally, word uses can be manipulated by taking for granted an unshared definition (persuasive definition, see Macagno and Walton, 2014), or advancing or presupposing an unaccepted or unacceptable value judgment on the denotatum of the word. Table 3 summarizes the fallacies coded, illustrating them through examples from the corpus.

Table 3

Categories of manipulation and fallacies.

\begin{tabular}{|c|c|c|}
\hline Manipulation strategy & Fallacy & Example \\
\hline $\begin{array}{l}\text { 1. Topical irrelevance (attacking } \\
\text { or using a viewpoint that is } \\
\text { not the one advanced) }\end{array}$ & $\begin{array}{l}\text { 1. Straw man (a modification of the viewpoint or } \\
\text { a claim of the interlocutor for attacking it more } \\
\text { easily). }\end{array}$ & $\begin{array}{l}\text { a. Remember when the failing @nytimes } \\
\text { apologized to its subscribers, right after the } \\
\text { election, because their coverage was so wrong. } \\
\text { Now worse! (The Times sent an email to } \\
\text { subscribers saying they "underestimated the } \\
\text { business mogul's chance of winning"a) }\end{array}$ \\
\hline \multirow[t]{4}{*}{$\begin{array}{l}\text { 2. Presuppositions in conflict } \\
\text { with the common ground } \\
\text { 2.1. Facts }\end{array}$} & $\begin{array}{l}\text { 2. False dichotomy (contrary or alternative } \\
\text { options or states of affairs presupposed as } \\
\text { contradictory) }\end{array}$ & $\begin{array}{l}\text { b. Somebody with aptitude and conviction should } \\
\text { buy the FAKE NEWS and failing @nytimes and } \\
\text { either run it correctly or let it fold with dignity! }\end{array}$ \\
\hline & $\begin{array}{l}\text { 3. Ignoring qualifications (presupposing that the } \\
\text { premise includes the qualifications necessary } \\
\text { for drawing the conclusion) }\end{array}$ & $\begin{array}{l}\text { c. After being forced to apologize for its bad and } \\
\text { inaccurate coverage of me after winning the } \\
\text { election, the FAKE NEWS @nytimes is still lost! } \\
\text { (The Times has not apologized for their } \\
\text { coverage of Trump during the election but did } \\
\text { send an email to subscribers saying they } \\
\text { underestimated the business mogul's chance of } \\
\text { winning.) }\end{array}$ \\
\hline & $\begin{array}{l}\text { 4. Question begging epithets (the use of a word } \\
\text { or syntactical structures presuppose unproven } \\
\text { or unaccepted judgments or states of affairs) }\end{array}$ & $\begin{array}{l}\text { d. Don't let the fake media tell you that I have } \\
\text { changed my position (presupposing that there } \\
\text { are fake media.) }\end{array}$ \\
\hline & & $\begin{array}{l}\text { e. January 20th, 2017, will be remembered as the } \\
\text { day the people became the rulers of this nation } \\
\text { again (presupposing that people were not rules } \\
\text { before } 2017 \text {.) }\end{array}$ \\
\hline \multirow[t]{3}{*}{ 2.2. Specific warrants } & $\begin{array}{l}\text { 5. Post hoc ergo propter hoc (a temporal or } \\
\text { spatial coincidence or succession presupposed } \\
\text { as a cause-effect relation) }\end{array}$ & $\begin{array}{l}\text { f. The weak illegal immigration policies of the } \\
\text { Obama Admin. allowed bad MS } 13 \text { gangs to form } \\
\text { in cities across U.S. We are removing them fast!" } \\
\text { (Obama introduced immigration measures and } \\
\text { MS } 13 \text { gangs developed in the US; the two } \\
\text { things are only temporally related - not by } \\
\text { cause-effect) }\end{array}$ \\
\hline & $\begin{array}{l}\text { 6. Hasty generalization (from specific events to } \\
\text { a universal generalization) }\end{array}$ & $\begin{array}{l}\text { g. The Fake News media is officially out of control. } \\
\text { They will do or say anything in order to get } \\
\text { attention - never been a time like this! }\end{array}$ \\
\hline & $\begin{array}{l}\text { 7. Slippery Slope (consequences unwarranted } \\
\text { by the facts, too exaggerated) }\end{array}$ & $\begin{array}{l}\text { h. If the ban were announced with a one-week } \\
\text { notice, the "bad" would rush into our country } \\
\text { during that week. A lot of bad "dudes" out there! }\end{array}$ \\
\hline \multirow[t]{2}{*}{$\begin{array}{l}\text { 2.3. Word meaning or } \\
\text { connotation }\end{array}$} & $\begin{array}{l}\text { 8. Persuasive definition (implicit modification of } \\
\text { the meaning of words) }\end{array}$ & $\begin{array}{l}\text { i. If our healthcare plan is approved, you will see } \\
\text { real healthcare and premiums will start tumbling } \\
\text { down. Obamacare is in a death spiral! }\end{array}$ \\
\hline & $\begin{array}{l}\text { 9. Quasi-definition (unshared or not commonly } \\
\text { accepted inferences from the use of a word } \\
\text { taken for granted) }\end{array}$ & $\begin{array}{l}j . \text { How strange, in these latter months, these } \\
\text { foreign "big journals" have become all experts in } \\
\text { Italian politics. ("Big journals" - giornaloni in } \\
\text { Italian - is associated with a negative } \\
\text { connotation) } \\
k \text {. The "democrats" daddy's boys occupy a building } \\
\text { in Milan, shouting "Salvini is shit." But haven't } \\
\text { they anything better to do? }\end{array}$ \\
\hline
\end{tabular}

\footnotetext{
${ }^{a}$ Borchers, C. (2017). No, the New York Times did not apologize because its Trump coverage was 'so wrong'. The Washington Post, March 29, 2017 (retrieved from https://www.washingtonpost.com/news/the-fix/wp/2017/03/29/no-the-new-york-times-did-not-apologize-because-its-trump-coveragewas-so-wrong/on 4 September 2020).
} 
These fallacies have been used as coding categories, which are described and distinguished in the corresponding Codebook. This coding system has been validated by interrater agreement on the same randomly selected sample size as above $(\mathrm{N}=530)$. The agreement between coders was substantial (Krippendorff's Alpha (categorial) $=0.776 ; \kappa=0.776, \mathrm{p}<.001)$ (Krippendorff, 2011). The detailed interrater reliability results per category are given below (Table 4).

Table 4

Detailed interrater reliability results per category.

\begin{tabular}{llll}
\hline Fallacy & Percent agreement & Cohen's kappa & Krippendorff's alpha (nominal) \\
\hline No fallacy & $96.8 \%$ & 0.899 & 0.899 \\
Straw man & $97.9 \%$ & 0.871 & 0.871 \\
Question begging & $92 \%$ & 0.808 & 0.808 \\
False dilemma & $96.8 \%$ & 0.768 & 0.769 \\
Hasty generalization & $97.9 \%$ & 0.703 & 0.704 \\
Post hoc & $94.1 \%$ & 0.591 & 0.59 \\
Ignoring qualifications & $93 \%$ & 0.672 & 0.672 \\
Slippery slope & $98.4 \%$ & 0.849 & 0.849 \\
Persuasive definition & $99.5 \%$ & 0.906 & 0.907 \\
Quasi-definition & $97.9 \%$ & 0.324 & 0.324 \\
\hline
\end{tabular}

\subsection{Emotive words and the use of emotions}

A common strategy in political discourse is the use of the so-called "loaded language," namely the use of words that can trigger automatic value judgments and affect the audience's decision-making by arousing emotions (Macagno, 2014; Walton, 1992). For example, by labeling a politician as "weak" or "corrupt," the speaker is not merely describing an individual, but inviting a value judgment that can result in an emotion (contempt or anger) and suggest an implicit practical conclusion (you should not vote for him/her). These "emotive words" (Stevenson, 1944) are in fact uses of words carrying positive or negative “connotations" (or commonplaces Jeshion, 2013; Macagno and Walton, 2014) to suggest a value judgment necessary for specific emotions to be triggered.

The use of emotive words is not an indicator of fallaciousness. However, when their use depends on a fallacy, they become manipulative tactics. Moreover, the frequency of the emotive words used by a speaker can reveal the emotive strategy - for example, the types of emotions that he or she seeks to trigger. The frequency of the use of pejoratives or derogatory words, eliciting emotions such as contempt, fear, or anger, can be analyzed in conjunction with the types of argument used in the same moves in which the emotive word occurs (for example, ad hominem), and the fallacies therein committed, unveiling specific strategies of attack or for diverting attention.

While the literature in pragmatics has developed several theories on the nature of the derogatory meaning of slurs and pejoratives (Hedger, 2013; Hom, 2008), its manipulative uses and most importantly the ways to detect them has been neglected. To this purpose, the fallacies aimed at distorting the common ground related to the word meaning (persuasive definitions and quasi-definitions) and the fallacy of question begging (presupposing a state of affairs that has not been proved nor accepted) (Bentham, 1824; Macagno and Walton, 2014) can be used as instruments for detecting the manipulative uses of emotive words. In particular, persuasive definitions are commonly detected by "dissociation" markers (Halldén, 1960; Van Rees, 2009), i.e., indicators of the distinction between the new meaning taken as granted (classified as the "real" or "true" meaning) and the existing one (presupposed as the "false" one). Quasi-definitions involve the use of a word to support an evaluative conclusion that would not normally follow from it ("These so-called 'big professors' keep attacking me. Poor them"). In this case, the speaker is taking for granted new premises that are presented as stereotypes (commonly accepted propositions) (Jeshion, 2013).

The frequency of the emotive words was calculated in this study considering the keywords, namely the words that, in corpus linguistics, are defined as the most frequent in a given corpus vis-à-vis the reference corpus (namely the one reflecting the common usage of a given language) (Kilgarriff, 2012). The processing tool used was Sketch Engine.7 (Kilgarriff et al., 2014), which calculates the ratio of the normalized frequencies of a lemma in the target corpus and the reference corpus (called "keywordness," a measure of the representativeness of a keyword). Among the most representative keywords, the ones used argumentatively for supporting value judgments and decisions (such as pejoratives) have been selected; this predisposition is the outcome of the associations of the word with related concepts, provided by the processing tool (for the complete description of this method, see Bourse, 2018). Two distinct tests were used to this purpose: 1) the argumentative function, namely whether a word is an essential element in the justification of an explicit or implicit value judgment or decision; and 2) the absence of other reasons in support of such a value judgment or decision. Thus, when the practical or evaluative conclusion is only backed by the use of a word, the latter can be classified as emotive.

The assessment of the use of emotive words involves distinct steps. First, the term under analysis is assessed considering the presuppositions that can be triggered by its use (in case it is a presupposition trigger) or syntactic position (Abrusán, 2010, 2011; Atlas, 1991; Levinson, 1983). In case the state of affairs or judgment presupposed is not part of the common ground (for example, in conflict with other information published on reliable sources or even the audience's comments), the possibility of 
a manipulative use of the emotive word can arise. The three types of possible fallacies can result from the deceitful use of an emotive word, namely persuasive definition, question begging, and quasi-definition. To detect them, specific tests are used.

First, the word use by the speaker is compared with the dictionary definitions thereof. In case there is a discrepancy, the conditions for the classification of the word use as a persuasive definition are evaluated (Macagno and Walton, 2010, 2014), which are the following: 1) the word meaning is different from common use, 2) an explicit redefinition is not given, and 3) the word denotation is in part commonly accepted. For example, if the speaker refers to a policy as the "true healthcare," he is referring to a state of affairs that is commonly accepted (a policy concerning healthcare). However, the meaning of "healthcare" is implicitly redefined, associating the "true" meaning thereof only to practices corresponding specifically to the policy referred to, without providing evidence. In case the word meaning is commonly accepted, but it is used to refer to a state of affairs not accepted and presupposed as such, the case can be classified as a question begging epithet. For example, when Trump claimed, "Why should I go to that cemetery [an American Cemetery in France with more than 1800 US marines buried]? It's filled with losers", 3 he presupposed that at least some of the individuals buried were "losers" (or that the victims of WW2 are "losers"). Considering the scandal that followed, he was using this epithet to take for granted a qualification that was not neither accepted nor proven.

In case the aforementioned tests are negative, the possibility of a quasi-definition is considered. To determine this fallacy, the probative function of the word and the evaluative inference that it is used to trigger are analyzed. If the type of evaluative conclusion is not commonly supported by the word use (and the evaluative inference or stereotype is not part of the common ground), the word can be considered as quasi-defined. To prove a case of quasi-definition, the best dictionary examples of the word use in the reference corpus of Sketch Engine (automatically selected) are considered and their collocations analyzed. If the word is normally used to suggest conclusions incompatible with or even with opposite evaluative polarity respect to the one suggested in the text, the word use is classified as a quasi-definition.

\section{Corpus}

This method for analyzing argumentation profiles is illustrated through a corpus of political tweets, freely available on the internet and not involving privacy issues. The choice of this platform is related to its relationship with the news world (Conway et al., 2013; Ott, 2017). The twofold interaction (disseminating and feeding in information) with the journalistic world turned Twitter into an extremely powerful, but risky, political tool (Lee and Queal, 2016; Mendes, 2016).

The corpus was built considering the institutional Twitter profiles of three political leaders commonly defined as "populists" ${ }^{4}$ both at the level of the minimal definitional criteria of this term (antagonistic depiction of the polity, moral interpretation of political actors, idealized construction of society, absence of limits to popular sovereignty, and reliance on charismatic leadership, see Olivas Osuna, 2021), and the most generic one, i.e., a strategic emphasis and echoing of the views, fears, and anger of the "common man" (Brunello, 2021). The leaders chosen were the Italian former minister for Internal Affairs, Matteo Salvini (Mcginnis, 2021), the US president, Donald Trump (Brunello, 2021), and the Brazilian president, Jair Messias Bolsonaro (Azevedo and Robertson, 2021). This choice is based on both the evidence from the literature and the matching of their behavior with the definitional features referred above. All the three charismatic leaders 1 ) rely on a Manichean view of politics, in which the appeal to the people is framed in opposition to both 2) minorities (immigrants, foreigners) and 3) "the establishment" and the values defended by it (Herkman, 2017), and 4) defend policy solutions based on "common sense," often in conflict with expert opinions. The online communication of these politicians has been compared with the tweets of a leader, Joe Biden, whose political proposals at the same time focused on the people's rights and welfare, without promoting a position against an alleged "elite" or the minorities. Indeed, Biden has been normally depicted as a representative of the "establishment" against which the populist rhetoric is directed. ${ }^{5}$

The tweets of the three politicians have been collected for 180 days starting from the date on which they took office providing a representative corpus of their official communications. The corpus has been constructed automatically through the program Chorus (Brooker et al., 2016), a software for the collection and analysis of tweets that visualizes the first 100 characters (out of 280) of each message. This initial corpus has been screened initially to identify only the argumentative tweets, based on the following four exclusionary criteria:

1. Formal criterion 1. Exclusion of the tweets consisting of links to articles or contents authored by third parties as not advancing an argument.

2. Formal criterion 2. Exclusion of the retweets or tweets substantially identical to previous ones, as not aimed at providing an argument, but rather reinforcing or reminding.

\footnotetext{
3 Goldberg, J. (2020). Trump: Americans Who Died in War Are 'Losers' and 'Suckers'. The Atlantic, 3 September 2020 (retrieved from https://www. theatlantic.com/politics/archive/2020/09/trump-americans-who-died-at-war-are-losers-and-suckers/615997/on 5 September 2020). A similar questionbegging example in the same article: “.'We're not going to support that loser's funeral."

4 Rachman, G. (2018). Sex, violence, and the rise of populism. The Financial Times, 1 October 2018 (retrieved from https://www.ft.com/content/dfcfc632c552-11e8-8670-c5353379f7c2 on 5 September 2020).

5 Sher, B. (2017). Joe Biden's Platform for 2020: Anti-Populism. Politico, 23 September 2017. Retrieved from https://www.politico.com/magazine/story/ 2017/09/23/joe-biden-president-2020-anti-populism-215638/on 9 December 2021.
} 
3. Pragmatic criterion. Exclusion of the tweets that only express feelings, emotions, or evaluations, or only information, as not presumptively argumentative (validated in Macagno and Bigi, 2020, 2017).

4. Structural criterion. Exclusion of the tweets that cannot mirror the basic argumentative structure (either complete or partial) outlined by Toulmin (see Fig. 1 above), as not presumptively argumentative (Dusmanu et al., 2017)

Further to the exclusionary criteria, the following inclusionary criterion has been used to assess the tweets not previously excluded:

5. Pragmatic-structural criterion. Inclusion of the tweets that: a) provide factual (verifiable) information (including also reported speech) or opinion to support a conclusion or backed by reasons; b) express conclusions as rhetorical questions (Bosc et al., 2016).

The use of these five criteria led to an argumentative comparative corpus consisting of $n=2657$ argumentative tweets (Fig. 2).

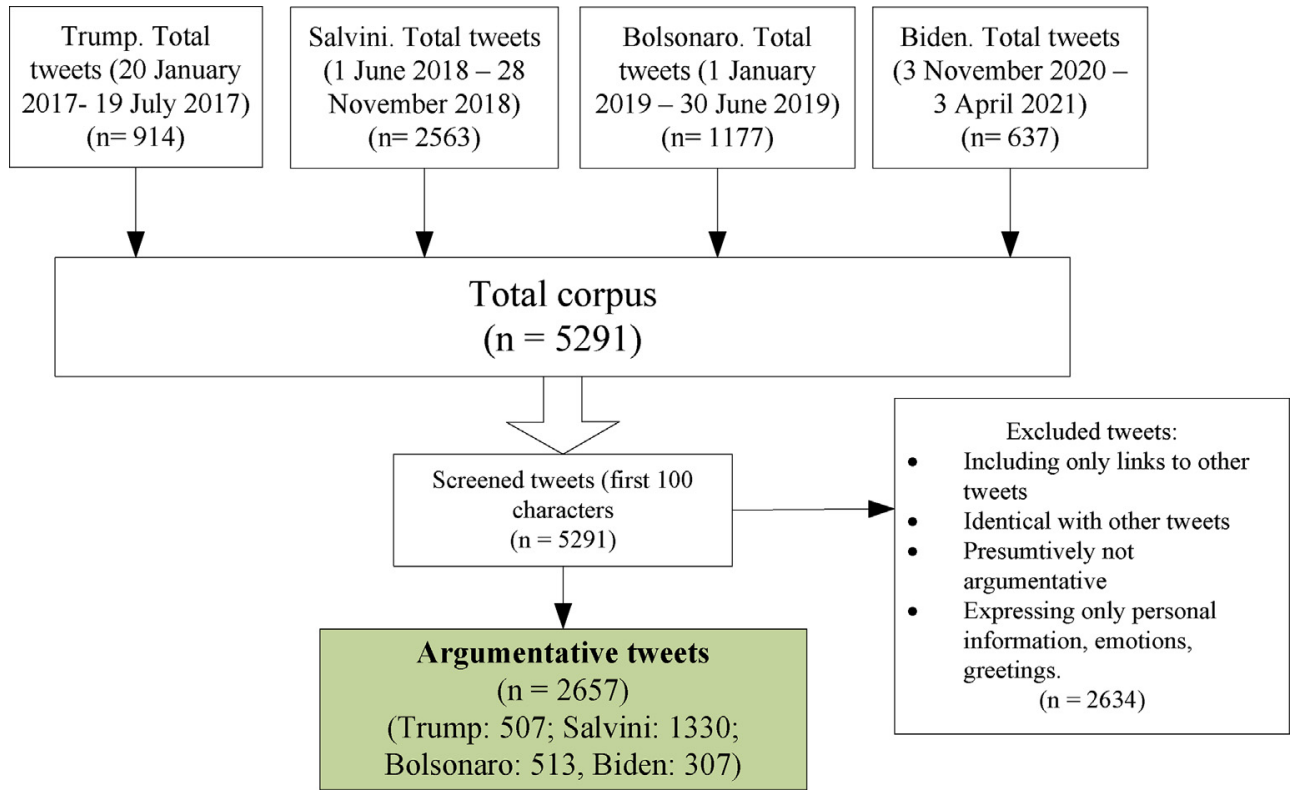

Fig. 2. Corpus construction.

As this corpus outline shows, the politicians show noticeable differences in the frequency of their tweets: Salvini posted more than 14 tweets per day, more than the double of both Bolsonaro (6.5) and Trump (5), and four times more than Biden (3.5). The argumentative corpus has been then analyzed considering the verbal dimension, taking into account multimedia information (links, images, videos, or comments) only for disambiguating the message or checking the correctness of the claims or presupposed contents for the evaluation purposes. All the tweets have been factchecked by comparing the information provided or taken for granted with original quotes, newspaper reports, legal documents, and regulations.

\section{Results}

\subsection{Types of argument}

The tweets have been analyzed by identifying their main argument (defending the conclusion that the tweet aims at putting forward) and the most important of the ancillary or secondary arguments, if any. For example, an argument from practical reasoning is often combined with an argument that defends a specific classification based on values (Macagno and Walton, 2018). In this case, the main argument would be the practical reasoning, and the ancillary one the argument from values. Table 5 outlines the argumentation profiles of the three politicians. 
Table 5

Types of argument.

\begin{tabular}{|c|c|c|c|c|c|c|c|c|c|c|c|c|c|c|}
\hline & \multicolumn{13}{|l|}{ Arguments } & \multirow[t]{2}{*}{ Total } \\
\hline & $\begin{array}{l}\text { Ad } \\
\text { hominem }\end{array}$ & Victimization & $\begin{array}{l}\text { Practical } \\
\text { reasoning }\end{array}$ & Consequences & Values & Commitment & Sign & $\begin{array}{l}\text { Popular } \\
\text { opinion }\end{array}$ & Sources & $\begin{array}{l}\text { Cause- } \\
\text { effect }\end{array}$ & $\begin{array}{l}\text { Best } \\
\text { explanation }\end{array}$ & Analogy & Classification & \\
\hline $\begin{array}{l}\text { BIDEN } \\
\quad \text { (baseline) } \\
\text { count }\end{array}$ & 8 & 0 & 138 & 53 & 61 & 24 & 51 & 5 & 15 & 19 & 0 & 1 & 22 & 397 \\
\hline $\begin{array}{l}\% \text { within } \\
\text { SPEAKER }\end{array}$ & $2.0 \%$ & $0 \%$ & $34.8 \%$ & $13.4 \%$ & $15.4 \%$ & $6.0 \%$ & $12.8 \%$ & $1.3 \%$ & $3.8 \%$ & $4.8 \%$ & $0 \%$ & $0.3 \%$ & $5.5 \%$ & $100.0 \%$ \\
\hline SALVINI count & 463 & 163 & 208 & 247 & 344 & 115 & 147 & 60 & 37 & 29 & 12 & 10 & 3 & 1838 \\
\hline $\begin{array}{l}\text { \% within } \\
\text { SPEAKER }\end{array}$ & $25.2 \%$ & $8.9 \%$ & $11.3 \%$ & $13.4 \%$ & $18.7 \%$ & $6.3 \%$ & $8.0 \%$ & $3.3 \%$ & $2.0 \%$ & $1.6 \%$ & $0.7 \%$ & $0.5 \%$ & $0.2 \%$ & $100.0 \%$ \\
\hline TRUMP count & 151 & 27 & 99 & 132 & 59 & 28 & 68 & 13 & 38 & 7 & 27 & 11 & 0 & 660 \\
\hline $\begin{array}{l}\% \text { within } \\
\text { SPEAKER }\end{array}$ & $22.9 \%$ & $4.1 \%$ & $15.0 \%$ & $20.0 \%$ & $8.9 \%$ & $4.2 \%$ & $10.3 \%$ & $2.0 \%$ & $5.8 \%$ & $1.1 \%$ & $4.1 \%$ & $1.7 \%$ & $0 \%$ & $100.0 \%$ \\
\hline $\begin{array}{l}\text { BOLSONARO } \\
\text { count }\end{array}$ & 111 & 19 & 144 & 181 & 103 & 52 & 68 & 16 & 20 & 7 & 6 & 7 & 0 & 724 \\
\hline $\begin{array}{l}\text { \% within } \\
\text { SPEAKER }\end{array}$ & $15.3 \%$ & $2.6 \%$ & $17.7 \%$ & $25.8 \%$ & $14.2 \%$ & $7.2 \%$ & $9.4 \%$ & $2.2 \%$ & $2.8 \%$ & $1.0 \%$ & $0.8 \%$ & $1.0 \%$ & $0 \%$ & $100.0 \%$ \\
\hline
\end{tabular}

The figures and the proportions indicated in the table above show some significant trends. First, the type of argument more used by Salvini (more than $25 \%$ ), and Trump (22.9\%) is the ad hominem, while for Bolsonaro this argument is only the third more frequent argument, after the practical ones (15.3\%). The personal attacks of the three populist leaders are significantly much more frequent than the ones used by Biden (amounting to $2 \%)\left(\chi^{2}(3)=123.71\right.$, p $<.001$ ). Salvini uses ad hominem arguments much more than Trump and Bolsonaro $\left(\chi^{2}(2)=53.255, \mathrm{p}<.001\right)$. These figures become even more significant if we consider the indirect version of the ad hominem, namely victimization. When pursuing this strategy, instead of attacking a specific individual, the speaker claims to be the victim of the abuses of an "evil" third party. This strategy is used much more more by Salvini (victimization is his 5th most frequent argument) than the other populist leaders $\left(\chi^{2}(2)=41.24\right.$, $\mathrm{p}<.001$ ), while it is not present in Biden's tweets.

Second, there is a significant difference in the uses of practical arguments (practical reasoning and from consequences) among the three leaders $\left(\chi^{2}(2)=91.29, \mathrm{p}<.001\right)$ : they represent only $24.8 \%$ of Salvini's arguments, compared to $35 \%$ in Trump's, $43.5 \%$ in Bolsonaro's (they correspond to more than $48 \%$ of Biden's arguments). Compared with the other leaders, Salvini's use of argument from values is significantly more frequent (it is the second most used type of argument, amounting to $18.7 \%$ in his corpus) $\left(\chi^{2}(3)=36.7, \mathrm{p}<.001\right)$. The other leaders also use this argument (Biden's arguments from values are $15.4 \%$ of the total), but in a much smaller proportion than the practical arguments.

The last significant difference in the rhetoric of the four leaders concerns the uses of sources, whose overall frequency in this corpus is low. Salvini tends to back his argument through appeals to authorities or individuals in position to know significantly less than the other leaders $\left(\chi^{2}(3)=24.4, \mathrm{p}<.001\right)$ : $2 \%$ vis-à-vis $5.8 \%$ (Bolsonaro), 3.8\% (Biden), and $2.8 \%$ (Trump). This trend is reversed when we consider the use of arguments from popular opinion. While they are almost absent in Biden's messages, they amount to $3.3 \%$ in Salvini's, significantly more than in all other leaders $\left(\chi^{2}(3)=24, p<.001\right)$.

The frequency of the types of argument needs to be combined to their quality in order to provide a complete picture of the speaker.

\subsection{Quality of the arguments}

The quality of the aforementioned arguments was assessed considering the criteria mentioned in Section 3.2 and summarized in Fig. 2 above. The overview of the quality of the argumentative tweets is reported below (Table 6).

Table 6

Quality of argument.

\begin{tabular}{|c|c|c|c|c|}
\hline & \multicolumn{3}{|l|}{ Quality of arguments } & \multirow[t]{2}{*}{ Total } \\
\hline & Tweets associated with at least one fallacy & $\begin{array}{l}\text { Non-fallacious tweets failing } \\
\text { to provide the necessary evidence }\end{array}$ & $\begin{array}{l}\text { Non-fallacious tweets and not failing } \\
\text { to provide the necessary evidence }\end{array}$ & \\
\hline BIDEN (baseline) count & 73 & 6 & 318 & 397 \\
\hline \% within SPEAKER & $18.9 \%$ & $1.9 \%$ & $79.2 \%$ & $100.0 \%$ \\
\hline SALVINI count & 1159 & 17 & 154 & 1838 \\
\hline \% within SPEAKER & $87.1 \%$ & $1.3 \%$ & $11.6 \%$ & $100.0 \%$ \\
\hline TRUMP count & 391 & 14 & 102 & 660 \\
\hline \% within SPEAKER & $77.1 \%$ & $2.8 \%$ & $20.1 \%$ & $100.0 \%$ \\
\hline BOLSONARO count & 311 & 9 & 193 & 724 \\
\hline \% within SPEAKER & $60.6 \%$ & $1.7 \%$ & $37.6 \%$ & $100.0 \%$ \\
\hline
\end{tabular}


Considering the number of fallacious tweets committed, the argumentation of the three populist leaders is significantly different from Biden's $\left(\chi^{2}(3)=533.3, p<.001\right.$; large effect size: $\left.\varphi=0.449\right)$. The significance of these differences is represented in Fig. 3 below.

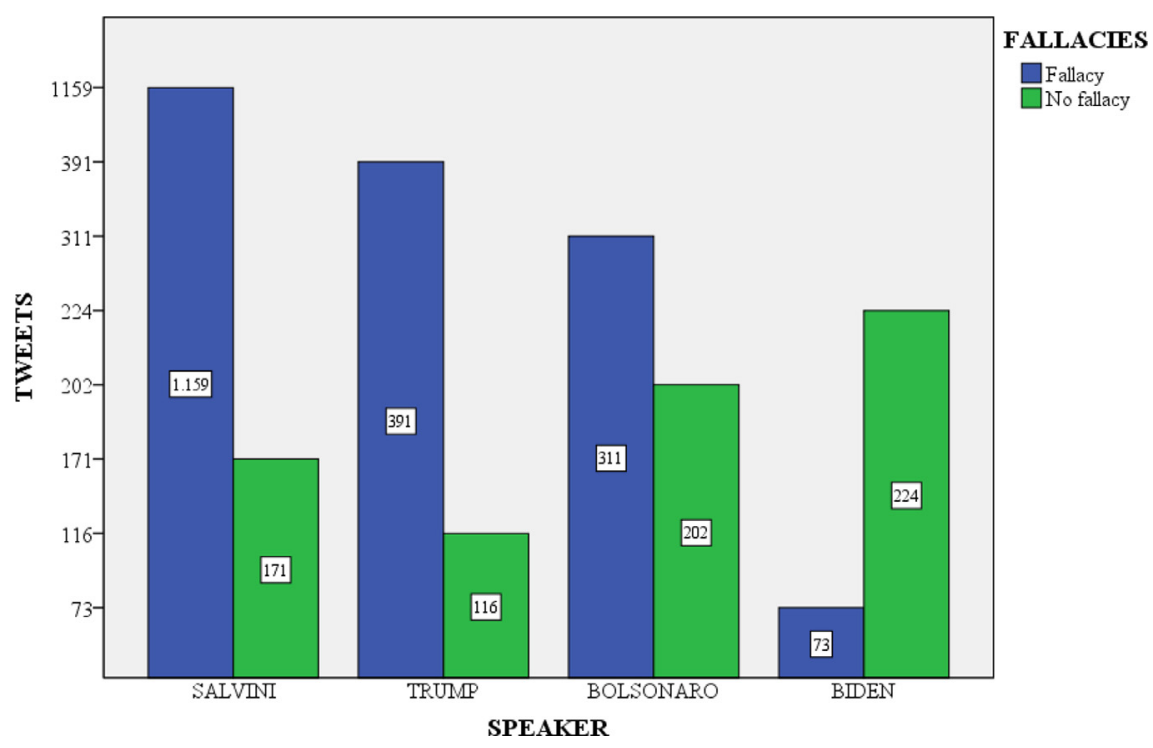

Fig. 3. Differences among leaders - Fallacious tweets.

The following table shows the distribution of the fallacies per tweet, namely the possibility of finding a specific fallacy in a tweet - considering that a tweet can include more than one fallacy (Table 7).

Table 7

Types of fallacies committed.

\begin{tabular}{|c|c|c|c|c|c|c|c|c|c|c|}
\hline & \multicolumn{9}{|c|}{ Arguments } & \multirow[t]{2}{*}{ Tot. } \\
\hline & $\begin{array}{l}\text { Straw } \\
\text { man }\end{array}$ & $\begin{array}{l}\text { False } \\
\text { dilemma }\end{array}$ & $\begin{array}{l}\text { Ignoring } \\
\text { qualifications }\end{array}$ & $\begin{array}{l}\text { Hasty } \\
\text { generalization }\end{array}$ & $\begin{array}{l}\text { Post } \\
\text { hoc }\end{array}$ & $\begin{array}{l}\text { Question- } \\
\text { begging }\end{array}$ & $\begin{array}{l}\text { Persuasive } \\
\text { definition }\end{array}$ & $\begin{array}{l}\text { Quasi- } \\
\text { definition }\end{array}$ & $\begin{array}{l}\text { Slippery } \\
\text { slope }\end{array}$ & \\
\hline $\begin{array}{l}\text { BIDEN (baseline) } \\
\text { count }\end{array}$ & 1 & 10 & 17 & 7 & 0 & 18 & 5 & 1 & 3 & 62 \\
\hline \% within SPEAKER & $0.3 \%$ & $3.3 \%$ & $5.5 \%$ & $2.3 \%$ & $0 \%$ & $5.9 \%$ & $1.6 \%$ & $0.3 \%$ & $1 \%$ & $20.2 \%$ \\
\hline SALVINI count & 187 & 125 & 281 & 128 & 211 & 479 & 152 & 122 & 18 & 1703 \\
\hline \% within SPEAKER & $14.1 \%$ & $9.4 \%$ & $21.1 \%$ & $9.6 \%$ & $15.9 \%$ & $36 \%$ & $11.4 \%$ & $9.2 \%$ & $1.4 \%$ & $128 \%$ \\
\hline TRUMP count & 28 & 27 & 88 & 31 & 94 & 237 & 11 & 8 & 14 & 538 \\
\hline \% within SPEAKER & $5.5 \%$ & $5.3 \%$ & $17.4 \%$ & $6.1 \%$ & $18.5 \%$ & $46.7 \%$ & $2.2 \%$ & $1.6 \%$ & $2.8 \%$ & $106.1 \%$ \\
\hline BOLSONARO count & 6 & 30 & 89 & 48 & 60 & 142 & 20 & 14 & 13 & 422 \\
\hline \% within SPEAKER & $1.2 \%$ & $5.8 \%$ & $17.3 \%$ & $9.4 \%$ & $13.5 \%$ & $27.7 \%$ & $3.7 \%$ & $2.7 \%$ & $2.5 \%$ & $82.1 \%$ \\
\hline
\end{tabular}

The distribution of the fallacies can provide some insights on the reasonableness of the strategies used by the leaders compared. The frequency of the fallacies committed clearly distinguishes Biden from the other three leaders. However, each populist leader has a specific manipulative style. Salvini uses significantly more than the other two leaders straw man fallacies (see Macagno and Walton, 2017) $\left(\chi^{2}(2)=85.63, \mathrm{p}<.001\right.$, almost medium effect size $\varphi=0.189$ ), persuasive definitions $\left(\chi^{2}(2)=59.04, \mathrm{p}<.001\right)$, and quasi-definitions $\left(\chi^{2}(2)=49.99, \mathrm{p}<.001\right)$. In contrast, Trump uses significantly more than the other populist leaders question begging epithets $\left(\chi^{2}(2)=40.31, \mathrm{p}<.001\right)$.

The three different manipulative styles emerge also from the association between most used types of arguments and fallacies. While Trump and Bolsonaro tend to attack the interlocutor fallaciously by using question begging epithets in most of their direct or circumstantial ad hominem or victimization arguments (75.5\% and 63\% of the attacks), Salvini uses different manipulative strategies (56\% of the attacks involve straw man, persuasive definitions, and quasi-definitions; the remaining involve question-begging epithets). While Trump and Bolsonaro use arguments from values (fallacious in more than $60 \%$ of the cases) mostly in association with question-begging epithets, Salvini combines them with persuasive definitions and quasi-definitions in almost $30 \%$ of the fallacious cases (which represent $87 \%$ of the total). 


\subsection{Emotive words and triggered emotions}

The impact of emotive words in populist leaders' tweets is extremely high. Salvini uses on average 1.3 emotive words per tweet; overall, $76 \%$ of the tweets include at least one emotive word. In $63 \%$ of the cases, emotive words are manipulated through the linguistic strategies (question-begging epithet, persuasive definition, or quasi-definition). Trump's use of emotive words is similar: 1.1 emotive word per tweet, $70 \%$ of the tweets present emotive words, in $46 \%$ of the cases fallaciously used. Bolsonaro uses this strategy less than the other two leaders ( 0.8 emotive word per tweet): $52 \%$ of the tweets include emotive words, which are in $60 \%$ of the cases associated with fallacies aimed at manipulating the meaning of a word or its use. Also considering this dimension, the profile of the three leaders is different from Biden's (emotive words occur in only $20 \%$ of his tweets, amounting to 0.27 per tweet).

In Salvini's corpus, the most frequent emotive word used is "buonsenso" ("common sense") with 36 occurrences (all used to support an evaluative conclusion), with a frequency significantly different from the reference corpus. All the occurrences are associated with fallacies, mostly question-begging epithets (78\%) and persuasive definitions (20\%). "Pacchia" (used mostly with the meaning "the party is over!") and "buonista" ("do-gooding") are other two crucial emotive words highly frequent and associated with question-begging epithets (51\% and 72\% respectively) and persuasive definitions. The keyword "perbene" ("decent" or "respectable") is instead associated in $60 \%$ of its occurrences with false dilemmas. A peculiar use is related to the word "NGO," an acronym normally not bearing any specific connotation, but appearing very frequently in the corpus and in $40 \%$ of the cases quasi-defined through associations with three phrases: "human trafficking," "people smugglers," or "business (of immigration)." "Respect" is another unusually frequent keyword used supporting Salvini's arguments - usually ad hominem or victimization arguments (60\%). The last interesting linguistic use is related to the words "Europe" or "European," (recurring in $12 \%$ of the posts), whose association with linguistic fallacies (question-begging, quasi-definition, and persuasivedefinition) is extremely high (60\%). In 60\% of the cases, these two lemmas co-occur with negative emotive words, such as "lessons," "bureaucrats," "speculators," "absurdity;" their most frequent collocations are "to change" and "to work" (used in the sense of "let work")

Trump's linguistic choices in terms of keywords appears almost monothematic. The most frequently used word (appearing in $16 \%$ of his argumentative tweets) is "fake," which in $85 \%$ of the cases appears as a qualification of "news." In $80 \%$ of the cases, the use of "fake" is associated with a question-begging fallacy, followed by the ignoring qualifications. The recurrent accusation of falsity against the press is manifested also by the use of epithets, words or phrases aimed at negatively qualifying the media (such as "real media," “false," "hoax", “scam," "lie," "witch hunt," “real story," “dishonest," "slanted," and even "garbage journalism”) (11\% of the tweets include such words associated with either the news or the media). Again, all these instances are fallacious (in $76 \%$ of the cases, the question-begging fallacy is committed). The word frequency reveals a strategy focused on the negative depiction of the opposing party or policies - referred to as the "Obamacare" or "Democrats," both scoring in the top 5 keywords and 10 more frequent words. The last unusually frequent word is "healthcare," which in $44 \%$ of the cases is associated with linguistic fallacies (mostly question-begging epithets).

Bolsonaro's use of emotive words shows a very high frequency of the phrase "fake news" (16 instances, much higher than in the reference corpus). However, considering related concepts (attributed without evidence) of "lies," "manipulation," "distortion" (attributed to news or the press) and the persuasively defined uses of "journalist," "press," and "scientific studies," the semantic area of attacks to the press amounts to the $6 \%$ of the tweets. The frequency of the words "population" and "citizen" is much higher than in the reference corpus. Considering their fallacious use, the semantic area of the "Brazilian population" involves $6 \%$ of the fallacious tweets - mostly hasty generalizations and ignoring qualifications. The phrase "good citizen" occurs 7 times associated to fallacies of false dilemma or persuasive definition. The other crucial keywords are "previdência" (social security) (48 occurrences) and "segurança" (security) (42 occurrences), which outline his politics. Another trend of his rhetoric emerges from the unusually frequent use of "corruption" (in 35\% of the cases fallaciously used to attack the previous government) and the phrase "previous governments." Finally, the unusual high frequency of "confidence" (fallacious in $75 \%$ of its uses) reveals another rhetorical strategy, attributing to the new government the (mostly unsupported by evidence) increase of world confidence in Brazil.

The last dimension of our analysis is the frequency and the distribution of the emotions, which are significantly associated with the presence of emotive words $\left(\chi^{2}(1)=283, \mathrm{p}<.01\right.$ ) (Table 8 ).

Table 8

Types of emotions triggered.

\begin{tabular}{|c|c|c|c|c|c|c|c|c|}
\hline \multirow[t]{2}{*}{ Types of emotion } & \multicolumn{2}{|c|}{ Salvini } & \multicolumn{2}{|c|}{ Trump } & \multicolumn{2}{|c|}{ Bolsonaro } & \multicolumn{2}{|c|}{ Biden } \\
\hline & No. & Freq. & No. & Freq. & No. & Freq. & No. & Freq. \\
\hline Admiration (gratitude) & 5 & $0.8 \%$ & 19 & $3.5 \%$ & 7 & $6.7 \%$ & 5 & $17.2 \%$ \\
\hline Anger & 123 & $20.3 \%$ & 28 & $9.7 \%$ & 14 & $13.5 \%$ & 0 & $0 \%$ \\
\hline Contempt & 189 & $31.2 \%$ & 149 & $51.6 \%$ & 49 & $47.1 \%$ & 7 & $24.1 \%$ \\
\hline Ridicule & 135 & $22.3 \%$ & 22 & $7.6 \%$ & 7 & $6.7 \%$ & 0 & $0 \%$ \\
\hline Indignation & 75 & $12.4 \%$ & 5 & $1.7 \%$ & 5 & $4.8 \%$ & 1 & $3.5 \%$ \\
\hline Fear & 63 & $10.4 \%$ & 49 & $17.0 \%$ & 17 & $16.3 \%$ & 9 & $31 \%$ \\
\hline Pity & 16 & $2.6 \%$ & 26 & $9.0 \%$ & 5 & $4.8 \%$ & 6 & $20.6 \%$ \\
\hline Other & 0 & $0 \%$ & 7 & $2.4 \%$ & 0 & $0 \%$ & 1 & $3.5 \%$ \\
\hline TOTAL & 606 & & 497 & & 104 & & 29 & \\
\hline
\end{tabular}


The emotional appeals are extremely low in number in Biden's messages (29, amounting to $9 \%$ of the tweets), while they characterize Salvini's (45.5\%) and even more Trump's (98\%) messages. Bolsonaro (20.2\%) relies on this strategy noticeably less than the other populist leaders, but his appeals to emotions are more than the double of Biden's. While there is nothing wrong in using emotional appeals in messages, the types of emotions used can reveal some underlying common strategies.

The "emotional" profile of the three populist leaders has a common trend, namely the tendency to use contempt and its related emotion of ridicule (Gervais and Fessler, 2017; Raskin, 1985, p. 229) to attack a target $\left(\chi^{2}(2)=1.5\right.$, n.s.), and a comparable frequency of strategies aimed at triggering fear $\left(\chi^{2}(2)=8\right.$, n.s.). Salvini uses the ridicule $\left(\chi^{2}(2)=39.9, p<.001\right)$, indignation $\left(\chi^{2}(2)=31.3, \mathrm{p}<.001\right)$, and anger $\left(\chi^{2}(2)=17.8, \mathrm{p}<.001\right)$ significantly more than the other leaders. In contrast, fear, pity, and admiration characterize Biden's uses of emotions.

\section{Discussion}

The analysis of the argumentation profiles brings to light some crucial aspects of the argumentation of the so-called "populist" leaders on Twitter. The first and most evident feature is the frequency of their manipulative moves - significantly and visibly much higher than the ones of non-populist ones (such as Biden). The tweets not associated with a fallacy are the minority in Salvini's, Trump's, and Bolsonaro's messages (with some significant differences between the three politicians); if we consider also the criterion of evidence, the argumentative tweets that can be considered as presumptively acceptable (Erduran et al., 2004; Rapanta and Walton, 2016) are almost an exception in Salvini, and very little frequent in the other two populist leaders. The second striking feature is the use of attacks, which are almost not used by Biden but are pervasive in other leaders' messages. Finally, the frequency of emotive words is much higher in Salvini, Trump, and Bolsonaro than in Biden.

The methodological combination of argument analysis, fallacy detection, and the identification of emotive words brings to light different strategies of common ground manipulation. The fallacies identified (as described in the Codebook for Fallacy Analysis) capture presuppositions of different kind, such as the other's explicit commitments which have become part of the interlocutors' common ground (straw man), shared facts or options (false dilemma, ignoring qualifications, question begging), warrants (post hoc, slippery slope, hasty generalization), or word meaning (persuasive definitions). Fallacious quasidefinitions constitute a different strategy. In quasi-definitions, the speakers trigger explicitly (through emotive words) or even take for granted (through other manipulative tactics) value judgments that do not correspond to the common knowledge or even challenge it without providing reasons.

A limitation of this study is constituted by the platform on which argumentation is expressed. Twitter allows a limited number of characters, which can hardly allow the development of a complex argument. Clearly, these messages are simple and short (even though they often reproduce the contents of speeches, debates, and discourses, supposedly more articulated and informative). However, the lack of space does not necessarily correspond to incomplete, weaker, or even fallacious arguments. The fallacy analysis brought to light attempts to manipulate the common ground, which in some cases (such as in the straw man) can be complex and carefully designed, involving a distorted reporting of the original speaker, explicitly mentioned, and an attack that is normally directed against both the reported speech and the original speaker. Moreover, the comparison between Biden's messages and the other leaders' clearly shows how the platform limitations are not necessarily affecting the quality of arguments.

While the results of this study are limited to a specific timeframe, a specific platform, and more importantly specific politicians, the instruments used for analyzing argumentation profiles can be applied to different types of discourses, messages, and contexts. This method provides theoretically grounded and reliable tools for outlining quantitatively the strategies used by a speaker, which can become the ground for further qualitative analyses (Macagno, 2022).

\section{Conclusion}

This paper intended to bring to light the complexity of argumentative speech, and the variety of strategies - especially implicit - that are used for manipulating the audience's opinion or perception of a state of affairs. The institutional role of the speakers and the time period of their tweets were chosen for bringing to light a crucial constraint in the political leaders' messages: even though they belonged to a specific party, due to their official institutional office they needed to address the whole population of their country. In this context, the problem of detecting the manipulations of the common ground becomes crucial. Some premises, values, or generalizations may be commonly accepted by an audience strongly supportive of a leader, especially in an aggressive context of a dispute or heated political discussion. However, in the (explicitly acknowledged) context of informing and updating the citizens on the actions of the government, such tacit commitments that the speakers take for granted become manipulations.

The data emerging from the analysis performed revealed a specific strategic use of Twitter by the three "populist" heads of government - even though in different degrees. Their tweets do not seem to be used for the institutional goal of communicating to the citizens, but for creating, keeping, and developing an unshared common ground. Instead of advancing arguments that can be understood, assessed, and discussed, Trump, Salvini, and Bolsonaro tend to ground their conclusions on premises that can be shared only by whom embraces their political view. Their presuppositions are thus used to define a political language and culture that is exclusive and divisive, defined by their specific, ungrounded, and not commonly shared presuppositions. Their arguments are clearly "persuasive," but only to the extent allowed by the boundaries of the blind acceptance of a ground that is not common to all the citizens. 


\title{
Conflict of interests
}

The author has no conflicts of interest to declare.

\section{Acknowledgments}

I would like to thank the Fundação para a Ciência e a Tecnologia for the research grants PTDC/FER-FIL/28278/2017, EXPL/ FER-FIL/0276/2021 and UIDB/00183/2020.

\section{Appendix A. Supplementary data}

\author{
Supplementary data to this article can be found online at https://doi.org/10.1016/j.pragma.2022.01.022.
}

\section{References}

Abrusán, M., 2010. Triggering verbal presuppositions. In: Li, N., Lutz, D. (Eds.), Semantics and Linguistic Theory. CLC Publications, Ithaca, NY, pp. 684-701. Abrusán, M., 2011. Predicting the presuppositions of soft triggers. Linguist. Philos. 34, 491-535. https://doi.org/10.1007/s10988-012-9108-y.

Aldwairi, M., Alwahedi, A., 2018. Detecting fake news in social media networks. Procedia Comput. Sci. 141, 215-222. https://doi.org/10.1016/j.procs.2018.10. 171.

Allcott, H., Gentzkow, M., 2017. Social media and fake news in the 2016 election. J. Econ. Perspect. 31, 211-236. https://doi.org/10.1257/jep.31.2.211.

Anand, P., King, J., Boyd-Graber, J., Wagner, E., Martell, C., Oard, D., Resnik, P., 2011. Believe me-we can do this! Annotating persuasive acts in blog text. In: Workshops at the Twenty-Fifth AAAI Conference on Artificial Intelligence. AAAI Press, Menlo Park, CA, pp. 11-15.

Aristotle, 1991. Sophistical refutations. In: Barnes, J. (Ed.), The Complete Works of Aristotle, vol. I. Princeton University Press, Princeton, NJ.

Atlas, J.D., 1991. Topic/comment, presupposition, logical form and focus stress implicatures: the case of focal particles only and also. J. Semant. 8, 127-147. https://doi.org/10.1093/jos/8.1-2.127.

Azevedo, M.L.N. de, Robertson, S.L., 2021. Authoritarian populism in Brazil: Bolsonaro's Caesarism, 'counter-trasformismo' and reactionary education politics. Glob. Soc. Educ. 1-12. https://doi.org/10.1080/14767724.2021.1955663.

Bentham, J., 1824. The Book of Fallacies. John and H.L. Hunt, London, UK.

Bianchi, C., 2014. Slurs and appropriation: an echoic account. J. Pragmat. 66, 35-44. https://doi.org/10.1016/j.pragma.2014.02.009.

Blitz, M.J., 2018. Lies, line drawing, and deep fake news. Oklahoma Law Rev. 71, 59-116.

Bosc, T., Cabrio, E., Villata, S., 2016. Tweeties squabbling: positive and negative results in applying argument mining on social media. In: Baroni, P., Gordon, T. , Scheffler, T., Stede, M. (Eds.), Computational Models of Argument. IOS Press, Amsterdam, Netherlands, pp. 21 -32.

Bourse, S., 2018. Conjuring up terror and tears: the evocative and persuasive power of loaded words in the political discourse on drug reform. Lexis. https:// doi.org/10.4000/lexis.3182.

Brooker, P., Barnett, J., Cribbin, T., 2016. Doing social media analytics. Big Data Soc 3, 1-12.

Brunello, A., 2021. The problem of populism in modern democracy: democratic Republics and America in the 21st century. In: Johansen, B., Akande, A. (Eds. ), Donald J. Trump: Notable or Notorious? Nova Science Publishers, New York, NY, pp. 277-297.

Carletta, J., Isard, S., Doherty-Sneddon, G., Isard, A., Kowtko, J.C., Anderson, A.H., 1997. The reliability of a dialogue structure coding scheme. Comput. Linguist. 23, 13-31.

Cohen, J., 1960. A coefficient of agreement for nominal scales. Educ. Psychol. Meas. 20, 37-46. https://doi.org/10.1177/001316446002000104.

Conway, B.A., Kenski, K., Wang, D., 2013. Twitter use by presidential primary candidates during the 2012 campaign. Am. Behav. Sci. 57, 1596-1610. https:// doi.org/10.1177/0002764213489014.

Davidson, T., Warmsley, D., Macy, M., Weber, I., 2017. Automated hate speech detection and the problem of offensive language. In: Proceedings of the Eleventh International AAAI Conference on Web and Social Media, Montréal, Québec, Canada, May 15-18. The AAAI Press, Palo Alto, CA, pp. 512-515.

Dumani, L., Biertz, M., Witry, A., Ludwig, A.-K., Lenz, M., Ollinger, S., Bergmann, R., Schenkel, R., 2021. The ReCAP corpus: a corpus of complex argument graphs on German education politics. In: Proceedings - 2021 IEEE 15th International Conference on Semantic Computing, ICSC 2021. IEEE Computer Society, Washington, DC, pp. 248-255. https://doi.org/10.1109/ICSC50631.2021.00083.

Dusmanu, M., Cabrio, E., Villata, S., 2017. Argument mining on Twitter: arguments, facts and sources. In: Palmer, M., Hwa, R., Riedel, S. (Eds.), Proceedings of the 2017 Conference on Empirical Methods in Natural Language Processing. Association for Computational Linguistics, Copenhagen, Denmark, pp. 2317-2322.

Duthie, R., Budzysnka, K., Reed, C., 2016. Mining ethos in political debate. In: Proceedings of the Sixth International Conference on Computational Models of Argument. IOS Press, Amsterdam, Netherlands, pp. 299-310.

Erduran, S., Simon, S., Osborne, J., 2004. TAPping into argumentation: developments in the application of Toulmin's Argument Pattern for studying science discourse. Sci. Educ. 88, 915-933. https://doi.org/10.1002/sce.20012.

Fairclough, I., Fairclough, N., 2012. Political Discourse Analysis: A Method for Advanced Students. Routledge, London, UK.

Geisler, C., Swarts, J., 2019. Coding Streams of Language: Techniques for the Systematic Coding of Text, Talk, and Other Verbal Data. University Press of Colorado, Boulder, CO. https://doi.org/10.37514/PRA-B.2019.0230.

Gervais, M.M., Fessler, D.M.T., 2017. On the deep structure of social affect: attitudes, emotions, sentiments, and the case of “contempt”. Behav. Brain Sci. 40. https://doi.org/10.1017/S0140525X16000352. E225.

Green, N., 2015. Annotating evidence-based argumentation in biomedical text. In: Proceedings - 2015 IEEE International Conference on Bioinformatics and Biomedicine, BIBM 2015. IEEE Computer Society, Washington, DC, pp. 922-929.

Green, N., 2018. Towards mining scientific discourse using argumentation schemes. Argument Comput. 9, $121-135$.

Habernal, I., Wachsmuth, H., Gurevych, I., Stein, B., 2018. Before name-calling: dynamics and triggers of ad hominem fallacies in web argumentation. In: Proceedings of the 2018 Conference of the North \{A\}merican Chapter of the Association for Computational Linguistics: Human Language Technologies, vol. 1. Association for Computational Linguistics, New Orleans, LA, pp. 386-396 (Long Papers).

Habgood-Coote, J., 2019. Stop talking about fake news. Inquiry 62, 1033-1065. https://doi.org/10.1080/0020174X.2018.1508363.

Halldén, S., 1960. True Love, True Humour and True Religion: a Semantic Study. Gleerlup, Lund, Sweden.

Hansen, H., Walton, D., 2013. Argument kinds and argument roles in the Ontario provincial election. J. Argum. Context 2, 226-258. https://doi.org/10.1075/ jaic.2.2.03han.

Hedger, J., 2013. Meaning and racial slurs: derogatory epithets and the semantics/pragmatics interface. Lang. Commun. 33, 205-213. https://doi.org/10. 1016/j.langcom.2013.04.004.

Herkman, J., 2017. Articulations of populism: the Nordic case. Cult. Stud. 31, 470-488. https://doi.org/10.1080/09502386.2016.1232421.

Hispanus, Petrus, 1990. Peter of Spain: Language in dispute. An English translation of Peter of Spain's "Tractatus" called afterwards Summulae Logicales, based on the critical edition by LM de Rijk. John Benjamins Publishing, Amsterdam, Netherlands.

Hom, C., 2008. The semantics of racial epithets. J. Philos. 105, 416-440. https://doi.org/10.2307/20620116. 
Iyer, R.R., Sycara, K., 2019. An unsupervised domain-independent framework for automated detection of persuasion tactics in text. arXiv Prepr. arXiv1912. 06745.

Jeshion, R., 2013. Slurs and stereotypes. Anal. Philos. 54, 314-329. https://doi.org/10.1111/phib.12021.

Kilgarriff, A., 2012. Getting to know your corpus. In: Sojka, P., Aleš, P., Ivan, H., Karel, K. (Eds.), International Conference on Text, Speech and Dialogue. Springer, Heidelberg, Germany, pp. 3-15.

Kilgarriff, A., Baisa, V., Bušta, J., Jakubíček, M., Kovář, V., Michelfeit, J., Rychlý, P., Suchomel, V., 2014. The Sketch Engine: ten years on. Lexicography 1, 7-36. https://doi.org/10.1007/s40607-014-0009-9.

Krippendorff, K., 2011. Agreement and information in the reliability of coding. Commun. Methods Meas. 5, 93-112. https://doi.org/10.1080/19312458.2011. 568376.

Kuhn, D., 1993. Science as argument: implications for teaching and learning scientific thinking. Sci. Educ. 77, 319-337. https://doi.org/10.1002/sce. 3730770306.

Kuhn, D., 2010. Teaching and learning science as argument. Sci. Educ. 94, 810-824. https://doi.org/10.1002/sce.20395.

Lawrence, J., Reed, C., 2016. Argument mining using argumentation scheme structures. In: Baroni, P., Gordon, T., Scheffler, T., Stede, M. (Eds.), Computational Models of Argument. IOS Press, Amsterdam, Netherlands, pp. 379-390. https://doi.org/10.3233/978-1-61499-686-6-379.

Lee, J., Queal, K., 2016. Introducing the Upshot's Encyclopedia of Donald Trump's Twitter Insults. New York Times.

Levinson, S., 1983. Pragmatics. Cambridge University Press, Cambridge, UK.

Lombardi Vallauri, E., Masia, V., 2014. Implicitness impact: measuring texts. J. Pragmat. 61, 161-184. https://doi.org/10.1016/j.pragma.2013.09.010.

Lombardi Vallauri, E., Baranzini, L., Cimmino, D., Cominetti, F., Coppola, C., Mannaioli, G., 2020. Implicit argumentation and persuasion. J. Argumentation Context 9, 95-123. https://doi.org/10.1075/jaic.00009.lom.

Macagno, F., 2008. Dialectical relevance and dialogical context in Walton's pragmatic theory. Informal Log. 28, 102-128. https://doi.org/10.22329/il.v28i2. 542.

Macagno, F., 2014. Manipulating emotions. Value-based reasoning and emotive language. Argum. Advocacy 51, $103-122$.

Macagno, F., 2015. A means-end classification of argumentation schemes. In: Eemeren, F. van, Garssen, B. (Eds.), Reflections on Theoretical Issues in Argumentation Theory. Springer, Cham, Switzerland, pp. 183-201.

Macagno, F., 2018a. Assessing relevance. Lingua 210-211, 42-64. https://doi.org/10.1016/j.lingua.2018.04.007.

Macagno, F., 2018b. A dialectical approach to presupposition. Intercult. Pragmat. 15, 291-313. https://doi.org/10.1515/ip-2018-0008.

Macagno, F., 2019. Analizzare l'argomentazione sui social media. Il caso dei tweet di Salvini. Sist. intelligenti, pp. 601-632. https://doi.org/10.1422/95091.

Macagno, F., 2022. Argumentation profiles and the pragmatics of argument. Informal Log.

Macagno, F., Bigi, S., 2017. Analyzing the pragmatic structure of dialogues. Discourse Stud. 19, 148-168. https://doi.org/10.1177/1461445617691702.

Macagno, F., Bigi, S., 2020. Analyzing dialogue moves in chronic care communication - dialogical intentions and customization of recommendations for the assessment of medical deliberation. J. Argum. Context 9, 167-198. https://doi.org/10.1075/jaic.18044.mac.

Macagno, F., Gil, B., forthcoming. Análise argumentativa nas redes sociais: Bolsonaro no Twitter. Uma abordagem preliminar. In: Ferreira, I., Mateus, S. (Eds.), Retórica Mediatizada- a Comunicação Persuasiva Através Dos Media. Sistema Solar e Documenta, Lisbon, Portugal.

Macagno, F., Walton, D., 2010. What we hide in words: emotive words and persuasive definitions. J. Pragmat. 42, 1997-2013. https://doi.org/10.1016/j. pragma.2009.12.003.

Macagno, F., Walton, D., 2014. Emotive Language in Argumentation. Cambridge University Press, New York, NY.

Macagno, F., Walton, D., 2015. Classifying the patterns of natural arguments. Philos. Rhetor. 48, 26-53. https://doi.org/10.1353/par.2015.0005.

Macagno, F., Walton, D., 2017. Interpreting Straw Man Argumentation. The Pragmatics of Quotation and Reporting. Springer, Amsterdam, Netherlands.

Macagno, F., Walton, D., 2018. Practical reasoning arguments: a modular approach. Argumentation 32, 519-547. https://doi.org/10.1007/s10503-018-94505.

Macagno, F., Walton, D., 2019. Emotive meaning in political argumentation. Informal Log. 39, 229-261. https://doi.org/10.22329/il.v39i3.5493.

Mcginnis, D.P., 2021. Anti-immigrant populism in Italy: an analysis of Matteo Salvini's strategy to push Italy's immigration policy to the far right. Yale Rev. Int. Stud. 12 .

Mendes, A.E., 2016. Digital demagogue: the critical candidacy of Donald. J. Trump. J. Contemp. Rhetor. 6, $62-73$.

Mizuta, Y., Korhonen, A., Mullen, T., Collier, N., 2006. Zone analysis in biology articles as a basis for information extraction. Int. J. Med. Inf. 75, 468-487. https://doi.org/10.1016/j.ijmedinf.2005.06.013.

Mochales Palau, R., Moens, M.F., 2009. Argumentation mining: the detection, classification and structuring of arguments in text. In: Proceedings of the 12th International Conference on Artificial Intelligence and Law (ICAIL’09). ACM, New York, NY, pp. 351-352. https://doi.org/10.1145/1568234.1568246.

Mochales Palau, R., Moens, M.F., 2011. Argumentation mining. Artif. Intell. Law 19, 1-22. https://doi.org/10.1007/s10506-010-9104-X.

Olivas Osuna, J.J., 2021. From chasing populists to deconstructing populism: a new multidimensional approach to understanding and comparing populism. Eur. J. Polit. Res. 60, 829-853. https://doi.org/10.1111/1475-6765.12428.

Ott, B.L., 2017. The age of Twitter: Donald J. Trump and the politics of debasement. Crit. Stud. Media Commun. 34, 59-68. https://doi.org/10.1080/15295036. 2016.1266686.

Pisarevskaya, D., 2017. Rhetorical structure theory as a feature for deception detection in news reports in the Russian language. In: Computational Linguistics and Intellectual Technologies: Proceedings of the International Conference "Dialogue 2017". HSE University Press, Moscow, Russia, pp. 191-200.

Rapanta, C., Walton, D., 2016. Identifying paralogisms in two ethnically different contexts at university level/Identificación de paralogismos en dos contextos universitarios diferenciados étnicamente. Infancia Aprendiz. 39, 119-149. https://doi.org/10.1080/02103702.2015.1111610.

Raskin, V., 1985. Semantic Mechanisms of Humor. Reidel, Dordrecht, Netherlands.

Rubin, V., Lukoianova, T., 2015. Truth and deception at the rhetorical structure level. J. Assoc. Inf. Sci. Technol. 66, 905-917. https://doi.org/10.1002/asi. 23216.

Rubin, V., Conroy, N., Chen, Y., 2015. Towards news verification: deception detection methods for news discourse. In: HICSS '15: Proceedings of the 2015 48th Hawaii International Conference on System Sciences. IEEE Computer Society, Washington, DC. https://doi.org/10.13140/2.1.4822.8166.

Schiappa, E., 2003. Defining Reality. Definitions and the Politics of Meaning. Southern Illinois University Press, Carbondale and Edwardsville, IL.

Schneider, J., Samp, K., Passant, A., Decker, S., 2013. Arguments about deletion. In: Proceedings of the 2013 Conference on Computer Supported Cooperative Work - CSCW '13. ACM Press, New York, NY, pp. 1069-1080. https://doi.org/10.1145/2441776.2441897.

Shu, K., Sliva, A., Wang, S., Tang, J., Liu, H., 2017. Fake news detection on social media: a data mining perspective. ACM SIGKDD Explor. Newsl. $19,22-36$. https://doi.org/10.1145/3137597.3137600.

Stalnaker, R., 1998. On the representation of context. J. Logic Lang. Inf. 7, 3-19. https://doi.org/10.1023/A:1008254815298.

Stanley, J., 2015. How Propaganda Works. Princeton University Press, Princeton, NJ.

Stevenson, C., 1944. Ethics and Language. Yale University Press, New Haven, CT.

Stump, E., 2004. Boethius's “De Topicis differentiis.”. Cornell University Press, Ithaca, IL and London, UK.

Van Rees, A., 2009. Dissociation in Argumentative Discussions: A Pragma-Dialectical Perspective. Springer, Amsterdam, Netherlands.

Visser, J., Lawrence, J., Wagemans, J., Reed, C., 2018. Revisiting computational models of argument schemes: classification, annotation, comparison. In: Modgil, S., Budzynska, K., Lawrence, John (Eds.), Computational Models of Argument. IOS Press, Amsterdam, Netherlands, pp. 313-324. https://doi.org/ 10.3233/978-1-61499-906-5-313.

Walton, D., 1987. Informal Fallacies. John Benjamins, Amsterdam, Netherlands.

Walton, D., 1990. What is reasoning? What is an argument? J. Philos. 87, 399-419. https://doi.org/10.2307/2026735.

Walton, D., 1992. The Place of Emotion in Argument. Pennsylvania State University Press, University Park, PA.

Walton, D., 1995. A Pragmatic Theory of Fallacy. University of Alabama Press, Tuscaloosa, AL. 
Walton, D., 1996. Argumentation Schemes for Presumptive Reasoning. Lawrence Erlbaum Associates, Inc, Mahwah, NJ.

Walton, D., 1999. The fallacy of many questions: on the notions of complexity, loadedness and unfair entrapment in interrogative theory. Argumentation 13 , 379-383. https://doi.org/10.1023/A:1007727929716.

Walton, D., 2004. Relevance in Argumentation. Routledge, Amsterdam, Netherlands-Philadelphia, PA.

Walton, D., 2007. Media Argumentation: Dialectic, Persuasion and Rhetoric. Cambridge University Press, New York, NY.

Walton, D., 2008. Informal Logic: a Pragmatic Approach. Cambridge University Press, New York, NY.

Walton, D., 2010. Why fallacies appear to be better arguments than they are. Informal Log. 30, 159-184. https://doi.org/10.22329/il.v30i2.2868.

Walton, D., Macagno, F., 2016. Profiles of dialogue for relevance. Informal Log. 36, 523-556. https://doi.org/10.22329/il.v36i4.4586.

Walton, D., Reed, C., Macagno, F., 2008. Argumentation Schemes. Cambridge University Press, New York, NY.

Wei Feng, V., Hirst, G., 2011. Classifying arguments by scheme. In: Proceedings of the 49th Annual Meeting of the Association for Computational Linguistics: Human Language Technologies-Volume 1. Association for Computational Linguistics, Stroudsburg, PA, pp. 987-996.

Fabrizio Macagno (Ph.D. UCSC, Milan, 2008) works as an assistant professor at the Universidade Nova de Lisboa. He is the Principal Investigator for the Portuguese team in the Consortium of the Horizon 2020 project "Dialogue and Argumentation for cultural Literacy Learning in Schools" and PI of the Portuguese Science Foundation project "Evidence-based metaphors for diabetes care." He is author of more than 100 papers on definition, interpretation, presupposition, argumentation schemes, and dialogue analysis published on major journals. His most important publications include the books Argumentation Schemes (CUP 2008), Emotive language in argumentation (CUP 2014), and Interpreting straw man argumentation (Springer 2017), and Statutory interpretation: Pragmatics and argumentation (CUP 2020). He has been published extensively on the use of logical methods and theories for the improvement of communication in crucial areas of practice, such as education, law, and medical discourse. 


\section{CODEBOOK FOR ARGUMENT ANALYSIS}




\section{Table of Contents}

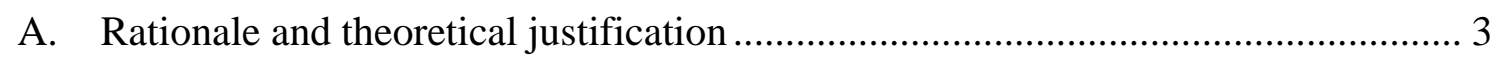

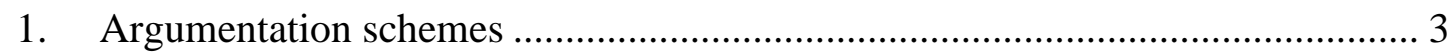

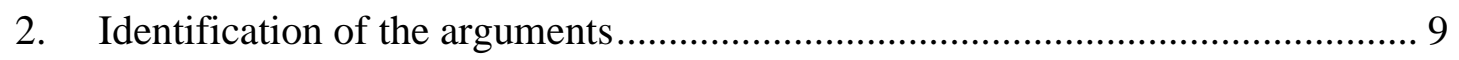

2.1. Criteria used for limiting the number of codes ......................................... 9

2.2. List of the coded arguments .................................................................... 9

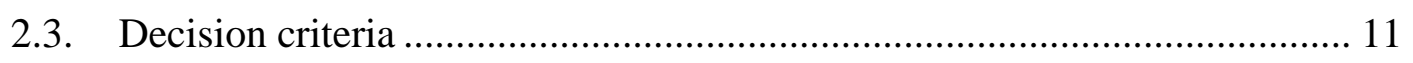

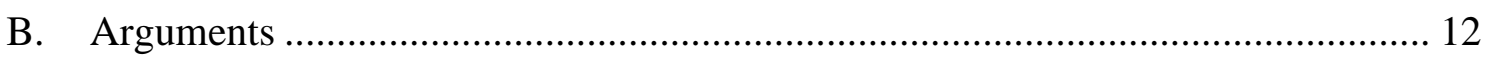

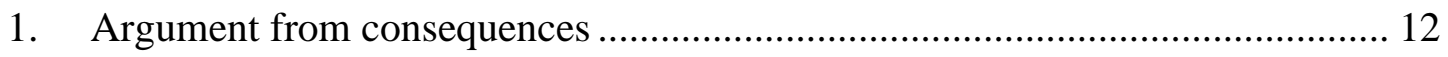

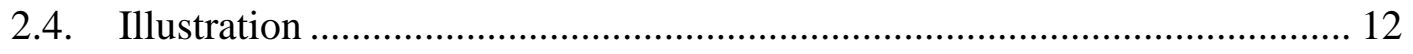

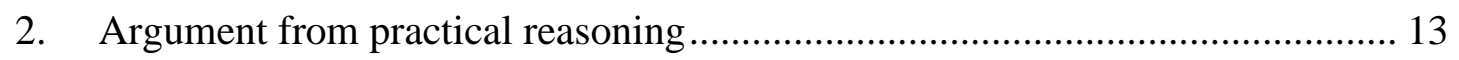

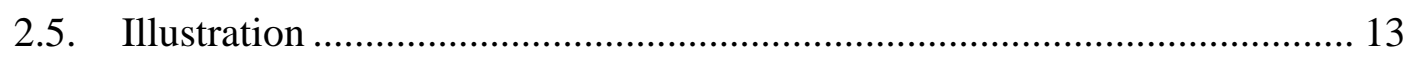

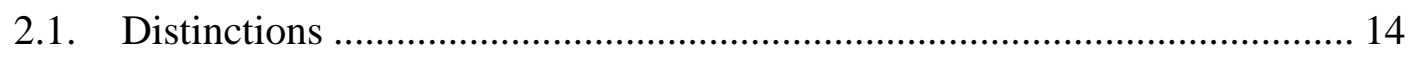

2.1.1. Argument from Practical Reasoning vs. Argument from Consequences 14

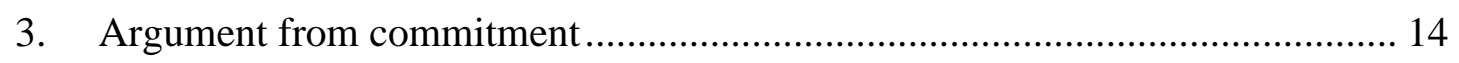

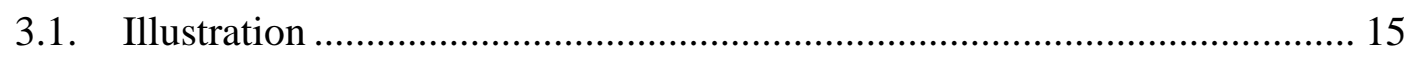

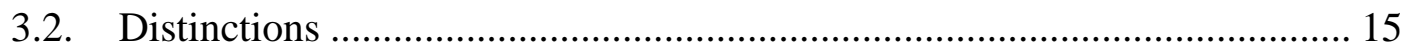

2.1.2. Argument from Commitment vs. Argument from Consequences ........ 15

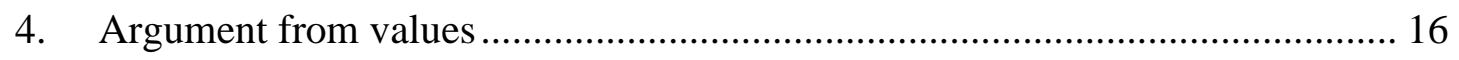

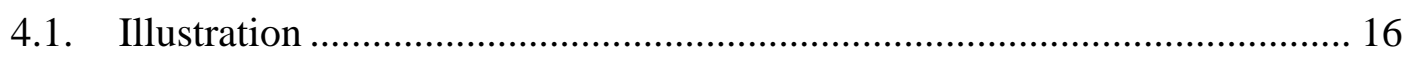

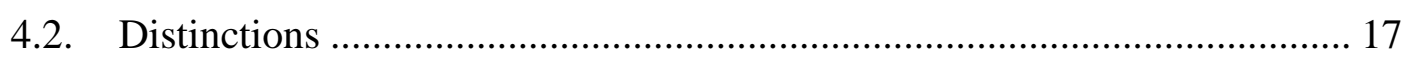

4.2.1. Argument from Values vs. Argument from Commitment.................... 17

4.2.2. Argument from Values vs. Practical reasoning .................................. 17

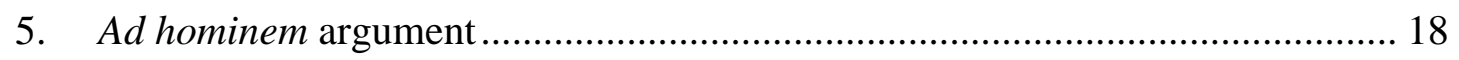

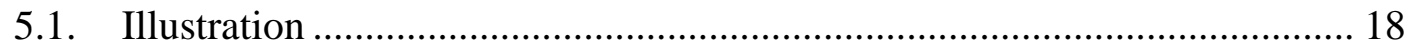

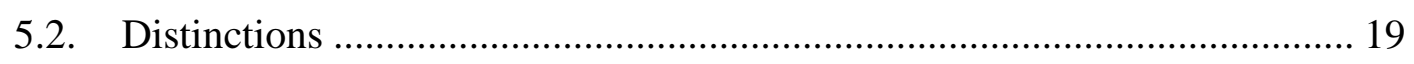

5.2.1. Ad hominem vs. Argument from Values ............................................ 19

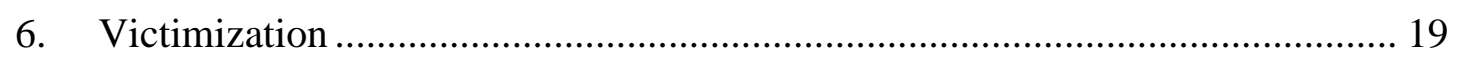

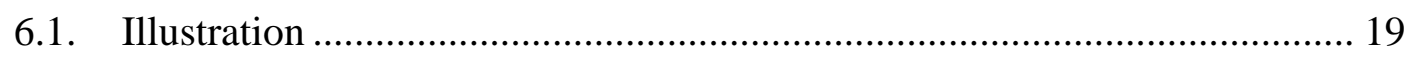

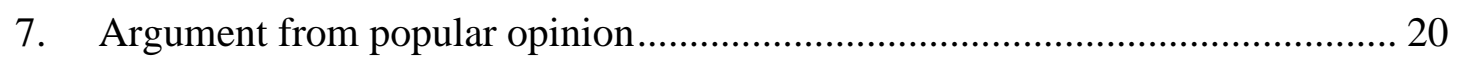

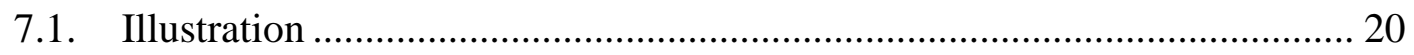

8. Argument from expert opinion/position to know ............................................ 21

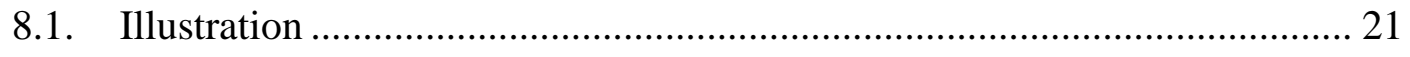

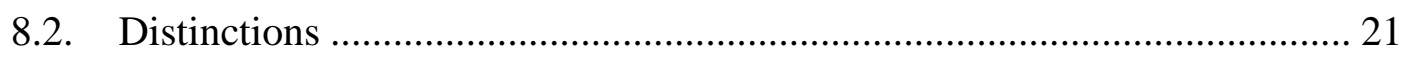


8.2.1. Argument from position to know vs. Argument from popular opinion 22

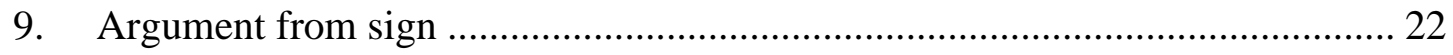

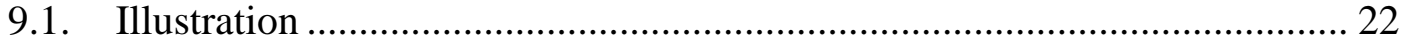

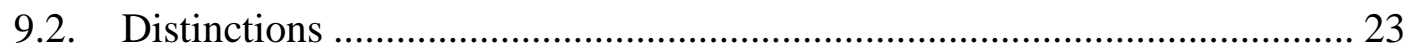

9.2.1. Argument from sign vs. Argument from Values ................................ 23

10. Argument from best explanation ................................................................. 23

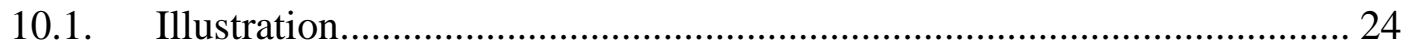

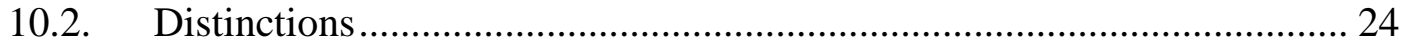

10.2.1. Argument from Best Explanation vs. Argument from Sign ............. 24

11. Argument from cause to effect ..................................................................... 25

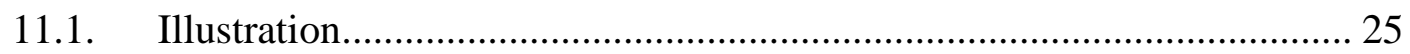

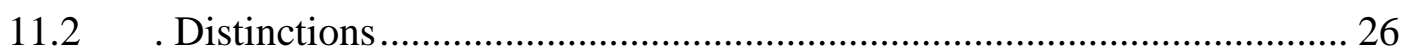

11.2.1. Argument from Cause to Effect vs. Argument from Sign ................ 26

11.2.2. Argument from Cause to Effect vs. Argument from Consequences. 26

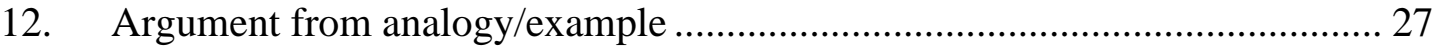

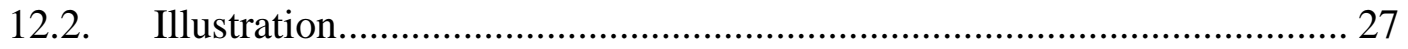

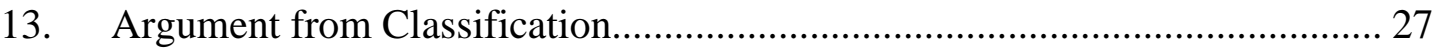

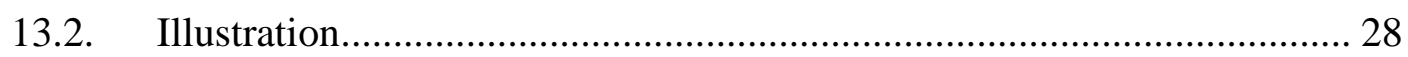

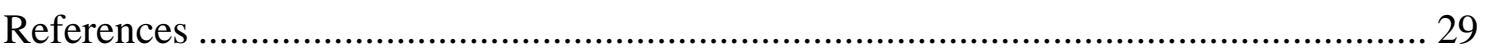




\section{A. Rationale and theoretical justification}

Argumentation schemes have been developed in argumentation theory as stereotypical patterns of inference, abstract structures representing the material (semantic) relation and logical relation between the premises and a conclusion in an argument with a corresponding set of critical questions indicating their defeasibility conditions. They can be regarded as the modern interpretation and reconsideration of the ancient maxims of inference (Macagno and Walton, 2014; Walton et al., 2008). Many authors in the last fifty years have proposed different sets and classifications of schemes (Grennan, 1997; Hastings, 1963; Kienpointner, 1992, 1987; Perelman and Olbrechts-Tyteca, 1969; Walton, 1995; Walton et al., 2008). These approaches raise crucial problems concerning the criteria used for distinguishing and classifying the schemes and defining the structure of an argumentation scheme. These apparently purely philosophical questions are becoming increasingly important for practical purposes, in particular the application of the schemes to the field of education ((Duschl, 2008; Kim et al., 2010;

Konstantinidou and Macagno, 2013; Macagno and Konstantinidou, 2013; Nussbaum, 2011; Rapanta and Walton, 2016a, 2016b) and Artificial Intelligence (Mochales Palau and Moens, 2011, 2009). Argumentation schemes have already been found to have acceptable or even high validity from an empirical perspective (Konstantinidou and Macagno, 2013; Lawrence and Reed, 2016; Wei Feng and Hirst, 2011). However, the schemes normally used for the purposes of testing accuracy are limited in number (Lawrence and Reed, 2016) or confined to a specific context (Konstantinidou and Macagno, 2013). For the purpose of analyzing a complex context such as the political one - or even the more complex one of social media messaging - some specifications are needed. Argumentation schemes will be classified and specified according to their purpose and the differences between them will be brought to light.

\section{Argumentation schemes}

Argumentation schemes can be conceived as the combination of semantic (or topical) relations with logical rules of inference. A classification based on the semantic link can provide an instrument for bringing to light the material relation between premises and conclusion. However, the same semantic relation can be combined with various logical rules, and lead to various types of conclusion. For example, causal relations are the ground of the argument from cause to effect, but also or arguments from sign and practical reasoning. A classification based only on the semantic content would blur these fundamental differences. For this reason, it is necessary to find an overarching classificatory principle.

Argumentation schemes can be thought of as instruments for reconstructing and building arguments (intended as discourse moves), i.e. analytical or invention tools. For this reason, in order to provide a classificatory system to retrieve and detect the needed scheme it can be useful to start from the intended purpose of an argumentation scheme. From an analytical point of view, the analysis of an argument in a discourse, a text, or dialogue presupposes a previous understanding of the communicative goal (and, therefore, the "pragmatic" meaning) of the argument and the components thereof. For 
example, an argument can be aimed at classifying a state of affairs, supporting the existence of a state of affairs, or influencing a decision-making process.

This teleological classification needs to be combined with a practical one, as the generic purposes of a move need to be achieved by means of an inferential passage. In this sense, the classificatory system needs to account for the possible means to achieve the pragmatic purpose of an argument. Not all the semantic (material) relations that are at the basis of the schemes can support all the possible conclusions or purposes of an argument. Definitional schemes are aimed at supporting the classification of a state of affairs and are unlikely to lead to the prediction or retrodiction of an event. Similarly, a pattern of reasoning based on the evaluation of the consequences of an action or an event can be used to establish the desirability of a course of action brining it about, but cannot reasonably lead to the truth or falsity (or acceptability) of a proposition. For this reason, the analysis of the pragmatic meaning (i.e. the purpose) of an argument provides a criterion for restricting the paradigm of the possible means to achieve it. The crucial problem is to find categories of argument purposes that can establish criteria for distinguishing among classes of semantic relations, which in turn can be specified further according to the means to achieve such goals.

The first distinction to be made is based on the nature of the subject matter, which can be a course of action ("practical” or "dynamic" arguments) or a state of affairs ("theoretical” or "descriptive" arguments) (Jonsen and Toulmin, 1988; Stevenson, 1944). In the first case, the goal is to support the desirability or nondesirability of an action, while in the second one the schemes are aimed at providing grounds for the acceptability of a judgment on a state of affairs. The ancient dialectical accounts (see (Cicero, Topica; Boethius, De Topicis Differentiis) distinguished between two types of argumentative "means" to bear out a conclusion, i.e. the "internal" and the "external" arguments. The first ones are based on the characteristics of the subject matter (such as arguments from definition or cause), while the others derive their force from the source of the statement, i.e. from the authority of who advances the judgment or the proposal (arguments from authority). This first distinction can be represented as follows (Figure 1):

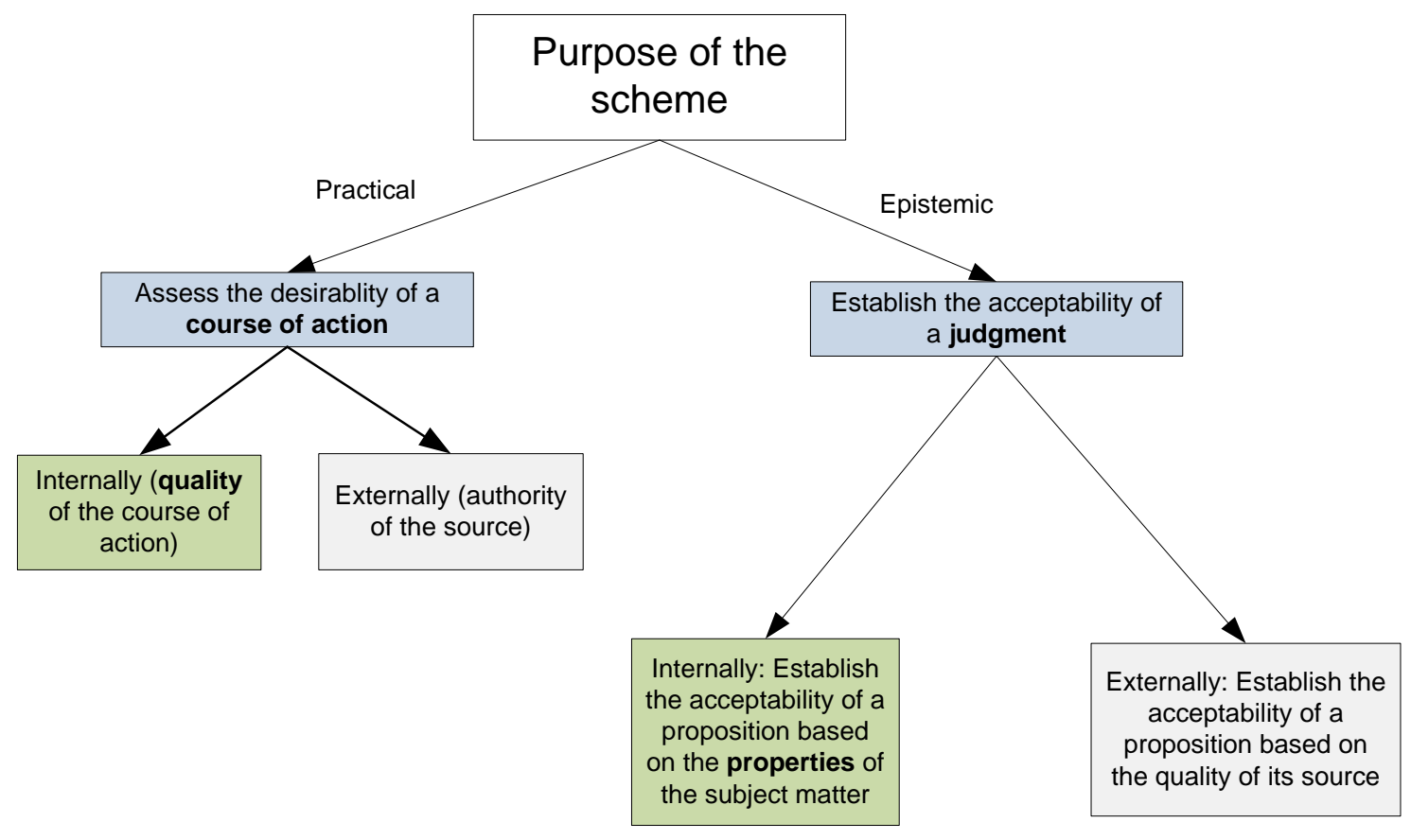




\section{Figure 1: Basic purposes of an argument}

The acceptability of a conclusion can be supported externally in two ways. If the argument is aimed at establishing the desirability of a course of action, the authority can correspond to the role of the source needed for recommending or imposing a choice ("You should do it because he told you that!"). Otherwise, the popular practice can be a reason for pursuing a course of action ("We should buy a bigger car. Everyone drives big cars here!”). When external arguments are used to support also a judgment on a state of affairs, the relevant quality of the source is not the speaker's authority (which is connected with the consequences of not complying with the orders/conforming to common behavior) but rather with his superior knowledge. The quality of the source can be also used negatively to show that a source is not reliable (it is not a good source), and that consequently the conclusion itself should be considered as doubtful (ad hominem arguments). The external arguments can be represented as follows (Figure 2):

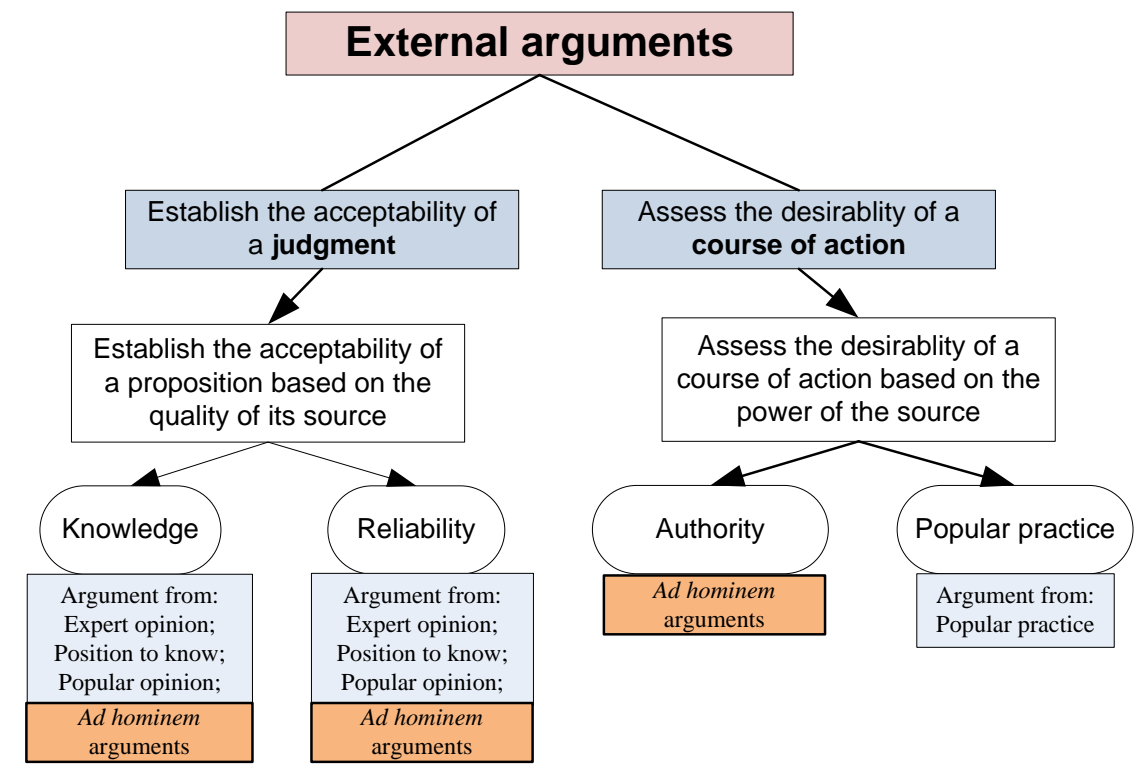

Figure 2: External arguments

Internal arguments need to be divided into the two categories of arguments aimed at assessing the desirability of a course of action (practical), and the ones supporting the acceptability of a judgment (epistemic) (Figure 3). 


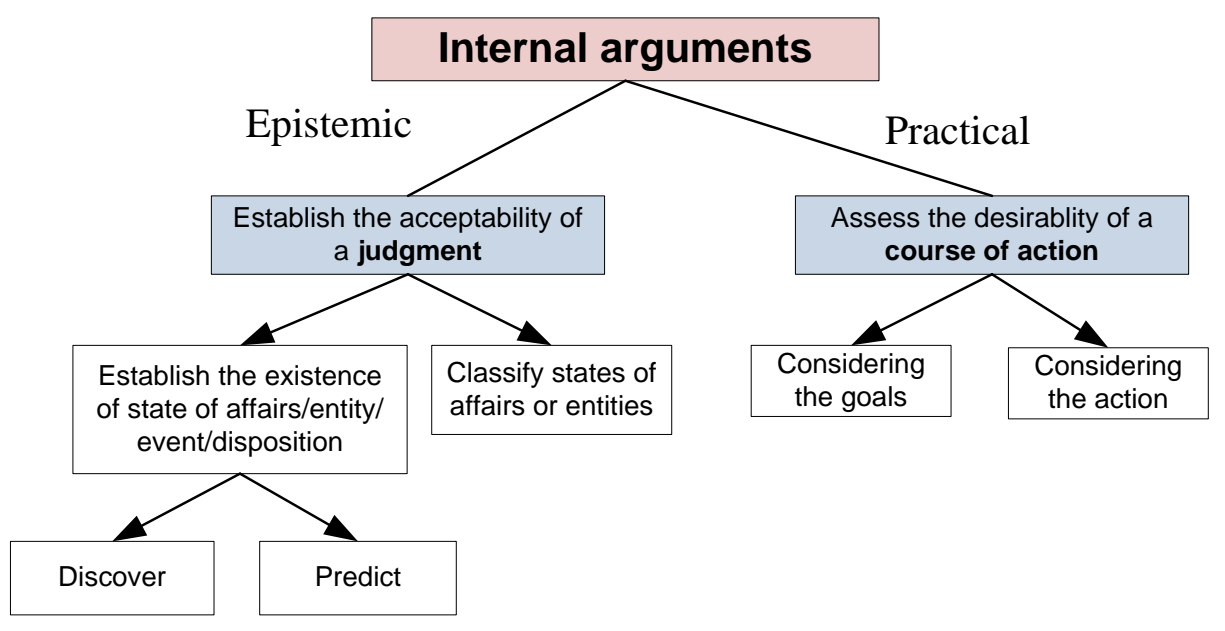

Figure 3: Internal arguments

The practical arguments concern the deliberation, namely the making of a decision. A course of action can be recommended based on two distinct types of categories of reasoning, one focusing on the action to be carried out, and the other on the goals. The reasoning from actions can be further divided in two distinct arguments. The first argument, called from consequences, is aimed at classifying a course of action as desirable or not depending on the quality of its consequences (the course of action is a condition of a resulting positive or negative state of affairs). The second argument, called from commitments, is intended to present a course of action as a result (implication) of the speaker's commitments (promises, character, etc.).

The reasoning from goals is focused on the objectives that an agent has or should have. It includes two arguments: the argument from values and the argument from practical reasoning. The argument from values determines the end, objective, or goal to be pursued based on the classification of a state of affairs as good, positive or not. The argument from practical reasoning presupposes a goal and justifies a course of action as a means to this goal. The classification is the following (Figure 4):

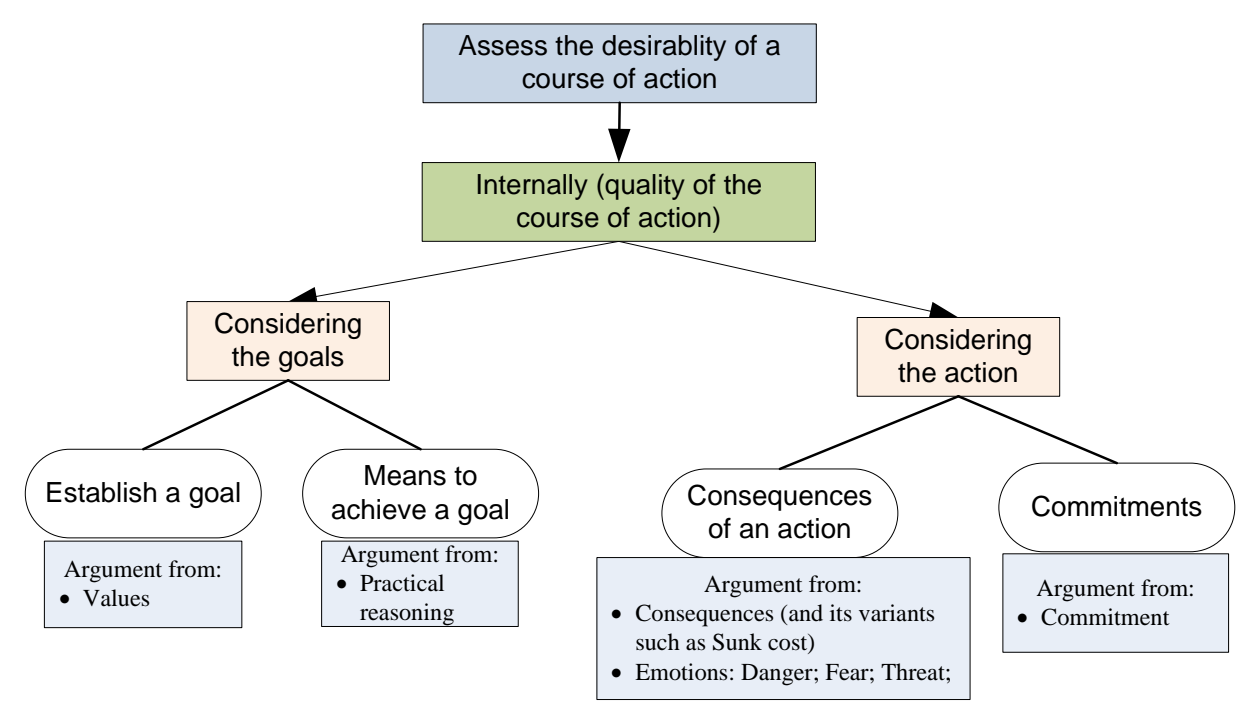

Figure 4: Internal practical arguments 
Epistemic arguments are aimed at increasing our knowledge or beliefs, and they can be divided in two distinct categories. The first category mirrors the dialogical activity of discovery, namely finding a state of affairs, entity, characteristic thereof, or relationship based on evidence and causal relations. The second category is the classification, namely the attribution of a predicate to a state of affairs or entity based on the available evidence and a definitional criterion.

The "discovery" (or causal) arguments can be used to either predict the occurrence of an event or state of affairs, or to "retrodict," namely establish the existence of something based on the available evidence. In the first case, the argument is from cause to effect. In the second case, it is necessary to distinguish whether the object of the discovery is a generalization or an occurrence/single entity. In case the speaker wants to establish a generalization between causes and effects, the argument is the correlation to cause. In case the speaker wants to establish the occurrence of events/entities or characteristics thereof, the arguments can be either from sign or from best explanation, depending on whether the reasoning takes into account the possible alternative explanations (best explanation) or the presumptive cause (sign). The retrodiction arguments can be used for both the discovery of events or entities (someone was here; someone did this) and the attribution of a stable property (disposition) to an agent, such as "to be a criminal." These latter arguments can be considered as belonging to causal arguments, as they are grounded on signs of an internal disposition of character, which in its turn is evaluated. The distinctions discussed above are summarized in Figure 5 below.

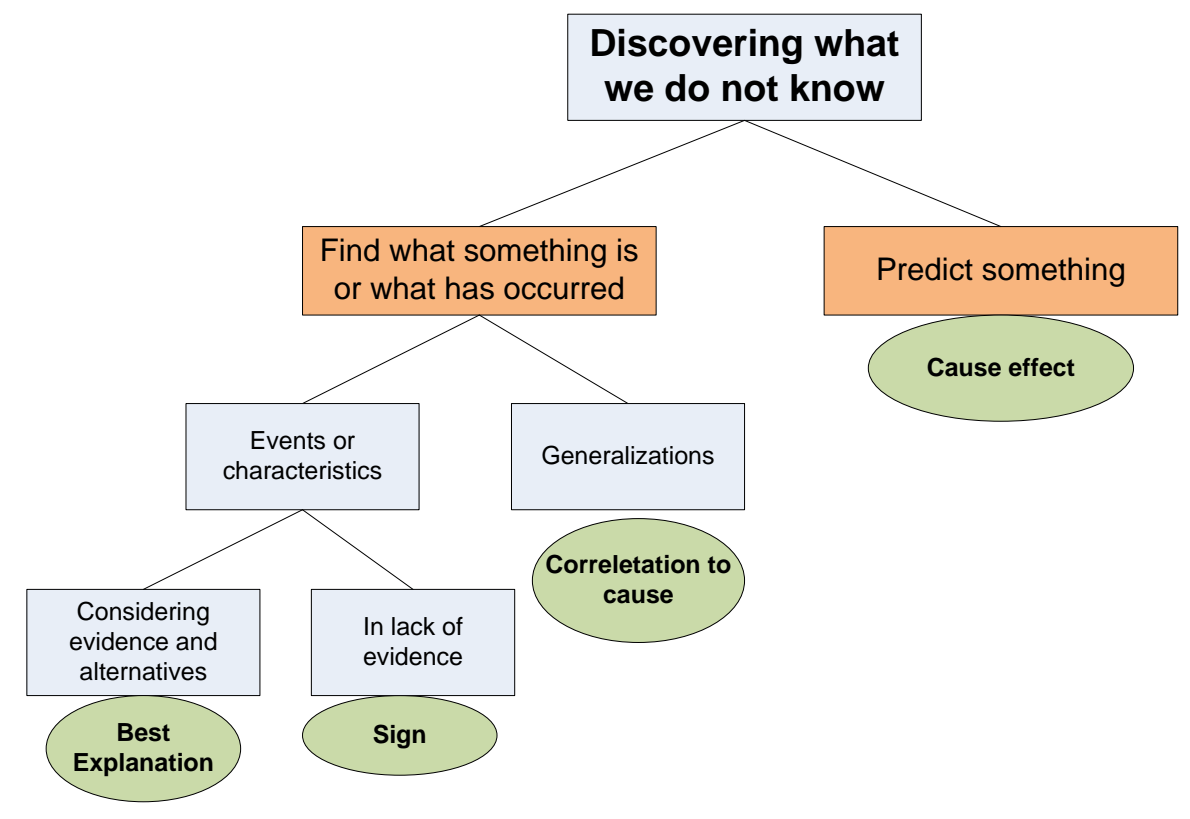

Figure 5: Internal epistemic arguments - discovery

The arguments from classification represent the other category of epistemic arguments, aimed at providing a classification of a state of affairs based on definitional criteria such as the definition, the description, etc.

To these arguments, we need to add two other schemes - the analogical argument and the argument from example. They do not express semantic relations, but rather convey other schemes (an analogy can be aimed at classifying something, or showing the consequences of an action...). For this reason, they are forms of expression of other schemes, and not only argumentation schemes. 
This system of classification of argumentation schemes is based on the interplay between two criteria, the (pragmatic) purpose of an argument and the means to achieve it. This dichotomic model can be used both for analytical and production purposes. In the first case, the speaker's intention is reconstructed by examining the generic purpose of his move, and then the possible choices that he made to support it, based on the linguistic elements of the text. Depending on the desired level of preciseness, the analysis can be narrowed down until detecting the specific scheme, i.e. the precise combination of the semantic principle and the logical rule supporting the conclusion. In this fashion, the analyst can decide where to stop his reconstruction. This analytical model can be of help also for educational purposes, as it can be adapted to various teaching needs and levels (detecting arguments in a text; reconstructing implicit premises, etc.). For production purposes, the nature of the viewpoint to be argued for opens up specific alternative strategies to support it, which in turn can be determined by the characteristics of the conclusion.

This model relies on the analyst's or the speaker's reconstruction (or awareness) of the purpose of a move, which can be partially identified by taking into consideration the nature of the subject matter (whether it is a decision or a judgment). The purpose then opens up possible choices according to the generic goal of the communicative act. The speaker's intention can be further specified by detecting the most generic strategy chosen to provide a basis for the acceptability of the conclusion. In this case, in order to reconstruct the move or provide an argument, the analyst or the speaker can choose whether to use some properties of the subject matter or to appeal to an external source. In the first case, the means used to achieve the goal are determined by the nature of the subject matter. In particular, the crucial distinction is between the classification and the prediction or retrodiction of an entity or state of affairs. This choice leads to a further specification of the nature of the viewpoint that the speaker intends to support with his argument (is the event a future or a past one? is the classification a value judgment or does it consist in the attribution of factual properties?), and then to the specific means that can be used to achieve this precise purpose (argument from values, from definition, etc.). In case of decision-making, the argumentation schemes are classified according to the same interrelation between goal and generic strategies. The internal arguments can be divided between reasoning from consequence and reasoning from means to goal.

An alternative to the internal, more complex arguments, is provided by external arguments, where the choice of backing the conclusion by means of the opinion of a knowledgeable and reliable source can be further made more specific by distinguishing between the kinds of sources (experts or the majority of people) and the nature of the support (knowledge or reliability).

The semantic relation characterizing a scheme can be "shaped" according to different types of reasoning, namely logical forms. For instance, the desirability of a course of action can be assessed internally by taking into consideration the means to achieve a goal. However, this pattern of reasoning can be stronger or weaker depending on whether there is only one or several alternatives. The paradigm of the possible means will determine whether the reasoning is abductive or deductive, resulting in a conclusion more or less defeasible. The same principle applies to the other semantic relations, such as the ones proceeding from cause or classification, which can be shaped logically according to inductive (or analogical), deductive, or abductive types of reasoning. 


\section{Identification of the arguments}

The most important criterion for identifying the argument that the speakers express through their messages is the perspective. The analyst should adopt an internal perspective, namely taking the view of the message - interpreting what it says, not what it can lead to or the implicit inferences a reader can draw from it. For example, we consider the following:

I am working 24 hours a day for the wellness of the Italians, as I promised.

In this message, the Speaker clearly wants to draw a positive judgment on himself. However, this is not what the messages says. The message is simply an argument from commitment: he promised something, and he is keeping it. Many messages are said to elicit a positive judgment for the fact that such messages are said: but this is a secondary (side) effect - a kind of perlocutionary effect (Austin, 1962). The focus should be on what the message conveys - the conclusion that it is aimed at supporting.

\subsection{Criteria used for limiting the number of codes}

The argumentation schemes selected were drawn from (Walton et al., 2008) and selected considering the basic schemes set out in (Walton, 2006, 1995) and the classification criteria proposed in (Macagno, 2015; Macagno and Walton, 2015; Walton and Macagno, 2015). Some schemes (such as position to know/expert opinion, and analogy/example) were combined in macro categories in order to allow an easier detection.

These criteria were combined with a bottom-up approach, in which a pilot study was conducted on two distinct corpora, using all the available schemes (Macagno, 2019; Macagno and Gil, 2021). The results showed how a limited number of schemes represented the most frequent types of argument, while the others represented less than $1 \%$ of the total arguments. The result of this twofold strategy was the following list of 13 argumentation schemes, which allows a reliable coding.

\subsection{List of the coded arguments}

\begin{tabular}{|l|l|l|}
\hline Argument category & \multicolumn{1}{|c|}{ Argument } & \multicolumn{1}{|c|}{ Example } \\
\hline \multirow{2}{*}{$\begin{array}{l}\text { 1. Practical } \\
\text { arguments }\end{array}$} & $\begin{array}{l}\text { 1. Argument from } \\
\text { consequences }\end{array}$ & $\begin{array}{l}\text { a. If the ban were announced } \\
\text { with a one week notice, the } \\
\text { "bad" would rush into our } \\
\text { country during that week. A } \\
\text { lot of bad "dudes" out there! }\end{array}$ \\
\cline { 2 - 3 } & $\begin{array}{l}\text { 2. Argument from practical } \\
\text { reasoning }\end{array}$ & $\begin{array}{l}\text { b. For criminals, drug } \\
\text { dealers, and murderers who } \\
\text { bring war to our home, there } \\
\text { is only one solution: } \\
\text { EXPULSION. }\end{array}$ \\
\hline
\end{tabular}




\begin{tabular}{|c|c|c|}
\hline & $\begin{array}{l}\text { 3. Argument from } \\
\text { commitment }\end{array}$ & $\begin{array}{l}\text { c. The crackdown on illegal } \\
\text { criminals is merely the } \\
\text { keeping of my campaign } \\
\text { promise. }\end{array}$ \\
\hline \multirow{2}{*}{$\begin{array}{l}\text { 2. Evaluative } \\
\text { arguments }\end{array}$} & 4. Argument from values & $\begin{array}{l}\text { d. Peaceful protests are a } \\
\text { hallmark of our democracy. } \\
\text { Even if I don't always agree, I } \\
\text { recognize the rights of people } \\
\text { to express their views. }\end{array}$ \\
\hline & 5. Victimization & $\begin{array}{l}\text { e. It is amazing how rude } \\
\text { much of the media is to my } \\
\text { very hard working } \\
\text { representatives. Be nice, you } \\
\text { will do much better! }\end{array}$ \\
\hline \multirow{3}{*}{$\begin{array}{l}\text { 3. Source-based } \\
\text { (external) arguments }\end{array}$} & $\begin{array}{l}\text { 6. Argument from expert } \\
\text { opinion/position to know }\end{array}$ & $\begin{array}{l}\text { f. FoxNews from multiple } \\
\text { sources: "There was } \\
\text { electronic surveillance of } \\
\text { Trump, and people close to } \\
\text { Trump. This is } \\
\text { unprecedented." @FBI }\end{array}$ \\
\hline & $\begin{array}{l}\text { 7. Argument from popular } \\
\text { opinion }\end{array}$ & $\begin{array}{l}\text { g. Everyone acknowledges } \\
\text { that the fundamentals of the } \\
\text { Italian economy are good and } \\
\text { do not correspond to the } \\
\text { present spread. }\end{array}$ \\
\hline & 8. Ad hominem argument & $\begin{array}{l}\text { h. The failing @nytimes does } \\
\text { major FAKE NEWS China } \\
\text { story saying "Mr.Xi has not } \\
\text { spoken to Mr. Trump since } \\
\text { Nov.14." }\end{array}$ \\
\hline \multirow[t]{3}{*}{$\begin{array}{l}\text { 4. Discovery } \\
\text { arguments }\end{array}$} & $\begin{array}{l}\text { 9. Argument from cause to } \\
\text { effect }\end{array}$ & $\begin{array}{l}\text { i. If people do not work, they } \\
\text { cannot invest in the FUTURE } \\
\text { and cannot have CHILDREN }\end{array}$ \\
\hline & $\begin{array}{l}\text { 10. Argument from best } \\
\text { explanation }\end{array}$ & $\begin{array}{l}\text { j. Watched protests yesterday } \\
\text { but was under the impression } \\
\text { that we just had an election! } \\
\text { Why didn't these people vote? }\end{array}$ \\
\hline & 11. Argument from sign & $\begin{array}{l}\text { k. Stock market hits new high } \\
\text { with longest winning streak in } \\
\text { decades. Great level of }\end{array}$ \\
\hline
\end{tabular}




\begin{tabular}{|c|c|c|}
\hline & & $\begin{array}{l}\text { confidence and optimism - } \\
\text { even before tax plan rollout! }\end{array}$ \\
\hline \multirow[t]{2}{*}{ 5. Other } & $\begin{array}{l}\text { 12. Argument from } \\
\text { analogy/example }\end{array}$ & $\begin{array}{l}\text { l. Thanks to Trump's tax } \\
\text { cuts, the American economy } \\
\text { started to grow again. Step by } \\
\text { step, by introducing the flat } \\
\text { tax also in Italy, the } \\
\text { production, the work, the } \\
\text { consumes, and our country } \\
\text { will start to grow again. }\end{array}$ \\
\hline & $\begin{array}{l}\text { 13. Argument from } \\
\text { Classification }\end{array}$ & $\begin{array}{l}\text { m. What we witnessed } \\
\text { yesterday was not dissent - } \\
\text { it was disorder. They weren't } \\
\text { protestors - they were } \\
\text { rioters, insurrectionists, and } \\
\text { domestic terrorists. }\end{array}$ \\
\hline
\end{tabular}

\subsection{Decision criteria}

The choice of an argumentation over another in case of doubt is based on the complexity criteria:

a. The argumentation scheme that describes more fully the argument prevails over the one that describes only one aspect, and

b. If an argumentation schemes explains more aspects of the argument than another argumentation scheme, the more explanatory argumentation scheme should be chosen.

For example, an ad hominem involves an evaluation - a value judgment on the speaker. However, an ad hominem is not only an evaluation, as the latter is the ground for attacking the credibility of what has been said. Thus, in case the speaker undermines the credibility of what the interlocutor or a third party claimed through a personal attack (negative evaluation), the argument is not from values, but ad hominem. 


\section{B. Arguments}

As pointed out above, the following fallacies represent the most frequent types of deception in political communication. These fallacies do not include some of the popular fallacies that are in fact legitimate types of argument in specific circumstances (such as the ad hominem). Instead, these fallacies can result in the fallaciousness of the arguments that the message expresses - in other words, an ad hominem is not necessarily fallacious, but one of the following fallacies is likely to be a possible cause of its fallaciousness (together with other factors such as relevance and dialogical appropriateness).

\section{Argument from consequences}

The argument from consequences connects the consequences of an action to the desirability of the action itself. The focus is on the action: independently of the possible goals of the agent (not taken into account), an action is proposed as desirable or not depending only on its consequences. The scheme has a positive and a negative variant (Walton et al., 2008, pp. 100-102). The positive one is the following:

\begin{tabular}{|l|l|}
\hline PREMISE & If $A$ is brought about, good consequences will plausibly occur. \\
\hline CONCLUSION & Therefore $A$ should be brought about. \\
\hline
\end{tabular}

The negative variant is the following:

\begin{tabular}{|l|l|}
\hline PREMISE & If $A$ is brought about, then bad consequences will occur. \\
\hline CONCLUSION & Therefore $A$ should not be brought about. \\
\hline
\end{tabular}

\subsection{Illustration}

The basic type of this argument connects consequences (which occur independently of the speaker) with a proposal of action. Emotional appeal such as fear increase the perception of the undesired consequences, leading to an "automatic" evaluation of the proposal. An example is the following:

If the ban were announced with a one week notice, the "bad" would rush into our country during that week. A lot of bad "dudes" out there!

Here, the focus of the argument is on the action - the decision to announce the ban giving a notice. The action is solely presented as desirable or not depending on is consequences, in this case the extreme bad outcome (an invasion of bad people). No goal is taken into account - only the action.

The argument has also an active variant, in the sense that a decision is influenced based on the consequences which are produced by the speaker himself. It is an argument from threat, which is simply a variant of a consequence. An example is the following: 
If U.C. Berkeley does not allow free speech and practices violence on innocent people with a different point of view - NO FEDERAL FUNDS?

Here, Trump is suggesting a decision of U.C. Berkeley based on the consequences that Trump himself would produce (cutting funds).

\section{Argument from practical reasoning}

The argument from practical reasoning places its focus on the goal. The agent aims at achieving a goal and is choosing the best means to do it. So, the means is the starting point and the action suggested is proposed as the best way to get to the desired result. This type of reasoning can be represented as follows (Brockriede and Ehninger, 1963; Brun and Betz, 2016; Clarke, 1979; Grennan, 1997, pp. 163-165; Hitchcock, 2017, chap. 15; Walton, 2015, 1992, pp. 89-90, 1990):

\begin{tabular}{|l|l|}
\hline PREMISE 1 & Agent $A$ has a goal $G$. \\
\hline PREMISE 2 & Carrying out this action $B$ is the best means to realize $G$. \\
\hline CONCLUSION & Therefore, $A$ should bring about action $B$. \\
\hline
\end{tabular}

The elements of this scheme are two: the Goal, which is the reason for action, and the evaluation of the best means.

\subsection{Illustration}

The basic type of this argument can be illustrated as follows:

Will be meeting at 9:00 with top automobile executives concerning jobs in America. I want new plants to be built here for cars sold here!

In this message, Trump is stating clearly his goal ("I want new plants to be built here") and the means to achieve it (a meeting with top automobile executives). This means is not evaluated as the best - but as what he chooses to do to pursue the goal.

A specific type of practical reasoning is expressed through the exclusion of the possible alternatives (we cannot do otherwise), through the use of dilemmas or the use of the adverb "only" An example is the following:

Welcoming people who are actually running away from the war, but for criminals, drug dealers, and murderers who bring war to our home, there is only one solution: EXPULSION.

Here, Salvini sets the goal (we need to solve the problem of criminal immigrants) and presents only two possibilities: either expulsion or living with them. The means to the goal is thus only one, unless one gives up the goal itself.

In some cases, the goal is presupposed, and only the actions are considered. For example, in the following example, Salvini is criticizing the behavior of the major of Napoli, De Magistris, for being too favorable to immigrants:

De Magistris should provide social housing for the Neapolitans instead of inviting all the immigrants of the world 
Here, two distinct courses of action are compared, clearly considering the goal of the major - promoting the interests of the city he manages. The actions are shown as incompatible, even though integrating or accepting immigrants has been shown to improve the city's economy or wellness.

\subsection{Distinctions}

The Argument from Practical Reasoning can be confused with the Argument from Consequences, as in some cases both schemes provide a suggestion of action.

\subsubsection{Argument from Practical Reasoning vs. Argument from Consequences}

The two arguments have different foci, namely they start from different perspectives. The argument from practical reasoning starts from a goal, and assesses the means thereto. The argument from consequences does not consider the goals, but only an action, which is evaluated considering its direct or indirect effects (which can be good or bad). An example is the following:

We need to stop being exploited by Mexico. Massive trade deficits \& little help on the very weak border must change, NOW!

Here, Trump takes into account a goal ("We need to stop being exploited by Mexico") which is already considered as worth pursuing - he is not providing arguments therefor. Then, he provides the "best" solution, namely changing some conditions of the relationship between the two countries. follows:

This argument can be transformed into an argument from consequences as

We need to reduce massive trade deficits with Mexico and getting their help on the very weak border, NOW! Otherwise, we will continue to be exploited by Mexico.

Here, the focus is on the action, not a goal. The goal is not considered; rather, only the action is evaluated. While the Practical reasoning allows thinking about alternatives, the argument from consequences do not consider this possibility, as it is not matter of reaching an objective, but deciding on whether to do or not to do something.

\section{Argument from commitment}

Argument from commitment encompass the relations between an interlocutor and his commitments. This scheme is represented as follows (Walton et al., 2008, p. 132):

\begin{tabular}{|l|l|}
\hline $\begin{array}{l}\text { COMMITMENT } \\
\text { EVIDENCE PREMISE: }\end{array}$ & $\begin{array}{l}\text { In this case it was shown that } a \text { is committed to proposition } A \text {, } \\
\text { according to the evidence of what he said or did. }\end{array}$ \\
\hline $\begin{array}{l}\text { LINKAGE OF } \\
\text { COMMITMENTS } \\
\text { PREMISE: }\end{array}$ & $\begin{array}{l}\text { Generally, when an arguer is committed to } A \text {, it can be inferred that he } \\
\text { is also committed to } B .\end{array}$ \\
\hline CONCLUSION: & In this case, $a$ is committed to $B$. \\
\hline
\end{tabular}


This scheme is normally used to represent arguments that establish a commitment to a future course of action (which is normally considered as good or as the consequence of a specific position).

\subsection{Illustration}

The simplest form of argument from commitment provides a relationship between an action (future, present, or past) and a promise or other forms of commitment-incurring behaviors. The argument is aimed at showing a coherence and thus a justification - or a need of action.

\section{The crackdown on illegal criminals is merely the keeping of my campaign} promise.

In this example, the action (the crackdown) is presented as matter of coherence with the past promises.

A most complex form of argument from commitment relates a person with his or her future actions - stemming from a general commitment - which carry a value judgment on his or her personality, such as in the following case:

\section{I promise that our administration will ALWAYS have your back. We will} ALWAYS be with you!

Here, Trump is committing himself to a future course of action to elicit a positive judgment on himself.

\subsection{Distinctions}

The Argument from Commitment can be confused with the Argument from Consequences, as in some cases both schemes provide an evaluation based on future actions.

\subsubsection{Argument from Commitment vs. Argument from Consequences}

The confusion between an argument from commitment and one from consequences results from the fact that in both cases, the action is in the future and it is aimed at proving an evaluation. We consider the following case:

The American dream is back. We're going to create an environment for small business like we haven't had in many, many decades!

In this message, Trump refers to a future action: is it a commitment or a consequence? The difference lies in the causality relation. Trump here is not presenting an effect of a choice, but rather a promise, a commitment to a future action that is positive. Trump has already been elected, and is only showing what he is going to do based on his promises. Moreover, his campaign was focused on the notion of "American Dream" and now he is stating the implications of his previous commitment.

This argument can be turned into an argument from commitment as follows: 
If I am elected, I will give you back the American Dream. We're going to create

an environment for small business like we haven't had in many, many decades!

Here, the audience is not faced with a plan of action coherent with a promise. Rather, the audience is called to act based on the consequences of their decision. The focus is on the action (voting for Trump) which is evaluated considering the consequences thereof.

\section{Argument from values}

Argument from values encompass the relations between an interlocutor and his goal. It is the starting point of a decision-making reasoning, as it sets or justifies the goal of specific actions. This scheme has two variants, one positive and one negative. The positive one is represented as follows (Walton et al., 2008, p. 321):

\begin{tabular}{|l|l|}
\hline PREMISE 1: & Value $V$ is positive as judged by agent $A$ (judgment value) \\
\hline PREMISE 2: & $\begin{array}{l}\text { The fact that value } V \text { is positive affects the interpretation and therefore } \\
\text { the evaluation of goal } G \text { of agent } A \text { (If value } V \text { is good, it supports } \\
\text { commitment to goal } G \text { ). }\end{array}$ \\
\hline CONCLUSION: & $V$ is a reason for retaining commitment to goal $G$ \\
\hline
\end{tabular}

The negative one is the following:

\begin{tabular}{|l|l|}
\hline PREMISE 1: & Value $V$ is negative as judged by agent $A$ (judgment value) \\
\hline PREMISE 2: & $\begin{array}{l}\text { The fact that value } V \text { is negative affects the interpretation and } \\
\text { therefore the evaluation of goal } G \text { of agent } A \text { (If value } V \text { is } \text { bad, it } \\
\text { supports commitment against goal } G \text { - or no commitment to } G \text { ). }\end{array}$ \\
\hline CONCLUSION: & $V$ is a reason not to commit to goal $G$ / commit to not- $G$ \\
\hline
\end{tabular}

\subsection{Illustration}

The most basic form of argument from values consists in setting a goal because it instantiates a value - namely a positive or negative evaluation of a state of affairs. An example is the following:

\section{We must keep "evil" out of our country!}

Here, Trump is merely setting a goal based on a value judgment (bad people need to be kept out of the country). He is not considering consequences or means - only the goal.

In the following argument, the speaker is justifying his goal based on its description:

Confindustria does not represent the true world of the companies; I care about the small companies, the "LITTLE".

Salvini is presenting a dichotomic world in which two different goals are pursued: the big companies vs. the small ones, which he describes as the "little," namely the ones who need protection and care. The goal is thus set by invoking the values of protection and (Christian) pity. 


\subsection{Distinctions}

Argument from Values needs to be distinguished from the Argument from Commitment and Argument from Practical reasoning.

\subsubsection{Argument from Values vs. Argument from Commitment}

Argument from values express the need of pursuing a goal, because it is good, just, necessary, etc. Argument from commitment is similar in the sense that it justifies a course of action or relates a course of action to one's commitments. However, the argument from values moves in the opposite direction: in the argument from values, the speaker has a goal because the goal is good; in the argument from commitment, the speaker does something to be coherent, good, etc. For example we consider the following argument from values:

Peaceful protests are a hallmark of our democracy. Even if I don't always agree, I recognize the rights of people to express their views.

Trump is classifying a behavior (protests) as good, and thus as a goal for future actions (we need to allow them). An argument from commitment would be quite different:

I will recognize the rights of people to express their views, as I am on the side of freedom.

Here, the action is justified based on a commitment. Or the argument from commitment can sound as follows:

I will recognize the rights of people to express their views, I will always protect freedom.

Here, the specific commitment (to freedom of expression) is related to a more generic commitment that mirrors the speaker's quality (he is then a good person...).

\subsubsection{Argument from Values vs. Practical reasoning}

The argument from values sets a goal, while the practical reasoning selects the means to achieve it. Thus, while both concern a goal, the practical reasoning presupposes an argument from values (I need to evaluate my goal first), but an argument from values does not necessarily lead to an argument from practical reasoning (I can set a goal but not indicate the means). An example is the following:

Mexico has taken advantage of the U.S. for long enough. Massive trade deficits \& little help on the very weak border must change, NOW!

Here, "Mexico has taken advantage of the U.S. for long enough" sets a goal - namely stopping the inequalities between the two countries. It is, therefore, an argument from values. Once this goal has been set, Trump provides a solution: "Massive trade deficits \& little help on the very weak border must change, NOW!" This is a practical reasoning, as it is a means for achieving the goal. 
The distinction between argument from practical reasoning and the argument from values hinges on the difference between actions and goals. A goal is an objective, a state of affairs that is considered as positive. An action is a sequence of steps taken willingly to achieve an end. The difference can be illustrated considering the following example:

De Magistris should provide social housing for the Neapolitans instead of inviting all the immigrants of the world

Here, two courses of action are compared, presupposing that the goal of a major is to take care of his citizens. Thus, it is a practical reasoning (to be a good major, he should do $\mathrm{X}$ instead of $\mathrm{Y}$ ). However, we can turn it into an argument from values as follows:

De Magistris should take care of the Neapolitans instead of the immigrants. He is the major of Neapoli, and not of Africa.

In this case, no actions are considered, but goals (taking care of citizens vs. immigrants) based on one's responsibilities as a major. The argument sets goals, not courses of action.

\section{Ad hominem argument}

The ad hominem argument connects the character of a person with the acceptability of his argument or viewpoint. By attacking the character, the acceptability of a speaker's position is undermined. The scheme is the following (Walton et al., 2008, p. 142):

\begin{tabular}{|l|l|}
\hline $\begin{array}{l}\text { CHARACTER ATTACK } \\
\text { PREMISE: }\end{array}$ & $a$ is a person of bad character. \\
\hline CONCLUSION: & $a$ 's argument $\alpha$ should not be accepted. \\
\hline
\end{tabular}

\subsection{Illustration}

The typical example of an ad hominem consists in a direct attack on the speaker's character in order to destroy the acceptability of his words. An example is the following:

The failing @nytimes does major FAKE NEWS China story saying "Mr.Xi has not spoken to Mr. Trump since Nov.14."

Here, Trump is not providing arguments against the quote; he is only attacking the credibility of the NY Times. By calling it "failing" (and labelling the story as "fake news”), Trump is diminishing its credibility.

The attack to a source of information or to a speaker can be unrelated to a specific claim, argument, or position. However, the goal of this argument can be to destroy the credibility of the source in order to undermine all past, present, and future claims. An example is the following:

FAKE NEWS media knowingly doesn't tell the truth. A great danger to our country.The failing@nytimes has become a joke.Likewise@CNN.Sad! 
Here, the target is the credibility of different sources of information, whose credibility is attacked through the label of "fake news media." All their reports, as a consequence, are undermined.

\subsection{Distinctions}

Ad hominem argument can be confused with the Argument from Values when a person is the target of the evaluation.

\subsubsection{Ad hominem vs. Argument from Values}

The two arguments can be distinguishing considering the purpose of the scheme. An ad hominem is aimed at undermining the acceptability of a viewpoint by attacking its source. An argument from values is used for providing a value judgment that can affect a decision or action. We consider the following argument:

The Fake News media is officially out of control. They will do or say anything in order to get attention - never been a time like this!

Here, Trump is attacking the media. However, his goal is to discredit whatever they are saying and will say. For this reason, it is an ad hominem. In contrast, we consider the following:

Nancy Pelosi and Fake Tears Chuck Schumer held a rally at the steps of The Supreme Court and mic did not work (a mess)-just like Dem party!

Also here we have an attack to persons. However, these persons are not sources of information or opinion; they are political opponents. Trump does not want to undermine their credibility, but their desirability as politicians. Is thus setting a goal (a negative one) for his audience.

\section{Victimization}

A variant of both the argument from values and ad hominem is the victimization. Instead of attacking the interlocutor directly to undermine his viewpoint (ad hominem) or providing a negative value judgment on an individual (argument from values), the speaker acts as the victim of an injustice. The effect is the implicit classification of the interlocutor or the individual as unjust, unfair, aggressive, etc. This value judgment can be used for depicting a person as bad, or even suggesting that what this person claims should not be accepted.

\subsection{Illustration}

A typical case of victimization is the following, in which the speaker (Trump) is presenting himself as the victim of a conspiracy of media:

It is amazing how rude much of the media is to my very hard working representatives. Be nice, you will do much better! 
Trump is not directly attacking the media (using terms such as "fake news media"). Rather, he expresses surprise before an injustice - the media are allegedly attacking his representatives in breach of any politeness. This surprise carries a negative value judgment on the media, which is a tool for undermining their reports (they are biased, impolite, etc.).

The victimization can be also used for triggering a negative value judgment on the opponents of a specific policy or the speaker. A clear case is the following:

Luxembourgh, Belgium, and now France... Now it is official, also in the rest of Europe, it is Salvini's fault!

Salvini is depicting himself as the victim of an international conspiracy, where not only political opponents, but whole countries are attacking him.

\section{Argument from popular opinion}

The argument from popular opinion is an appeal to what people believe, think, or (in the practical version) do. The reasoning underlying this type of argument is grounded on the presumption that what is common knowledge can be presumed to be accepted or acceptable. However, this is only a presumption, and it depends on the actual size of the reference group, the access to information it can have, and the actual words or beliefs attributed to the community. The argument has the following pattern (Walton et al., 2008, pp. 122-125):

\begin{tabular}{|l|l|}
\hline $\begin{array}{l}\text { GENERAL ACCEPTANCE } \\
\text { PREMISE: }\end{array}$ & $A$ is generally accepted as true. \\
\hline PRESUMPTION PREMISE: & $\begin{array}{l}\text { If } A \text { is generally accepted as true, that gives a reason in favor of } \\
A \text {. }\end{array}$ \\
\hline CONCLUSION: & There is a reason in favor of $A$. \\
\hline
\end{tabular}

\subsection{Illustration}

The typical example is an appeal to the community of people, which is frequently not identified nor quantified:

Everyone acknowledges that the fundamentals of the Italian economy are good and do not correspond to the present spread.

Here, Salvini is arguing in favor of the decision not to take into account the financial indicators and continue his plan aimed at increasing the spending. The conclusion is only supported by the appeal to the "everybody," a group that is not identified (it can refer to ordinary people, experts, politicians, etc.) nor quantified (it may refer to a majority, a group, the totality of the people).

The reference to the popular or common opinion can be made through statistics which suggest that the "people" have a shared opinion that needs to be followed. 
According to a poll of the European Parliament, only 44\% of the Italians would vote to stay in the EU. Everyone acknowledges now that it is necessary to REBUILD IT.

Here, Salvini is presenting a popular will that justifies his actions and choices.

\section{Argument from expert opinion/position to know}

The other type of argument from external sources is the argument based on the knowledge of the source. The strength of the argument is grounded on the fact that the source has either a superior knowledge in a specific field (expert) or has privileged access to information (position to know) due to his/her position, conditions, profession, etc. The two distinct types of knowledge are distinguished in argumentation, but they can be considered jointly as in many contexts (such as political discourse) it is hard to distinguish between position to know and expertise. The unified scheme is the following (Walton et al., 2008, pp. 89-92):

\begin{tabular}{|l|l|}
\hline PREMISE 1: & $\begin{array}{l}\text { Source } a \text { is in position to know about things (is an expert) in a certain subject } \\
\text { domain } S \text { containing proposition } A \text {. }\end{array}$ \\
\hline PREMISE 2: & $a$ asserts that $A$ is true (false) \\
\hline & $\begin{array}{l}\text { If source } a \text { is in position to know about things (is an expert) in a certain } \\
\text { subject domain } S \text { containing proposition } A \text {, and asserts that } A \text { is true (false), } \\
\text { then } A \text { can be accepted as true (false). }\end{array}$ \\
\hline CONCLUSION: & A can be accepted as true (false) \\
\hline
\end{tabular}

\subsection{Illustration}

The typical case is the appeal to the words of a person who has privileged access to information. The acceptability of the conclusion depends on how knowledgeable he is, and how trusted he can be. An example is the following:

\section{According to General Mattis, soldier Ryan died on a winning mission, not a} "failure."

Here, the topic is the death of a US soldier - allegedly in a mission that was useless. Trump reports the words of the individual who can have the best access to the information on the mission, namely the secretary of defense.

The appeal to sources of information can be further backed by the reference to the grounds on which such sources base their claims. An example is the following:

.@FoxNews from multiple sources: "There was electronic surveillance of Trump, and people close to Trump. This is unprecedented." @FBI

Here, the appeal to a newspaper is further backed by the reference to the "multiple sources" on which FoxNews allegedly relied to provide this piece of information.

\subsection{Distinctions}


The argument from position to know/expertise can be hardly confused with other schemes. However, there is a specific case in which the boundaries with the popular opinion are blurred.

\subsubsection{Argument from position to know vs. Argument from popular opinion}

The possible confusion can result from an argument that cites a source of information that reports a popular opinion. In this case, the two arguments seem to be intertwined, such as the following case:

The new Rasmussen Poll, one of the most accurate in the 2016 Election, just out with a Trump 50\% Approval Rating. That's higher than O's \#'s!

In this case, the conclusion is that Trump is liked more than Obama, as the majority of people supports him. The ground is the popular opinion is, however, a position to know argument based on the source of the poll, which is extremely reliable. Thus, the two arguments are involved in this message - the position to know provides credibility to the popular opinion.

\section{Argument from sign}

The argument from sign connects an event, a behavior, an entity to its possible cause based on a presupposed causal relationship. The structure of this argument is the following (Walton et al., 2008, p. 169):

\begin{tabular}{|l|l|}
\hline SPECIFIC PREMISE: & $A$ (a finding) is true in this situation. \\
\hline $\begin{array}{l}\text { GENERAL } \\
\text { PREMISE: }\end{array}$ & $B$ is generally indicated as true when its sign, $A$, is true. \\
\hline CONCLUSION: & $B$ is true in this situation. \\
\hline
\end{tabular}

The argument from sign is the discovery of something that produced the event under consideration.

\subsection{Illustration}

The argument from sign is used for two distinct purposes. The first purpose is to provide an indicator from which the speaker concludes a specific quality or cause. An example is the following:

Stock market hits new high with longest winning streak in decades. Great level of confidence and optimism - even before tax plan rollout!

The speaker is not confronted with an event - he is providing one to the public for a specific purpose. The event is an indicator - something that is naturally connected to a presumptive cause, in this case, the positive politics or economic environment. The relationship between the effect and its cause is clearly weak and not acceptable, but this does not diminish its argumentative role as a sign of the alleged good politics of Trump.

A more complex use is the relation between a specific even and a causal relation that is generalized. The argument from sign can be used to find a generalize cause or trend from one or more instances. An example is the following: 
In Brazil, Bolsonaro got many votes. The wind is changing everywhere.

Here, Salvini is presenting an indicator of a general cause - Bolsonaro is depicted as the epiphenomenon of a change of views.

The argument from sign is also used for showing a bad habit or value of a person. The speaker provides an indicator that he then links to a belief, a character aspect or a disposition that can lead to a judgment on the person. An example is the following:

Democrat Jon Ossoff, who wants to raise your taxes to the highest level and is weak on crime and security, doesn't even live in district.

Here, Trump is providing a sign (the fact that a candidate does not live in the district that he wants to run) of the candidates' poor commitment to his people.

\subsection{Distinctions}

The Argument from Sign can be confused with the Argument from Values

\subsubsection{Argument from sign vs. Argument from Values}

Both the argument from sign and from values can be used for expressing a value judgment on a person. However, while the argument from sign provides a reason (an indicator) of a bad quality, the argument from values moves from a judgment to an explicit or implicit suggestion of action or commitment. An example is the following:

\section{Mark Cuban is not smart enough to run for president!}

Here, Trump is giving a sign (Cuban decided not to run for president) of a bad quality (he is not smart enough). For this reason, it is an argument from sign. It is possible to turn this argument into one from values as follows:

I know Mark Cuban well. He backed me big-time but I wasn't interested in taking all of his calls. He's not smart enough!

Here, Trump provides a value judgment without any backing or indicator. He simply justifies his commitment not to have anything to do with him because he is not smart (bad quality).

\section{Argument from best explanation}

The argument from best explanation provides an explanation to a phenomenon that the speaker takes into account. The scheme is the following (Walton et al., 2008, p. 171):

\begin{tabular}{|l|l|}
\hline PREMISE 1 & F is a finding or given set of facts. \\
\hline PREMISE 2 & E is a satisfactory explanation of F. \\
\hline PREMISE 3 & No alternative explanation E\& given so far is as satisfactory as E. \\
\hline CONCLUSION & Therefore, E is plausible, as a hypothesis. \\
\hline
\end{tabular}


The argument from best explanation starts with something that has apparently no explanation, and the speaker claims or suggest an interpretation thereof.

\subsection{Illustration}

The argument from best explanation is aimed at providing an interpretation of an apparently strange phenomenon. Therefore, the starting point is something unusual, which is explained by the speaker. An example is the following:

Watched protests yesterday but was under the impression that we just had an election! Why didn't these people vote?

In this message, Trump considers an event that is unusual (protests against him). To account for it, he provides an (unreasonable) explanation of what is happening in the protesters' minds - namely that they did not vote, so they need to express their preference by protests. Here, Trump is giving the best explanation (according to him) of why these protesters are rallying against him.

The argument from best explanation is also used to depict conspiracy scenarios. An example is the following:

The real story here is why are there so many illegal leaks coming out of Washington? Will these leaks be happening as I deal on N.Korea etc?

Here, Trump is proposing an explanation of the leaks, which is related to a conspiracy by the "deep state" against him while he is addressing some hot topics such as North Korea.

\subsection{Distinctions}

The Argument from Best Explanation can be confused with the Argument from Sign

\subsubsection{Argument from Best Explanation vs. Argument from Sign}

The two arguments are very similar. However, the type of event to be accounted for is different. The argument from sign uses an indicator - namely an event (such as smoke) presumptively associated with a cause (fire). In contrast, an argument from best explanation is "passive" in the sense that it starts from an event that is puzzling - at least for the speaker. The event is not an indicator, but simply an event whose explanation is needed. An example is the following:

Interesting that certain Middle-Eastern countries agree with the ban. They know if certain people are allowed in it's death \& destruction!

The agreement of the Middle-East countries with the ban is not an indicator. It is a behavior that is not presumptively related to any specific cause. Trump provides an interpretation thereof (the "evil" nature of some countries), which is thus his "best explanation.” 


\section{Argument from cause to effect}

The argument from cause to effect is used to predict a future event from an observed cause. The scheme is the following (Walton et al., 2008, p. 168):

\begin{tabular}{|l|l|}
\hline PREMISE 1 & Generally, if $A$ occurs, then $B$ will (might) occur. \\
\hline PREMISE 2 & In this case, $A$ occurs (might occur). \\
\hline CONCLUSION & Therefore, in this case, $B$ will (might occur). \\
\hline
\end{tabular}

This scheme has two crucial uses:

1. Applying a causal/legal law or generalization and drawing a conclusion on what happens

2. Predicting a behavior from some stable characteristics of a person

\subsection{Illustration}

The argument from cause to effect can be used to predict a future event or a future behavior. An example of the first use is the following:

As president, I'll put America on a path to achieve a carbon-pollution free electricity sector by 2035 - a path that no future president can turn back.

Here, Biden is providing a prediction on what is going to happen after his policies. It is worth noticing that the stress of the argument is on the occurrence of the event, and not on its quality (the evaluative dimension is left in the background).

The argument from cause to effect is used also for stressing causal relations. Instead of stating a prediction, the speaker can state the causal generalization only, as in the following case:

If people do not work, they cannot invest in the FUTURE and cannot have CHILDREN

Here, Salvini is stating a cause-effect relationship that is used to show the future effects of the current situation of unemployment.

The argument from cause to effect also captures the relationship between a law and its effects - a law is a cause of a specific punishment. An example is the following:

There are rules. If you run away from the war, you are my brother, but if you do not run from any war and you bring war to our place, I will send you back to where you came from.

Here, the effects are not matter of a decision - they are presented as what follows from the application of a law, which can be considered similar to a law of physics.

The second use is more complex, as it connects a stable characteristic of an individual (for instance, loyalty or untrustworthiness) with his or her future actions. An example is the following: 
As a legendary career diplomat, he is honest, integer, and skillful. That's exactly

how he'll lead the CIA.

Here, the chief of the Central Intelligence Agency is claimed to have specific features namely he is a legendary diplomat characterized by honesty, integrity, and skill. These stable dispositions are a cause of his future behavior - as they represent his "nature."

\subsection{Distinctions}

The Argument from Cause to Effect can be confused with the Argument from Sign and the Argument from Consequences.

\subsubsection{Argument from Cause to Effect vs. Argument from Sign}

Both arguments can be used in relationship with a characteristic of human personality. However, the argument from Cause to Effect presupposes a disposition, while the argument from Sign establishes such a disposition. An example in which the two arguments combine is the following:

I'm asking Ambassador Bill Burns to lead the Central Intelligence Agency because he's dealt with many of the thorniest global challenges we face. As a legendary career diplomat, he approached complex issues with honesty, integrity and skill. That's exactly how he'll lead the CIA.

Here, Biden first provides an outline of Burns' personality based on his past achievements: Burns is honest, integer and skilful because he acted in this way during his office and in many situations (Argument from Sign). Once this character has been established, Biden provides a prediction: he will lead the CIA in the same way. This is an argument from cause to effect stemming from his character.

\subsubsection{Argument from Cause to Effect vs. Argument from Consequences}

The argument from cause to effect is similar to an argument from consequences because in both cases the argument is based on an effect. However, in the argument from cause to effect, the speaker is simply providing what follows from a cause. In contrast, when using an argument from consequences, the speaker intends to modify the interlocutors' behavior by showing the good outcomes for them of a specific policy, event, decision. An example in which the two arguments are used at the same time is the following:

85\% of American households will get direct checks from the American Rescue Plan. For so many Americans, that means they can pay the rent. That means they can put food on the table. Share below what the American Rescue Plan will do for you.

First, Biden is showing the effects of the Rescue Plan: it will cause this specific effect. This is an argument from cause to effect. Then, he argues in favor of it considering the consequences: he is showing how this plan can change for the better the life of many Americans. 


\section{Argument from analogy/example}

The argument from analogy is used to transfer a predicate from one entity to another. By relying on a similarity between two cases, the speaker can argue that what applies to the former also applies to the latter. The scheme is the following (Macagno, 2017; Macagno et al., 2017; Walton et al., 2008, pp. 55-56):

\begin{tabular}{|c|c|}
\hline $\begin{array}{l}\text { SIMILARITY } \\
\text { PREMISE: }\end{array}$ & $\begin{array}{l}\text { Generally, case } C 1 \text { is similar to case } C 2 \text { as they share a characteristic } \\
G \text {. }\end{array}$ \\
\hline $\begin{array}{l}\text { BASE } \\
\text { PREMISE: }\end{array}$ & $A$ is true (false) in case $C 1$ \\
\hline $\begin{array}{l}\text { ABSTRACTION } \\
\text { PREMISE }\end{array}$ & $A$ is true (false) in what is $G$. \\
\hline CONCLUSION: & $A$ is true (false) in case $C 2$. \\
\hline
\end{tabular}

This argument can be extended to cover the use of examples, namely situations similar to the one under concerns, to draw a generalization. By showing that something has been the case in one or more instances, it is possible to suggest that it can happen in another situation. The argument from analogy basically presupposes a generalization ( $A$ is true (false) in what is $G$ ) that can be used for a further conclusion or left as a generalization.

\subsection{Illustration}

The argument from cause to effect can be used to predict a future event or a future behavior. An example of the first use is the following:

Thanks to Trump's tax cuts, the American economy started to grow again. Step by step, by introducing the flat tax also in Italy, the production, the work, the consumes, and our country will start to grow again.

Here, the US policies are compared to the Italian ones. Therefore, the effects that are obtained by such policies in the US are claimed to have the same effects in Italy.

A distinct use of analogy is the following, in which the speaker suggests a generalization or a specific conclusion, depending on the interpretation:

The threat from radical Islamic terrorism is very real, just look at what is happening in Europe and the Middle-East.

Here, Trump is using two distinct cases of terrorism to claim that the US are subject to the same threat. The comparison between the cases of terrorist acts that happen to have been brought about by extremists leads to a generalization (terrorist acts can be brough about in any place for religious extremism), which is used to show how the US can be the next victim (there are extremists coming in the US, therefore, terrorist attacks).

\section{Argument from Classification}


The argument from classification is used to attribute a predicate to an entity based on the definitional criteria of the predicate. The scheme is the following (Walton et al., 2008, p. 68; Walton and Macagno, 2010):

\begin{tabular}{|l|l|}
\hline $\begin{array}{l}\text { INDIVIDUAL } \\
\text { PREMISE: }\end{array}$ & $a$ has property $F$. \\
\hline $\begin{array}{l}\text { CLASSIFICATION } \\
\text { PREMISE: }\end{array}$ & $\begin{array}{l}\text { For all } x \text {, if } x \text { has property } F \text {, then } x \text { can be classified as having } \\
\text { property } G .\end{array}$ \\
\hline CONCLUSION: & $a$ has property $G$. \\
\hline
\end{tabular}

This argument is based on the meaning of the predicates $F$ and $G$ : $G$ can be the definition of $F$, or an element thereof, or a description thereof.

\subsection{Illustration}

The argument from classification can be used to name reality, denying or affirming that a state of affairs should be named in a certain way. An example of the first use is the following:

What we witnessed yesterday was not dissent - it was disorder. They weren't protestors - they were rioters, insurrectionists, and domestic terrorists.

In this example, Biden is naming the assault to the Capital by the protesters. However, he denies the common classifications to provide a new description of the situation. In this sense, he is presupposing the definitions of disorder, riot, insurrection, terrorism, and applying them to the situation observed. 


\section{References}

Austin, J.L., 1962. How to do things with words. Oxford University Press, Oxford, UK. Brockriede, W., Ehninger, D., 1963. Decision by debate. Dodd, Mead \& Co, New York. Brun, G., Betz, G., 2016. Analysing practical argumentation, in: Hansson, S.O., Hirsch Hadorn, G. (Eds.), The Argumentative Turn in Policy Analysis. Springer, Cham, pp. 39-77.

Cicero, M.T., 2003. Topica. Oxford University Press, Oxford, UK.

Clarke, D.S., 1979. Varieties of practical inference. South. J. Philos. 17, 273-286.

Duschl, R., 2008. Science education in three-part harmony: Balancing conceptual, epistemic, and social learning goals. Rev. Res. Educ. 32, 268-291. https://doi.org/10.3102/0091732X07309371

Grennan, W., 1997. Informal logic. McGill-Queen’s University Press, Montreal, Quebec.

Hastings, A., 1963. A reformulation of the modes of reasoning in argumentation. Ph.D. Dissertation, Northwestern University, Evanston, IL.

Hitchcock, D., 2017. On reasoning and argument: Essays in informal logic and on critical thinking. Springer International Publishing, Cham, Switzerland.

Jonsen, A., Toulmin, S., 1988. The abuse of casuistry. A history of moral reasoning. University of California Press Journals, Berkeley, CA.

Kienpointner, M., 1992. Alltagslogik: Struktur und Funktion von Argumentationsmustern. Fromman-Holzboog, Stuttgart, Germany.

Kienpointner, M., 1987. Towards a typology of argumentative schemes, in: Eemeren, F. van, Grootendorst, R., Blair, A., Willard, C. (Eds.), Argumentation: Across the Lines of Discipline. Foris, Dordrecht, Netherlands, pp. 275-287.

Kim, M., Anthony, R., Blades, D., 2010. Argumentation as a tool to understand complexity of knowledge integration, in: Proceedings of the 2nd International STEM in Education Conference - Beijing - 24-27 November 2012. Beijing Normal University, Beijing, China, pp. 154-160.

Konstantinidou, A., Macagno, F., 2013. Understanding students’ reasoning: Argumentation schemes as an interpretation method in science education. Sci. Educ. 22, 1069-1087. https://doi.org/10.1007/s11191-012-9564-3

Lawrence, J., Reed, C., 2016. Argument Mining Using Argumentation Scheme Structures, in: Baroni, P., Gordon, T., Scheffler, T., Stede, M. (Eds.), Computational Models of Argument. IOS Press, Amsterdam, Netherlands, pp. 379-390. https://doi.org/10.3233/978-1-61499-686-6-379

Macagno, F., 2019. Analizzare l'argomentazione sui social media. Il caso dei tweet di Salvini. Sist. intelligenti 601-632. https://doi.org/10.1422/95091

Macagno, F., 2017. The logical and pragmatic structure of arguments from analogy. Log. Anal. 60, 465-490. https://doi.org/10.2143/LEA.240.0.3254093

Macagno, F., 2015. A means-end classification of argumentation schemes, in: Eemeren, F. van, Garssen, B. (Eds.), Reflections on Theoretical Issues in Argumentation Theory. Springer, Cham, Switzerland, pp. 183-201.

Macagno, F., Gil, B., 2021. Análise argumentativa nas redes sociais: Bolsonaro no Twitter. Uma abordagem preliminar, in: Ferreira, I., Mateus, S. (Eds.), Retórica Mediatizada- a Comunicação Persuasiva Através Dos Media. Sistema Solar e Documenta, Lisbon, Portugal.

Macagno, F., Konstantinidou, A., 2013. What students’ arguments can tell us: Using 
argumentation schemes in science education. Argumentation 27, 225-243.

https://doi.org/10.1007/s10503-012-9284-5

Macagno, F., Walton, D., 2015. Classifying the patterns of natural arguments. Philos.

Rhetor. 48, 26-53. https://doi.org/10.1353/par.2015.0005

Macagno, F., Walton, D., 2014. Argumentation schemes and topical relations., in:

Gobber, G., Rocci, A. (Eds.), Language, Reason and Education. Peter Lang, Bern, Switzerland, pp. 185-216.

Macagno, F., Walton, D., Tindale, C., 2017. Analogical arguments: Inferential structures and defeasibility conditions. Argumentation 31, 221-243. https://doi.org/10.1007/s10503-016-9406-6

Mochales Palau, R., Moens, M.F., 2011. Argumentation mining. Artif. Intell. Law 19, 1-22. https://doi.org/10.1007/s10506-010-9104-X

Mochales Palau, R., Moens, M.F., 2009. Argumentation mining: The Detection, Classification and Structuring of Arguments in Text, in: Belgian/Netherlands Artificial Intelligence Conference. ACM, New York, pp. 351-352. https://doi.org/10.1145/1568234.1568246

Nussbaum, M., 2011. Argumentation, dialogue theory, and probability modeling: Alternative frameworks for argumentation research in education. Educ. Psychol. 46, 84-106. https://doi.org/10.1080/00461520.2011.558816

Perelman, C., Olbrechts-Tyteca, L., 1969. The New Rhetoric: A treatise on argumentation. University of Notre Dame Press, Notre Dame, IN.

Rapanta, C., Walton, D., 2016a. Identifying paralogisms in two ethnically different contexts at university level/Identificación de paralogismos en dos contextos universitarios diferenciados étnicamente. Infanc. y Aprendiz. 39, 119-149. https://doi.org/10.1080/02103702.2015.1111610

Rapanta, C., Walton, D., 2016b. The use of argument maps as an assessment tool in higher education. Int. J. Educ. Res. 79, 211-221. https://doi.org/10.1016/j.ijer.2016.03.002

Stevenson, C., 1944. Ethics and language. Yale University Press, New Haven, CT.

Stump, E., 2004. Boethius’s “De topicis differentiis.” Cornell University Press, Ithaca, IL and London, UK.

Walton, D., 2015. Goal-based reasoning for argumentation. Cambridge University Press, Cambridge, MA.

Walton, D., 2006. Fundamentals of critical argumentation. Cambridge University Press, New York, NY.

Walton, D., 2004. Classification of fallacies of relevance. Informal Log. 24, 183-185. https://doi.org/10.22329/il.v24i1.2133

Walton, D., 1995. Argumentation schemes for presumptive reasoning. Routledge, Mahwah, NJ.

Walton, D., 1992. Slippery Slope Arguments. Oxford University Press, Oxford, UK.

Walton, D., 1990. Practical Reasoning. Rowman and Littlefield, Savage, MD.

Walton, D., Macagno, F., 2015. A classification system for argumentation schemes. Argument Comput. 6, 219-245. https://doi.org/10.1080/19462166.2015.1123772

Walton, D., Macagno, F., 2010. Defeasible classifications and inferences from definitions. Informal Log. 30, 34-61. https://doi.org/10.22329/il.v30i1.692

Walton, D., Reed, C., Macagno, F., 2008. Argumentation schemes. Cambridge University Press, New York, NY.

Wei Feng, V., Hirst, G., 2011. Classifying arguments by scheme, in: Proceedings of the 49th Annual Meeting of the Association for Computational Linguistics: Human Language Technologies-Volume 1. Association for Computational Linguistics, 
Stroudsburg, PA, pp. 987-996. 


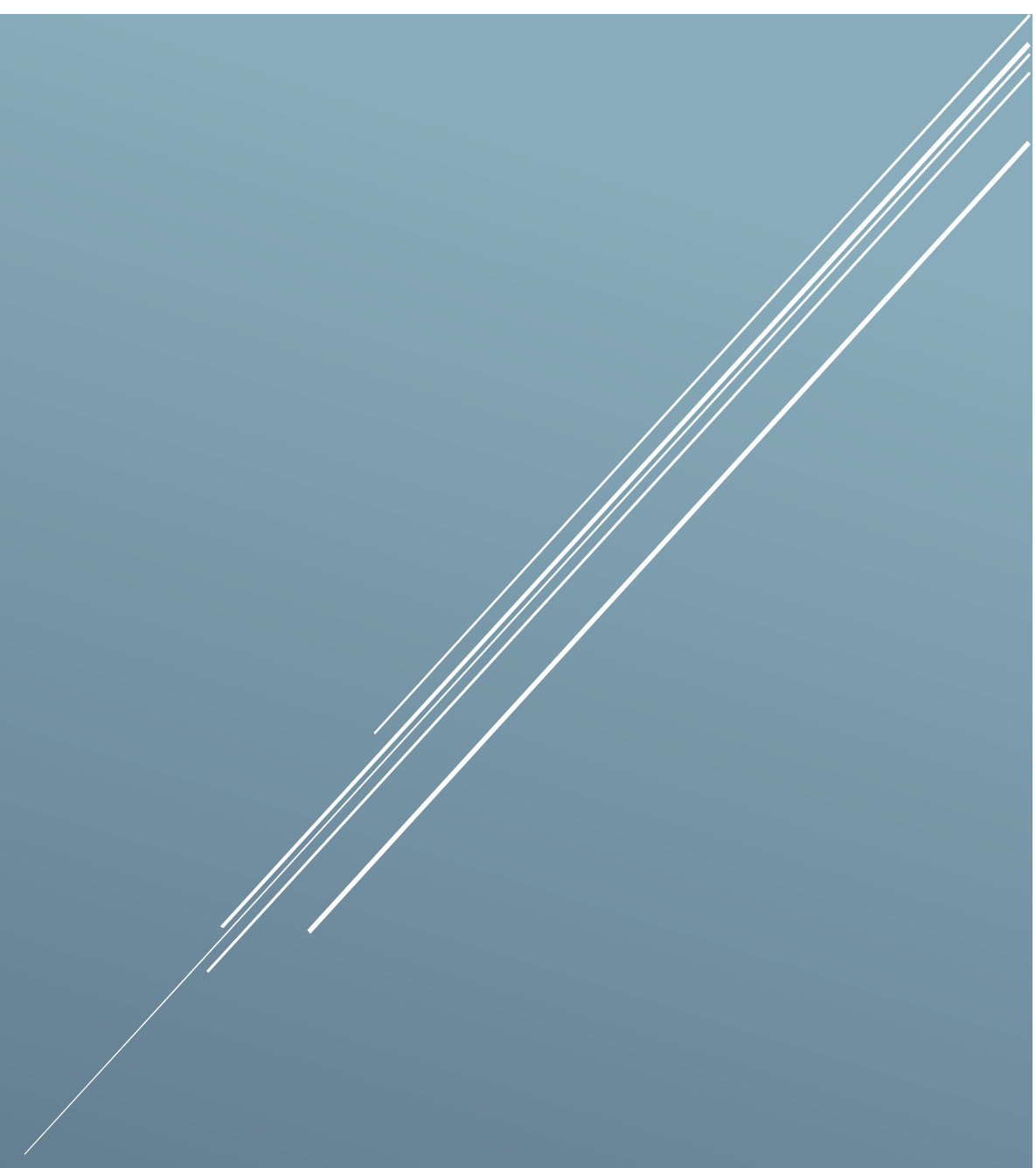

CODEBOOK FOR

FALLACY ANALYSIS 


\section{Table of Contents}

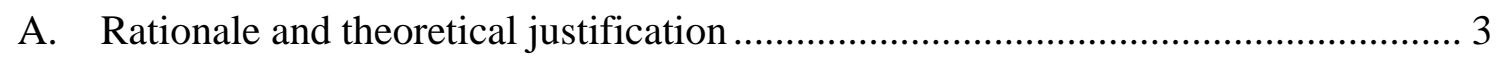

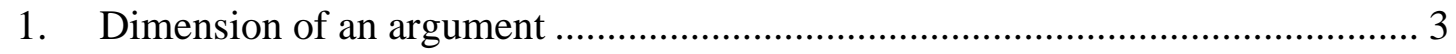

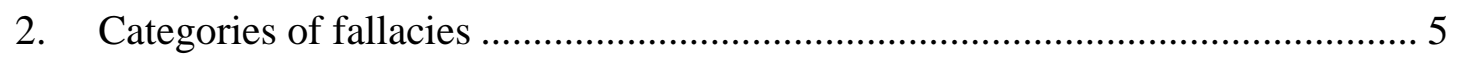

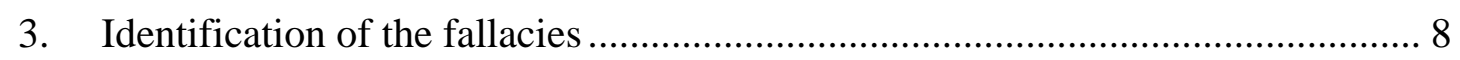

3.1. Criteria used for limiting the number of codes .......................................... 8

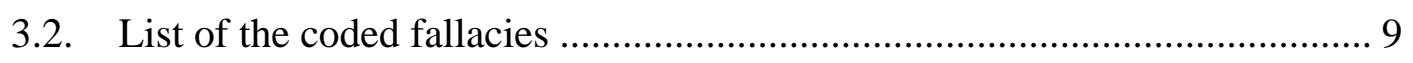

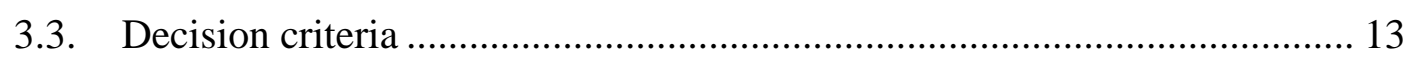

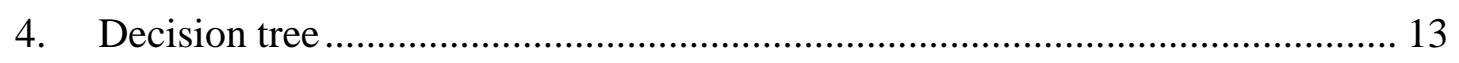

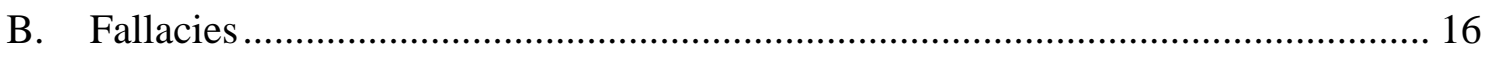

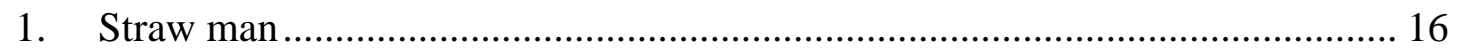

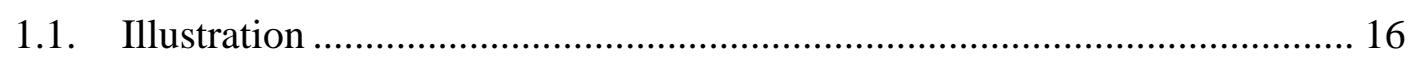

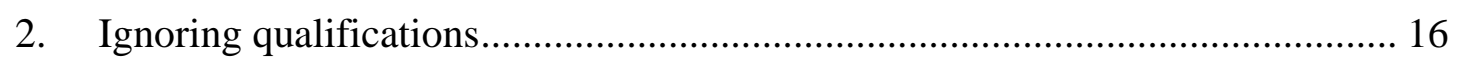

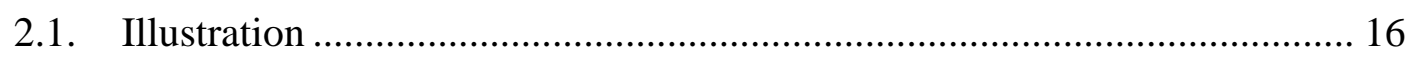

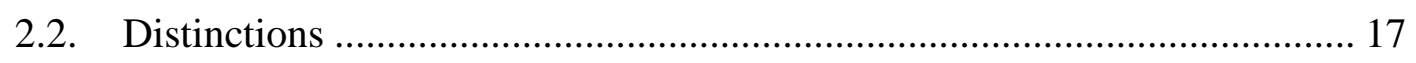

2.2.1. Ignoring qualifications vs. Straw man ............................................ 17

2.2.2. Ignoring qualifications vs. Question begging ................................... 18

2.2.3. Ignoring qualifications vs. Hasty generalization ................................ 18

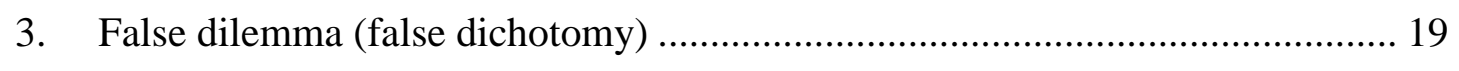

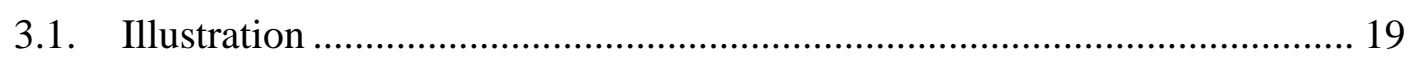

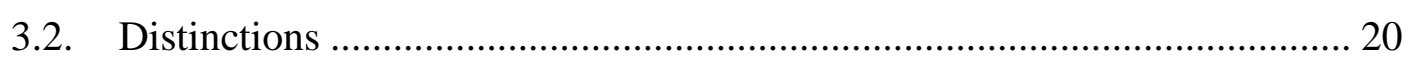

3.2.1. False dilemma vs. Ignoring qualifications............................................ 21

3.2.2. False dilemma vs. Question begging ................................................ 21

3.2.3. False dilemma vs. Persuasive definition........................................... 22

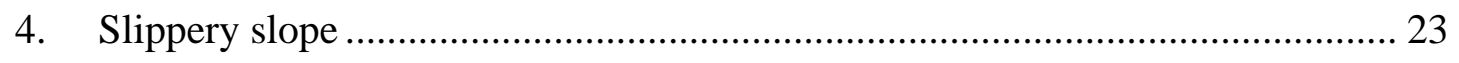

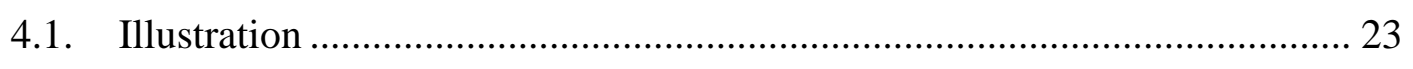

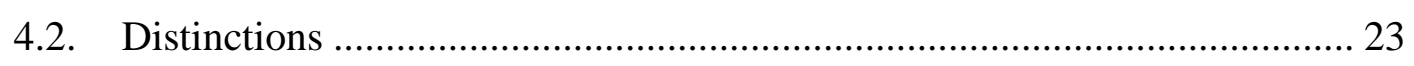

4.2.1. Slippery slope vs. Ignoring qualifications ........................................ 23

4.2.2. Slippery slope vs. False dilemma ...................................................... 24

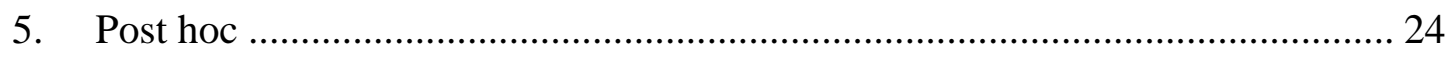

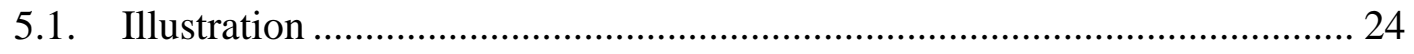

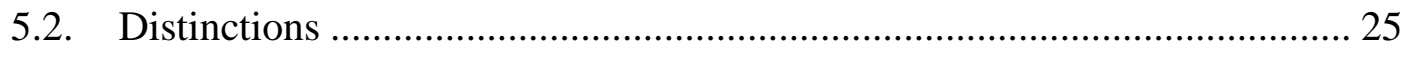

5.2.1. Slippery slope vs. Ignoring qualifications ........................................ 25

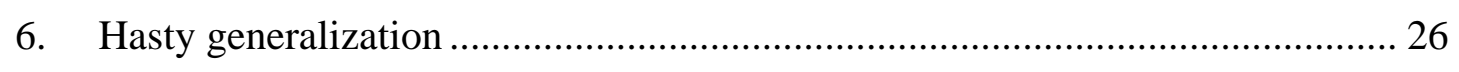

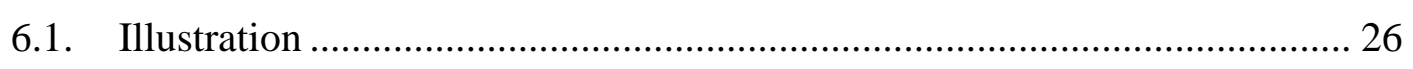




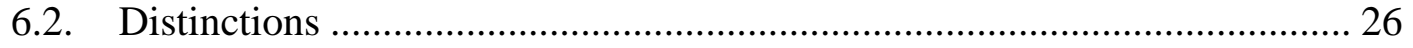

6.2.1. Hasty generalization vs. Post hoc ….................................................. 26

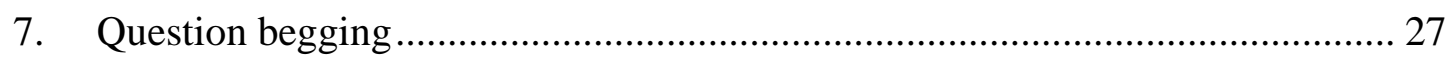

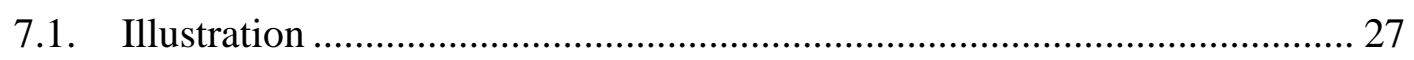

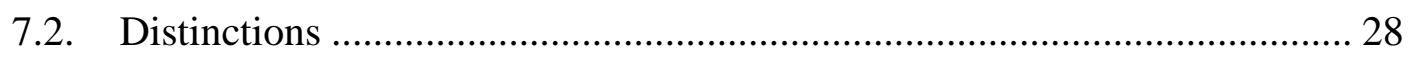

7.2.1. Question-begging vs. Persuasive definition........................................ 28

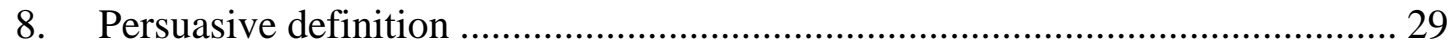

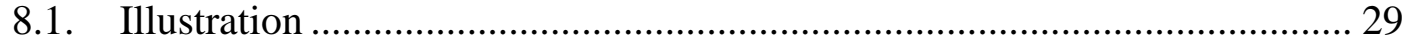

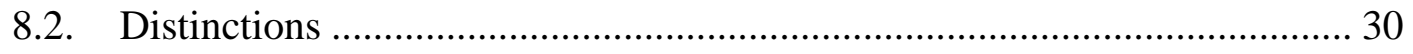

8.2.1. Persuasive definition vs. false dilemma............................................ 30

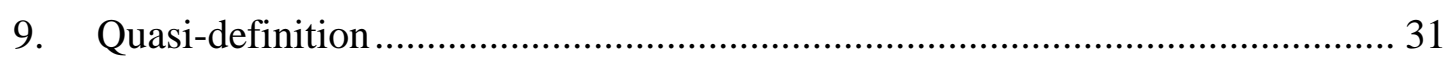

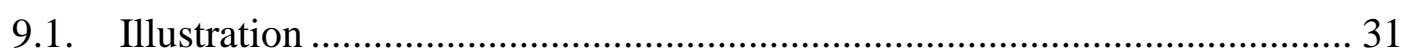

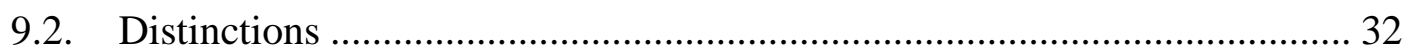

9.2.1. Quasi-definition vs. Persuasive definition .......................................... 32

9.2.2. Quasi-definition vs. Question-begging ............................................. 32

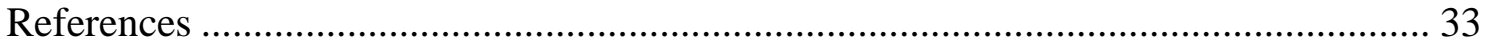




\section{A. Rationale and theoretical justification}

\section{Dimension of an argument}

A fallacy has been traditionally defined as an argument that appears to be valid, but in fact is not. The logical tradition has drawn a clear distinction between good and bad arguments, where the latter are detected through two criteria: soundness, namely the truth of the premises, and validity, namely the compliance with logical axioms generally the deductive ones (Reed and Walton, 2003). However, an argument is not only a logical construct - and deductive axioms are not the only ones characterizing arguments. Moreover, truth can be established only in very few cases of arguments exchanged in real-life contexts. More commonly, arguments are based on premises that represent the commitments of the interlocutor - directly based on evidence, or indirectly based on what is commonly accepted. In this framework, validity and soundness are not sufficient for analyzing the quality of an argument - nor are they necessary. Arguments can be deceptive for pragmatic or dialogical reason, and the backing or lack of backing of a premise can be hardly captured using the dichotomy between "true" and "false." Finally, dichotomy between good or bad arguments fails to acknowledge the fact that between these two extremes there are arguments that are weak or inadequate to the conclusion defended.

In order to analyze a fallacy, it is necessary to outline the dimensions of an argument. First, an argument is clearly a logical construct, namely a dialectical instrument in the classical meaning of the word. An argument consists in a series of statements (premises) logically related to a further statement called "conclusion," and transfers the acceptability of the premises to the conclusion based on some principles, indemonstrable and commonly accepted rules of inference (Aristotle, Topics, 100a 31b1-5) called topics or maximae propositiones in the ancient tradition and corresponding to the modern notion of warrant (Hitchcock, 2003; Toulmin, 1958).

Second, an argument is dialectical in the sense that it is part of a dialogue, and pursues a specific communicative goal, to "do things with words" (Austin, 1962) in a specific dialogical context. In the dialectical tradition, a clear distinction was drawn between the logical dimension (argument) and its pragmatic one, consisting in its expression and role in discourse (argumentation) (Boethius, De Topicis Differentiis, 1173D 22-31). In a modern perspective, an argument is not only regarded as a logical and semantic relationship between propositions, but as a complex speech act (van Eemeren and Grootendorst, 1984, pp. 40-46) pursuing different communicative goals. Walton clearly explained this dialogical dimension of arguments showing its essential relation with the types of dialogue in which they are used (Walton, 1990, p. 411):

Argument is a social and verbal means of trying to resolve, or at least to contend with, a conflict or difference that has arisen or exists between two (or more) parties. An argument necessarily involves a claim that is advanced by at least one of the parties. [...] The claim is very often an opinion, or claim that a view is right, but it need not be. In a negotiation argument, the claim could be to goods or to financial assets. The conflict or difference (stasis) that is the origin of the argument could be of different kinds-it could be a conflict of opinions, an unsolved problem, an unproven hypothesis, or even a situation where both 
parties are blocked from further actions they are trying to carry out. The different kinds of argument are different ways of trying to resolve these conflicts.

On this perspective, arguments are instruments in a specific conversational context characterized by specific dialogical goals, or rather interactional intentions (Bellack, 1968; Bellack et al., 1966; Gumperz, 1982, pp. 31-32; Merin, 1994, p. 238; Sinclair and Coulthard, 1992; Stubbs, 1983; Walton, 2007; Widdowson, 1979, p. 144). In this sense, arguments become essentially intertwined with the dialogical goal that a speaker proposes through his or her argument, which Walton captured in the theory of types of dialogue.

The third dialectical aspect of an argument concerns the common ground, which underlies both its logical and dialogical faces. This dimension can be defined "pragmatic" in the sense that refers to how an argument (the linguistic expression of a goal-directed reason) is related to the interlocutors (Kecskes, 2013, p. 21) and the dialogue in which it occurs (Hamblin, 1970, p. 40). The common ground dimension involves two interrelated aspects of an argument, its endoxical nature (an argument is grounded on what is commonly accepted, as underscored by Aristotle) and its defeasibility, namely the acceptability of its conclusion until contrary evidence is provided. The first aspect was addressed by Walton through the notion of commitment (Macagno, 2018; Macagno and Walton, 2017; Walton and Krabbe, 1995), while the second was developed in his theory of evidence and burden of proof (Walton, 2016, 2002).

Commitments are dialogical obligations, what a participant to a dialogue holds as true and thus accepts and is disposed to defend in case it is challenged. Commitments are thus the dialectical image of the logical concept of "truth" and the psychological notion of "belief" (Hamblin, 1971, 1970; Walton, 2010). An argument is intended to modify what an interlocutor accepts or is committed to (see Hamblin, 1970; Walton \& Krabbe, 1995) starting from his or her existing commitments, which can include not only encyclopedic information, but generalizations, definitions and word uses, and values and hierarchies thereof (Macagno and Walton, 2017). Such previous commitments of the interlocutor can be drawn from the evidence of previous dialogues or by presumption, namely relying on what is commonly accepted in a given culture (Macagno, 2015). Thus, commitments are not only the result of explicit dialogical acts; they also represent what is taken for granted by advancing an argument. Thus, implicit or "dark-side" commitments include distinct phenomena that in pragmatics would be classified as "pragmatic presuppositions," namely propositions taken for granted by a person in performing a speech act (whether an assertion or a different speech act), whose felicity, or conversational acceptability depends on the interlocutor's acceptance of such propositions (Allan, 2013; Stalnaker, 2002, 1974). Implicit commitments thus include not only the classical "semantic" presuppositions triggered by various grammatical phenomena (such as factives, etc.) and the theme-focus articulation of an utterance (Abrusán, 2011, 2010; Atlas, 1991; Gazdar, 1979; Kay, 1992; Levinson, 1983, chap. 4), but also the needed tacit assumptions (Ennis, 1982) necessary for the reasonableness of the argument and some conventional implicatures (such as the ones triggered by "but” or “only”) (Ducrot, 1980, 1972). Such “hidden” or dark-side commitments are the core of the argumentative strategies and the manipulative tactics, as the speaker needs to start from what an audience has accepted to prove a further point, but she or he can also present an unproven, unaccepted or even unacceptable proposition as commonly accepted, shared, and known (Macagno, 2018, 2015; 
Macagno and Walton, 2014). This implicit dimension of arguments draws the line between acceptable arguments and the sophistical ones.

The last dimension is the epistemic one, and concerns the role of evidence. An argument provides a presumptive reason to accept a conclusion, in the sense that the latter can be accepted and acceptable unless and until contrary and stronger arguments are advanced - namely arguments grounded not only on more accepted or acceptable premises, but also on (more) evidence (Walton, 2001, 1995a). Moreover, an argument modifies a status quo, namely the dialectical relation between a participant to a dialogue and a proposition. An argument modifies the attitude of the interlocutor towards a proposition that he or she considers as doubtful or unacceptable, turning it into a commitment. Thus, the speaker needs to fulfil a burden of proof: the reasons provided in favor of its acceptance need to overcome the reasons to doubt or not accept it. The notion of strength of argument is thus as crucial as the problem of its fallaciousness, as the potentially doubtful premises need to be grounded on sufficient backings (evidence) to provide probative weight on the conclusion (Walton, 2016, 2002, p. 16).

The four dimensions of dialectics can be represented as four vectors that shape the concept of argument (Figure 2).

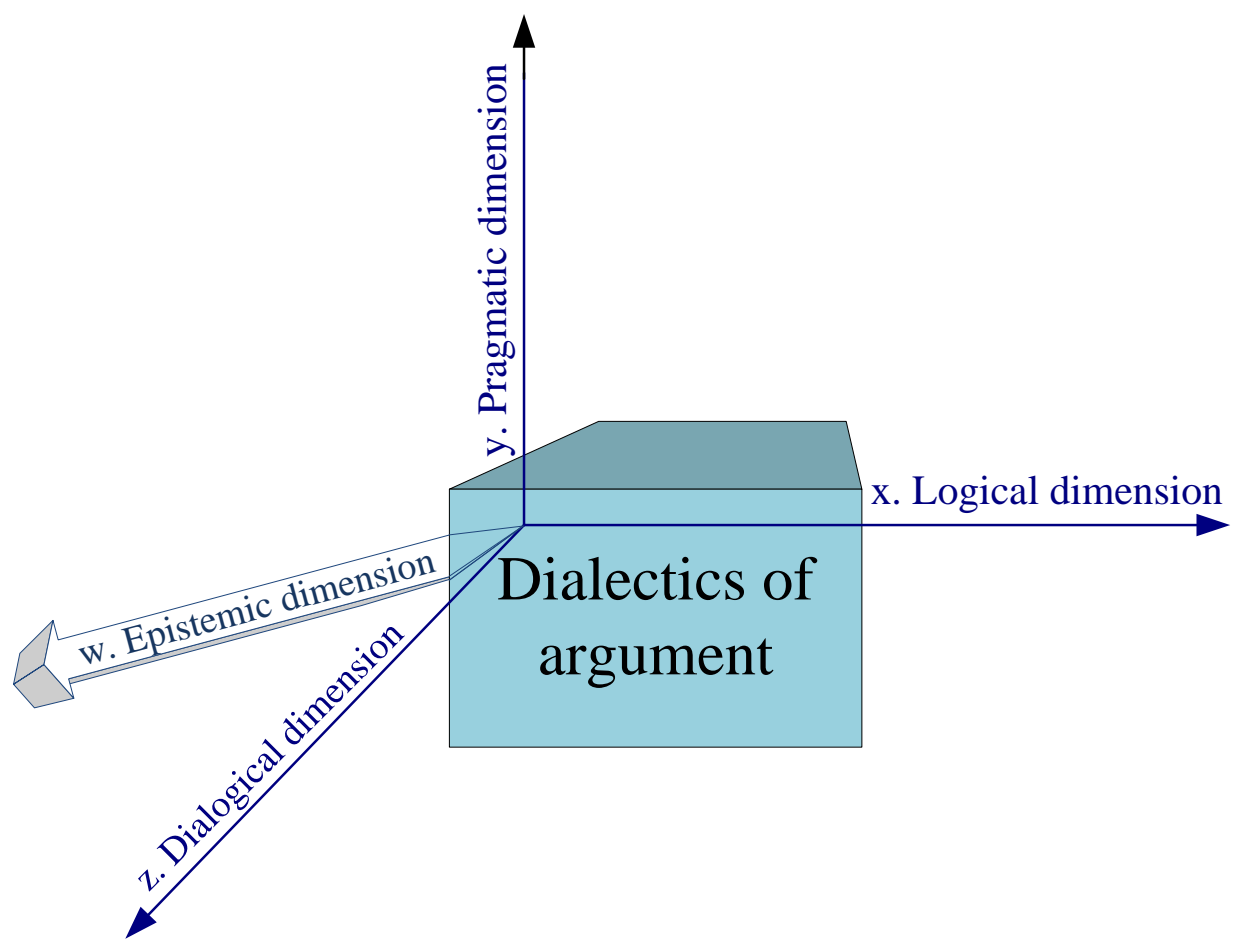

Figure 1: The dialectics of argument

These dimensions can be used for assessing an argument.

\section{Categories of fallacies}

Fallacies are distinguished in macro-categories based on the cause of the deceit (Kretzmann et al., 1982, p. 124), namely the reason that makes an argument a fallacy. The most basic level of analysis consists in considering the object, namely what goes 
wrong in a fallacious argument - and more precisely what dimension of an argument is used for deceptive purposes (Walton, 2008, 1995b).

The first dimension is the dialogical one, which addresses the relationship between the interlocutors and the activity they are engaging in. A speaker can manipulate the dialogue in two distinct ways: 1) by not complying with the dialogue game the interlocutors are engaging with, or 2) by failing to address or report correctly the commitments of the speaker (or other parties involved in a dialogue). The first category of fallacies includes the fallacies of irrelevance (Walton, 2004a, 2004b), namely fallacies named in different ways in the modern logical tradition to refer to continuations of the dialogue that do not address the topic or the goal of the dialogue (or the interlocutor's previous moves). For example, a speaker can divert the dialogue on a different issue ("handwaving" or "red herring", see Walton, 2004a). The second category of "dialogical" fallacies concern the commitments of the interlocutors, namely how what is said is reported and used according to its presumptive meaning, or instead it is distorted or manipulated. In this category of fallacies two cases are distinguished: 1) when the speaker interprets a statement (of the interlocutor or another party) in a nonstandard or non-presumptive way, ignoring qualifications that were stated or intended, or including ones that were not stated nor intended ("ignoring qualifications"), and 2) when the interlocutor's viewpoint/claim is misrepresented in order to attack him ("straw man," which includes classical fallacies such as "wrenching from context" or "misquotation"). Clearly, the straw man can rely inter alia on ignoring qualifications, but ignoring qualifications is not necessarily used to attack the interlocutor (for example, it is possible to misquote someone, or a law, to draw a conclusion).

The first group of fallacies can be summarized as follows:

A. Dimension 1 (Dialogical)

1. Relevance

1.1. Irrelevance

2. Commitments

2.1. Ignoring qualifications

2.2. Straw man

The alternative to the dialogical fallacies is a broad category that includes manipulations involving the representations of states of affairs provided by the speaker, or the conclusions drawn from them. The fallacies focusing on the reporting of others' commitments are thus distinguished from the ones that have as their object the speaker's representation of a state of affairs or the conclusions drawn from it.

This category is distinguished in two macro-categories: the classical group of the "linguistic" fallacies, and the ones involving how a state of affairs (a fact, a generalization) is represented and used for drawing further conclusions. Linguistic fallacies include the manipulation of the relationship between a state of affairs and its linguistic representation, namely how words, phrases, and sentences are used for representing facts or entities. The first distinction is between 1) the use of linguistic elements and 2) their modification. We will start with the latter. Some deceptive strategies focus on modifying the meaning of words, namely their definition or their "connotation," i.e. the evaluative inferences (resulting in value judgments or even emotive reactions) that result from the use of a word/phrase. Two fallacies can be found: the persuasive definition (modifying the meaning, for instance through the classical redefinition strategy "the true $\mathrm{X}$ is $\mathrm{Y}$ ”), and the quasi-definition (modifying the 
connotation of a term by providing a description of its referent aimed at drawing a specific and uncommon evaluative inference).

The alternative to the modification of a word's meaning is the uncommon, nonpresumptive, or non-defaultive use of a word/phrase. Two types of fallacies are committed in this case: the question-begging epithet, and the fallacies of ambiguity. The first type of fallacy is committed when the speaker uses a word or phrase in conflict with the common ground, without providing the necessary evidence for its use. For example, an epithet (such as "terrorist") is used to refer to an entity that has not been accepted or proven to be such, and the speaker does not provide evidence to this purpose. The question-begging is thus using a controversial or potentially controversial classification as it were accepted. The fallacies of ambiguity are based on the possible different meanings of an expression (or sentence). Fallacies of ambiguity can be the equivocation (the same expression used with two different meanings), amphiboly (the grammar of a statement allows different meanings, used strategically), and accent (a statement can bear distinct meanings depending on which word is stressed). To these fallacies, a non-dialogical use of the fallacy of ignoring qualifications should be added, addressing the unacceptable and non-presumable passage from utterance to propositional meaning.

This dimension of fallacies can be named "pragmatic" as it concerns the use of linguistic terms and their relationship with the interlocutors' commitments. The fallacies falling under it can be summarized as follows:

B. Dimension 2 (Pragmatic: Word use)

3. Unpresumable word use

3.1. Unpresumable state of affairs taken for granted (Question-begging)

3.2. Unpresumable use of word or sentence ambiguity (Equivocation, Amphiboly, Accent)

3.3. Unpresumable passage from utterance to propositional content (Ignoring qualifications)

4. Unpresumable word meaning

4.1. Definitional meaning (Persuasive definition)

4.2. Connotative meaning (Quasi-definition)

The pragmatic fallacies are opposed to the deceptive strategies that have as an object the "content" dimension - or the states of affairs that fallacies represent. This broad category is divided in two sub-categories: C) the representation of states of affairs and their relationships, and D) the representation of the available options for suggesting or supporting a decision.

The first sub-category includes the so-called "formal fallacies" (Hurley and Watson, 2018, pp. 125-126) and the "inductive” fallacies (Walton, 2008, chap. 8), namely 1) fallacies that deductively draw a necessary conclusion from a conditional and deductive axioms (affirming the consequent and denying the antecedent), and 2) the ones that establish the conditional, either by using induction (hasty generalization) or abduction (post hoc) in an unwarranted or unreasonable way. The fallacies falling under it can be summarized as follows:

C. Dimension 3 (Logical: Formal axioms and generalizations)

5. Wrong use of deductive axioms

5.1. Affirming the consequent

5.2. Denying the antecedent 
6. Unacceptable generalizations

6.1. By induction (Hasty generalization)

6.2. By abduction (Post-hoc)

The second sub-category (D), in contrast, is intended to present the possible options for a decision in a deceptive way. It includes the fallacies of false dilemma and slippery slope, which involve respectively alternatives and consequences unbacked by evidence or contrary to the common knowledge. For this reason, they can be considered as epistemic fallacies - insufficient evidence is given for taking for granted a specific alternative or consequence. The fallacies falling under it can be summarized as follows:

D. Dimension 4 (Epistemic: Unbacked alternatives and consequences)

7. Unbacked proposals for action

7.1. False dilemma

7.2. Slippery slope

\section{Identification of the fallacies}

The number and the types of fallacies varied across the tradition. Aristotle identified 13 fallacies (Aristotle, Sophistical Refutations), but this number increased over the years to include deceptive strategies based on emotions (fear, threats), personal attacks (ad hominem), and other misuses of generally acceptable patterns of reasoning (such as the ad verecundiam, etc.) (Hamblin, 1970; Walton, 1987; Woods et al., 2000). The problem of fallacy identification lies in the constantly growing number and thus in the difficulty in tracing clear-cut criteria between them.

\subsection{Criteria used for limiting the number of codes}

To limit the fallacies to a set that can be manageable in coding, two criteria have been used: 1) the simplification of the types of fallacies to classes that may include other subfallacies; and 2) the limitation of the types of fallacies to be coded to the most frequent ones in the given type of discourse to be analyzed, including the others in a "other" category.

The first issue was resolved by combining a top-down and a bottom-up strategy. First, the type of discourse under analysis - the political discourse - was analyzed considering its specific features that can lead to a preliminary exclusion of types of fallacies that are unlikely to occur. The specific type of discourse to which this coding system is designed to be primarily applied is political discourse, commonly defined as a "realm of action," namely a decision-making activity, where solutions to present or future problems are defended and attacked (Fairclough and Fairclough, 2011, p. 244). When a politician acts in his or her institutional role, the primary presumed goal is to justify and argue for and against decisions of different kind before an audience constituted by all the citizens. This global goal is pursued primarily through deliberation moves (Walton, 1989, 1990, 1998a; Walton and Krabbe, 1995), but also by persuasion (when the acceptability of a value judgment is disputed) or information sharing moves whose acceptability can be the object of explanations or inquiry. Eristic moves can be used exceptionally, even though they characterize antagonistic scenarios, such as direct confrontations in election campaigns. 
The types of moves outline the possible fallacies to be committed and the ones that are likely to be excluded. Deductive fallacies (affirming the consequent, denying the antecedent) require laws and universal generalizations, unlikely to be used in political scenarios. Moreover, considering the prevailing goal (decision-making), the scenario (communication to all the citizens) and the medium (in this case, written communication), linguistic fallacies (amphiboly, equivocation, etc.) are expected to be used as part of other fallacies, especially the straw man. Finally, other fallacies (such as fear appeals, ad verecundiam, ad hominem, etc.) instantiate argumentation schemes that are normally acceptable, but are associated with deceptive elements. Such sources of deception can be question-begging epithets, ignoring qualifications, slippery slope, etc. Therefore, an argument that is commonly considered as fallacious - the ad hominem is not coded as a fallacy, as its deceptiveness depends on elements different from the simple personal attack (Macagno, 2013; Walton, 1998b). Moreover, in a context of dialogue that might be interpreted as adversarial, such attacks can be legitimate, even though their high frequency is a strong sign of an extremely aggressive attitude. What the fallacy detection coding reveals is the presence of other deceptive tactics in such attacks.

These criteria were combined with a bottom-up approach, in which a pilot study was conducted on two distinct corpora, using all the available fallacies (Macagno, 2019; Macagno and Gil, 2021). The results showed how a limited number of fallacies (straw man, false dichotomy, hasty generalization, ignoring qualifications, post hoc, questionbegging epithets, persuasive definition, quasi-definition) represented the most frequent fallacies, while the others represented less than $1 \%$ of the total fallacies.

The second strategy consisted in simplifying the fallacies to macro-categories that can include other traditional fallacies extremely related thereto. In particular, the post-hoc fallacy was broadened to include the fallacy of the "false cause" and some cases of "ignoratio elenchi" (Walton, 2004a). The criterion of using an unacceptable causal generalization either as a premise or as a conclusion constituted the characterizing feature of this macro-fallacy. The straw-man fallacy included other types of linguistic fallacies that are instrumental to modifying the interlocutor's viewpoint in this case, the more complex strategy includes and prevails over the simpler strategies.

The result of this twofold strategy was the following list of 9 fallacies (plus an Other category), which allows a coding.

\subsection{List of the coded fallacies}

\begin{tabular}{|l|l|l|}
\hline \multicolumn{1}{|c|}{$\begin{array}{c}\text { Manipulation } \\
\text { strategy }\end{array}$} & \multicolumn{1}{c|}{ Fallacy } & \multicolumn{1}{c|}{ Example } \\
\hline $\begin{array}{l}\text { 1. Topical irrelevance } \\
\text { (attacking or using a } \\
\text { viewpoint that is not } \\
\text { the one advanced) }\end{array}$ & $\begin{array}{l}\text { 1. Straw man (a } \\
\text { modification of the } \\
\text { viewpoint or a claim of the } \\
\text { interlocutor for attacking it } \\
\text { more easily). }\end{array}$ & $\begin{array}{l}\text { a. "Remember when the } \\
\text { failing @nytimes apologized } \\
\text { to its subscribers, right after } \\
\text { the election, because their } \\
\text { coverage was so wrong. Now } \\
\text { worse!"1 }\end{array}$ \\
\hline
\end{tabular}

\footnotetext{
${ }^{1}$ Borchers, C. (2017). No, the New York Times did not apologize because its Trump coverage was 'so wrong'. The Washington Post, March 29, 2017 (retrieved from https://www.washingtonpost.com/news/the-fix/wp/2017/03/29/no-the-new-york-times-did-not-apologizebecause-its-trump-coverage-was-so-wrong/ on 4 September 2020).
} 


\begin{tabular}{|c|c|c|}
\hline & $\begin{array}{l}\text { 2. False dichotomy } \\
\text { (contrary or alternative } \\
\text { options or states of affairs } \\
\text { presupposed as } \\
\text { contradictory) }\end{array}$ & $\begin{array}{l}\text { b. "Somebody with aptitude } \\
\text { and conviction should buy the } \\
\text { FAKE NEWS and failing } \\
\text { @nytimes and either run it } \\
\text { correctly or let it fold with } \\
\text { dignity!" }\end{array}$ \\
\hline & & $\begin{array}{l}\text { c. "The threat from radical } \\
\text { Islamic terrorism is very real, } \\
\text { just look at what is happening } \\
\text { in Europe and the Middle- } \\
\text { East. Courts must act fast!" } \\
\text { (taking for granted that the } \\
\text { attacks in EU and Middle } \\
\text { East were provoked by } \\
\text { Radical Islamic terrorism, } \\
\text { and not terrorism in general) }\end{array}$ \\
\hline $\begin{array}{l}\text { 2. Presuppositions in } \\
\text { conflict with the } \\
\text { common ground }\end{array}$ & & $\begin{array}{l}\text { d. We will follow two simple } \\
\text { rules: BUY AMERICAN \& } \\
\text { HIRE AMERICAN! (it does } \\
\text { not specify what "American" } \\
\text { means in the context of } \\
\text { immigration and } \\
\text { multinationals) }\end{array}$ \\
\hline 2.1. Facts & $\begin{array}{l}\text { 3. Ignoring qualifications } \\
\text { (presupposing that the } \\
\text { premise includes the } \\
\text { qualifications necessary for } \\
\text { drawing the conclusion) }\end{array}$ & $\begin{array}{l}\text { e. We must keep "evil" out of } \\
\text { our country! (i.e. blocking } \\
\text { immigrants) (evil is } \\
\text { undefined, and migrants are } \\
\text { not all evil) }\end{array}$ \\
\hline & & $\begin{array}{l}\text { f. Meeting with biggest } \\
\text { business leaders this morning. } \\
\text { Good jobs are coming back to } \\
\text { U.S., health care and tax bills } \\
\text { are being crafted NOW! } \\
\text { (Good jobs were not away, } \\
\text { some jobs were lost; a } \\
\text { meeting on regulations does } \\
\text { not mean that jobs will be } \\
\text { back) }\end{array}$ \\
\hline & & $\begin{array}{l}\text { g. After being forced to } \\
\text { apologize for its bad and } \\
\text { inaccurate coverage of me } \\
\text { after winning the election, the } \\
\text { FAKE NEWS @nytimes is } \\
\text { still lost! (The Times has not }\end{array}$ \\
\hline
\end{tabular}




\begin{tabular}{|c|c|c|}
\hline & & $\begin{array}{l}\text { apologized for their coverage } \\
\text { of Trump during the election, } \\
\text { but did send an email to } \\
\text { subscribers saying they } \\
\text { underestimated the business } \\
\text { mogul's chance of winning.) }\end{array}$ \\
\hline & \multirow{3}{*}{$\begin{array}{l}\text { 4. Question begging } \\
\text { epithets (the use of a word } \\
\text { or syntactical structures } \\
\text { presupposes unproven or } \\
\text { unaccepted judgments or } \\
\text { states of affairs) }\end{array}$} & $\begin{array}{l}\text { h. "Don't let the fake media } \\
\text { tell you that I have changed } \\
\text { my position." (presupposing } \\
\text { that there are fake media) }\end{array}$ \\
\hline & & $\begin{array}{l}\text { i. Today we are not merely } \\
\text { transferring power from one } \\
\text { Administration to another, or } \\
\text { from one party to another - } \\
\text { but we are transferring power } \\
\text { from Washington, D.C. and } \\
\text { giving it back to you, the } \\
\text { American People. } \\
\text { (presupposing that before the } \\
\text { power was not with the } \\
\text { people) }\end{array}$ \\
\hline & & $\begin{array}{l}\text { j. January } 20 \text { th } 2017 \text {, will be } \\
\text { remembered as the day the } \\
\text { people became the rulers of } \\
\text { this nation again. } \\
\text { (presupposing that people } \\
\text { were not rules before } 2017 \text { ) }\end{array}$ \\
\hline \multirow[t]{2}{*}{$\begin{array}{l}\text { 2.2. Specific } \\
\text { warrants }\end{array}$} & \multirow[t]{2}{*}{$\begin{array}{l}\text { 5. Post hoc ergo propter } \\
\text { hoc (a temporal or spatial } \\
\text { coincidence or succession } \\
\text { presupposed as a cause- } \\
\text { effect relation) }\end{array}$} & $\begin{array}{l}\text { k. "The weak illegal } \\
\text { immigration policies of the } \\
\text { Obama Admin. allowed bad } \\
\text { MS } 13 \text { gangs to form in cities } \\
\text { across U.S. We are removing } \\
\text { them fast!" (Obama } \\
\text { introduced immigration } \\
\text { measures and MS } 13 \text { gangs } \\
\text { developed in the US; the two } \\
\text { things are only temporally } \\
\text { related - not by cause-effect) }\end{array}$ \\
\hline & & $\begin{array}{l}\text { l. Watched protests yesterday } \\
\text { but was under the impression } \\
\text { that we just had an election! } \\
\text { Why didn't these people vote? } \\
\text { (one can vote but still protest, }\end{array}$ \\
\hline
\end{tabular}




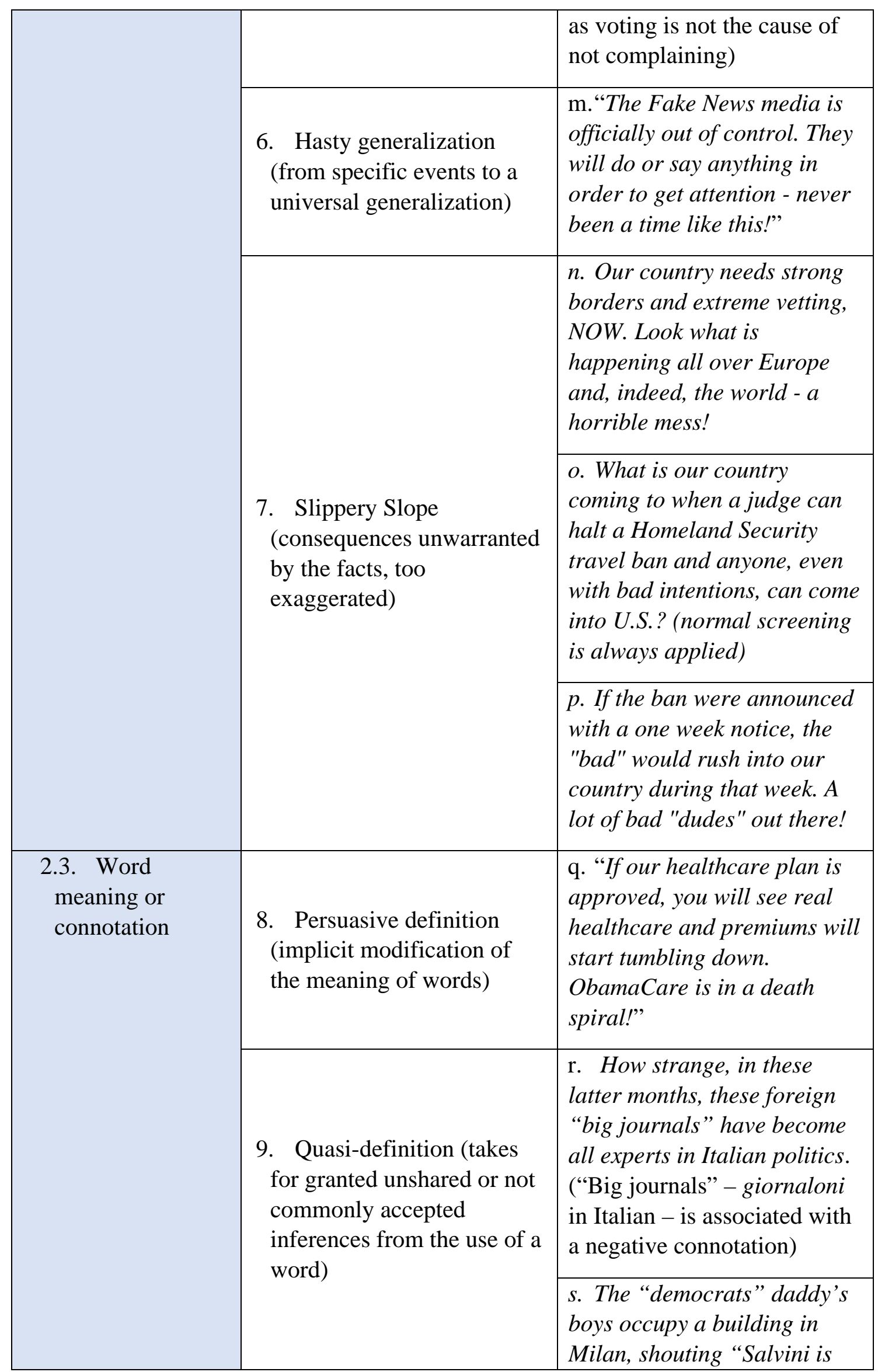




\begin{tabular}{|l|l|}
\hline & $\begin{array}{l}\text { shit.” But haven't they } \\
\text { anything better to do? }\end{array}$ \\
\hline
\end{tabular}

\subsection{Decision criteria}

The choice of a fallacy over another in case of doubt is based on the complexity criteria:

a. The fallacy that describes more fully the deceptive move prevails over the one that describes only one dimension, and

b. If a fallacy explains more aspects of the deceptive move than another fallacy, the more explanatory fallacy should be chosen.

For example, a straw man can be based on ignoring qualifications. However, the straw man describes a manipulation (through ignoring qualifications) that is used to attack the interlocutor. Thus, the straw man is more complex and more explanatory than the ignoring qualification (describes the whole fallacy in all its dimensions).

A move can involve more fallacies. The choice of coding a move with more fallacies depends on the fact that the two fallacies are distinguishable and one cannot be included in another.

\section{Decision tree}

The fallacies can be organized considering their differences. The choices to be made are based on the intuition that something is wrong with the speaker's message, and the tree is intended to guide this intuition to its description.

The first choice to make is to distinguish to whom the words belong - whether to the Speaker (he is describing or proposing something) or someone else (including the interlocutor). If the Speaker is reporting or quoting someone else's viewpoint, there can be a problem in its reporting (ignoring qualifications and straw man). If the Speaker is accountable for what he says, then we need to make a further choice.

The second choice concerns the level - whether linguistic or content-related. The Speaker can use words in an inappropriate or problematic way (manipulating the word meaning or the use of words). Otherwise, he can manipulate how a state of affairs is commonly accepted. Both levels imply further choices.

The third type of choice concerns the linguistic level, we need to choose between the use of a word or its meaning. In the first case, the Speaker is using a word with its accepted meaning, but s/he is taking for granted information that is not shared or even in conflict with what is commonly accepted. So, the word is misused because it introduces details or facts that have not been proven or neglects the accepted ones. In the second case, the Speaker is modifying the meaning of a word, either considered as its definition (s/he changes the definition) or its "connotation." So, the Speaker is modifying our vocabulary to change our perception of reality.

The fourth type of choice concerns the content level, and it is between the purposes of the move - whether to describe a state of affairs or make a proposal. In the first case, two options are available: either s/he is using a generalization incorrectly to draw a conclusion, or s/he is drawing a generalization - from a small sample or from a cooccurrence of events. In the second case, s/he manipulating a decision either by 
restricting the number of available alternatives, or exaggerating the consequences of an option.

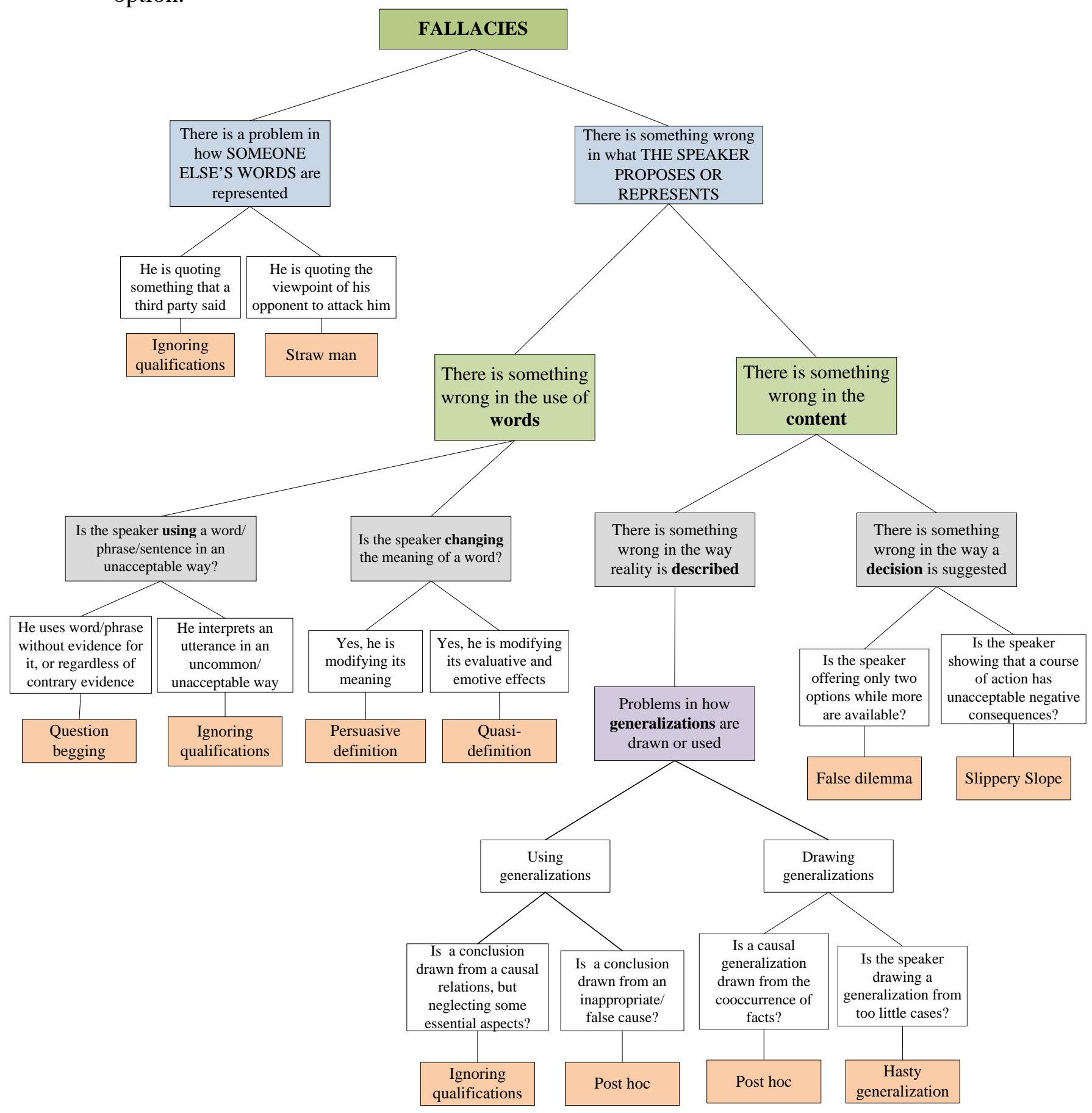

Two fallacies are repeated in this scheme (the post-hoc and the ignoring qualifications). The reason is that these fallacies have different manifestations: ignoring qualifications consists in using language with a meaning that is not the default one (either in case of quoting or in reasoning); post-hoc concerns causal generalizations (either their use or their development). 



\section{B. Fallacies}

As pointed out above, the following fallacies represent the most frequent types of deception in political communication. These fallacies do not include some of the popular fallacies that are in fact legitimate types of argument in specific circumstances (such as the ad hominem). Instead, these fallacies can result in the fallaciousness of the arguments that the message expresses - in other words, an ad hominem is not necessarily fallacious, but one of the following fallacies is likely to be a possible cause of its fallaciousness (together with other factors such as relevance and dialogical appropriateness).

\section{Straw man}

The straw man fallacy (Macagno and Walton, 2017) consists in misrepresenting the words of the interlocutor or a third party in order to attack him/her or support a specific viewpoint. For this reason, it can involve other fallacies (such as ignoring qualifications). Its characteristics are the following: 1) a distortion of a someone's words through direct or indirect reporting; and 2) the use of such a quote to attack the interlocutor (or pursuing another argumentative goal).

\subsection{Illustration}

In the following example, Trump is using a message sent by the NY Times in which the newspaper admitted that the predictions on the elections were wrong:

Remember when the failing @nytimes apologized to its subscribers, right after the election, because their coverage was so wrong. Now worse!

Here Trump is misrepresenting the NYT's admission of having predicted the wrong results. Instead of paraphrasing their admission, he is distorting it by qualifying it as an "apology" and by explaining that the reason was "wrong coverage." Both elements do not correspond to the original message. This distortion qualifies as a straw man because 1) it involves a distortion of a viewpoint expressed (by the NYT in this case); and 2) it is used to attack the Original Speaker itself (the NYT).

\section{Ignoring qualifications}

This fallacy consists in using a premise that is similar to the one that is commonly accepted (we can call it " $p$ ”), but includes or excludes some qualifications that are not shared (" $p+1$ " or " $p-1$ "). The premise can be stated or taken for granted, and thus it can be used for manipulating the interlocutors' background knowledge.

\subsection{Illustration}

In the following example, the message aims at showing the need to increase controls on immigrants or visitors from Muslim countries. The speaker (Trump) is using an argument from consequences, based on the premise that "Radical Islamic terrorism" 
provoked the attacks in Europe and Middle East, and thus it can attack in a similar way the United States.

The threat from radical Islamic terrorism is very real, just look at what is happening in Europe and the Middle-East. Courts must act fast!

The attacks in France, however, are extremely different from the ones in Middle East, and the terroristic groups and the reasons underlying the killings are hardly comparable. Moreover, the political and social background in France is different not only from the other European countries and other Middle East countries, but also from the United States. Ignoring such differences leads to a generalization that is not acceptable.

In the following post, the speaker is arguing in favor of increasing the controls on Muslim countries and reducing immigration:

We must keep "evil" out of our country!

The argument from practical reasoning (the best way to keep evil out of the country is to reduce immigration/banning some countries) is based on the fear of terrorism and crime. Here "evil" is used to refer to possible sources of crime or terrorist attacks, including whole countries and populations under a category under which most of them would not fall. If rightly qualified (we must keep who commits evil acts out of the country) the claim would be obvious but would hardly justify a ban against Muslim countries.

\subsection{Distinctions}

Ignoring qualifications needs to be distinguished from three similar fallacies: 1) the straw man, 2) the question-begging, and 3) the hasty generalization.

\subsubsection{Ignoring qualifications vs. Straw man}

The straw man is a distortion of the interlocutor's or a third party's viewpoint, claim, or commitments in order to attack his position or himself. The distortion is frequently carried out through ignoring qualifications, by omitting part of what the speaker said, or ignoring the qualifications that characterize what the original speaker intended. However, the straw man uses these distortions not only for manipulating what the audience holds (what is generally accepted), but also for attacking the original speaker. Thus, the test for distinguishing ignoring qualifications from the straw man is whether an attack has been carried out. We consider the following example:

After being forced to apologize for its bad and inaccurate coverage of me after winning the election, the FAKE NEWS @nytimes is still lost!

Here, the NY Times did not apologize for their coverage of Trump during the election; rather, the newspaper sent an email to subscribers saying they underestimated the business mogul's chance of winning. A qualification is omitted (inaccurate coverage concerning the predictions), and qualifications are included and suggested (bad and inaccurate coverage <in general > of me after winning the election); however, the move does not stop there. Trump attacks the NY Times by claiming that it is lost, and that it publishes fake news. 


\subsubsection{Ignoring qualifications vs. Question begging}

Ignoring qualifications can be confused with question begging, as in both cases the speaker manipulates the common ground. However, question-begging is related to the use of a specific word, whose use presupposes certain conditions or states of affairs that has not been ascertained nor accepted. In contrast, ignoring qualifications is a modification of what is accepted - it does not consist in including something that has not been accepted in the common ground. Thus, the test to distinguish the two fallacies is: Does the speaker invent a new presupposition, or does s/he only modify what the audience accepts/can accept? We consider the following examples:

After being forced to apologize for its bad and inaccurate coverage of me after winning the election, the FAKE NEWS @nytimes is still lost!

Let us consider the statement “the FAKE NEWS @nytimes is still lost!”. Trump is taking for granted that it is commonly known that the newspaper is publishing fake news. This presupposition is included in the audience's common ground, but it is neither accepted nor proven. It is not a modification of what the audience holds or what has been proven, as a newspaper can be inaccurate in some cases, but it is extremely difficult to prove that it published wrong some news intentionally - much less a habit of publishing false information with malice. For this reason, it is not ignoring qualifications, but question-begging. Let us compare it with the following:

Meeting with biggest business leaders this morning. Good jobs are coming back to U.S., health care and tax bills are being crafted NOW!

Trump is taking for granted that "good jobs went away" from the US. This presupposition is similar to what is commonly accepted (due to delocalization, some jobs - normally production jobs - were lost). Trump is not taking for granted something that is not accepted - rather, it does not qualify what jobs are "coming back" and qualifies the jobs as "good" independently of their differences (many of these jobs are not well paid). For this reason, it is ignoring qualifications.

\subsubsection{Ignoring qualifications vs. Hasty generalization}

Ignoring qualifications can be confused with hasty generalization, as in both cases the fallacy can involve a general claim. However, the hasty generalization is an inductive fallacy consisting in passing from a limited number of observations to a statement concerning how things are generally or normally. Thus, no qualifications are involved; it is simply matter of passing from few to many or even all. An example is the following message after an attack to republican students (gathered for a speech of right-wing commentator Yiannopoulos at the Berkeley university). The attackers were not affiliated with the university.

If U.C. Berkeley does not allow free speech and practices violence on innocent people with a different point of view - NO FEDERAL FUNDS?

Here we notice two fallacious moves. First, Trump ignores the qualifications - the attackers were not students, Berkeley university suffered from very high damages caused by these agitators. Thus, he commits ignoring qualifications (the presupposition 
is similar to what is accepted, but not quite the same). However, Trump presents this isolated case as a behavior, a habit ("does not allow"; "practices"). This is an unwarranted passage from one case to a generality, which qualifies as a hasty generalization.

The use of examples can be a problem in the choice between Hasty generalization and Ignoring qualifications. The distinction can be drawn at the level of the reasoning: is the speaker comparing or generalizing? In the first case, the inductive process is not marked - what is relevant is the similarity. In the second case, the focus is not the quantity of cases in the conclusion that is not supported by the limited sample. An illustration of this issue can be the following:

I am reading that the great border WALL will cost more than the government originally thought, but I have not gotten involved in the...design or negotiations yet. When I do, just like with the F-35 FighterJet or the Air Force One Program, price will come WAY DOWN!

Here, Trump is comparing three different negotiations (the airplane discounts were already advertised by the companies before Trump took office), ignoring the reasons that led to a discount. The problem is bigger than a hasty generalization: if we want to draw the intended generalization that Trump is able to obtain discounts through negotiations we need to start from accepted cases; but in this case we cannot even accept the sample. The cases are not comparable with the conclusion and the speaker ignores relevant qualifications that would make the conclusion impossible. Thus, a fallacy more serious (more complex) than a hasty generalization is involved, namely the ignoring qualifications.

\section{False dilemma (false dichotomy)}

This fallacy consists in proposing a choice between two alternatives (either $p$ or $q$ ), which are not, however, exclusive (in fact, it is possible to choose between $p, q, r, s \ldots$ ), or presenting a black or white perspective. This fallacy can be committed in two different settings:

1. Deliberation: the speaker proposes a decision, either to the audience (you should do either $p$ or $q$ ), or to a third party (s/he should do either $p$ or $q$ ). Normally, one of these two options needs to be excluded as unreasonable, dangerous, or unacceptable, which leads to only one possibility.

2. Description and evaluation: the speaker describes a state of affairs ( $X$ is either $p$ or $q$ ). Normally, one of these two options (for example $p$ ) needs to be excluded as bad, dangerous, or unacceptable, which leads to excluding or criticizing the "bad" X who commits or is $q$.

\subsection{Illustration}

Deliberative context. In the following example, Salvini is criticizing the behavior of the major of Napoli, De Magistris, for being too favorable to immigrants:

De Magistris should care about social housing for the Neapolitans instead of inviting all the immigrants of the world 
Salvini uses a dichotomy, a dilemma: increasing social housing for the Neapolitans is incompatible with accepting immigrants. This dilemma is not acceptable, as social housing has very little to do with accepting immigrants (which are never defined by Salvini, ignoring the distinction between refugees and migrants). While social housing depends on the availability of municipality funds, immigrants can even result in profits for the city (in case of refugees, against whom Salvini builds his campaign, the EU provides funding).

Descriptive context. In the following example, Salvini is criticizing some priests who are condemning racist behaviors and decisions against hosting refugees.

There is a part of the church that engages in politics; and then there is a part of the church that asks me not to give up.

The dichotomy is between two "parts" of the church, one that is politicized (namely criticizing Salvini's political proposals against migration), and another (or even "the" other, as in Italian it is ambiguous) that supports Salvini. Apart from the fact that the two "parts" are not the only ones, they are not alternatives, as both represent a position of the Church towards some decisions, which happen to be political.

Mixed. In some cases, the dichotomy concerns the description of a state of affairs, and is used to propose or justify a course of action, such as in the following example:

Confindustria does not represent the true world of the companies; I care about the small companies, the "LITTLE". In the past, one the "BIG" ones were supported, in order to receive the praises from Confindustria. Now everyone wants to do the opposite of what has been done so far.

Salvini is proposing a dichotomy between "little" and "big" companies. This distinction is completely artificial, as (at least in Italy) most of the companies are middle-sized, and supporting a type of company often results in supporting the other(s), as they are often related in the production process (small/medium companies produce components for the bigger ones).

A specific type of false dilemma is manifested by the adverb "only," which presupposes (or implies, depending on the theory, see Atlas, 2018; Horn, 2011, 1969) that there is no alternative, or rather that the alternative is the status quo in case of a deliberation. An example is the following:

Welcoming people who are actually running away from the war, but for criminals, drug dealers, and murderers who bring war to our home, there is only one solution: EXPULSION.

Here Salvini presents only two possibilities: either expulsion or living with criminal immigrants. In a context in which the very concept of "immigrant” is left undefined, these two options are extremely controversial and legally incorrect.

\subsection{Distinctions}

The false dilemma introduces a distorted presupposition, and thus it can be confused with ignoring qualifications and question begging. Moreover, the false dilemma is often 
the result of a dissociation, namely the persuasive redefinition of a word where the "true" meaning is distinguished from the "apparent" one.

\subsubsection{False dilemma vs. Ignoring qualifications}

The purpose of the false dilemma is to provide a black and white depiction of reality or propose a forced choice. To construct this dichotomic perspective, the qualifications that characterize the shared view on a state of affairs are frequently ignored; in this sense, false dilemma may involve ignoring qualifications. However, the false dilemma is not only ignoring a qualification; it is presenting an incompatibility when there is no one. The omission of a qualification is thus functional to a more complex move. For example, we consider the following:

There is a part of the church that engages in politics; and then there is a part of the church that asks me not to give up.

Salvini is ignoring the qualifications related to "asks me not to give up," as it is highly unlikely that different individuals express the same praise, and "giving up" is in itself underspecific (giving up what exactly?). However, Salvini is using the omission of the qualifications for developing a more dangerous fallacy, namely showing that the Church is divided in a "politicized" and a "rightful/non-political" faction. The false dilemma encompasses the ignoring qualifications in this case.

\subsubsection{False dilemma vs. Question begging}

A similar explanation applies to the distinction between question begging and false dilemma. Question begging is the use of term, phrase, or syntactical construction that introduces unshared presuppositions. The false dilemma can be confused with this fallacy for two reasons: 1) the speaker can presuppose the dilemma (for example, using the adverb "only"), and 2) the speaker can use a question begging epithet in the dichotomy. In the first case, the criterion of complexity prevails: the more complex fallacy prevails over the simpler. The unacceptable presupposition is a dichotomy, which has potentially the effect of reducing the possible choices or limiting the complexity of a state of affairs. In this sense, false dilemma introduces an unacceptable presupposition of a specific kind, which can be unveiled by asking the question: Is the speaker introducing or presupposing an unacceptable alternative? The use of "only" in "there is only one solution: EXPULSION," is a clear case of a dichotomy that is also a false presupposition. However, the presupposition is an unacceptable alternative, and thus it qualifies as a false dilemma.

The second case involves the identification of two distinct fallacies, as in the following examples:

The joint statement of former presidential candidates John McCain \& Lindsey Graham is wrong - they are sadly weak on immigration. The two Senators should focus their energies on ISIS, illegal immigration and border security instead of always looking to start World War III.

Here, the adverb "instead" introduces the presupposition that the senators want to start a new world war, which can be hardly acceptable (question begging). However, this is not 
the only problem; Trump is presenting their options as limited to two incompatible possibilities, when these are neither exhaustive, nor incompatible.

The following case combines the two possible types of confusion with the question-begging epithet:

Somebody with aptitude and conviction should buy the FAKE NEWS and failing @nytimes and either run it correctly or let it fold with dignity!

Here Trump presents an alternative, namely a forced choice between "running (the newspaper) correctly" or "fold it with dignity." Clearly these are not the only options, especially when it implies that at present the newspaper is not run correctly. In addition, Trump uses a question-begging epithet (failing/Fake News NYtimes), presupposing falsely that the newspaper is failing and is publishing fake news. This is a fallacy of question-begging, which is committed in addition to the false dilemma.

\subsubsection{False dilemma vs. Persuasive definition}

A persuasive definition is normally expressed through a dissociation, namely a dichotomy between the true and the apparent or false meaning of an expression or classification principle. Clearly, this type of fallacious persuasive definition results in a dichotomy, but it does not mean that this dichotomy is a false dilemma. In order to be also a false dilemma, the linguistic distinction needs to be used for a specific purpose, namely a decision, a justification, or an explicit evaluation. Thus, the redefinition of a word is often used for using the (false) dichotomy that results, but it is not necessary. The questions that can be used for distinguishing the two fallacies are: Is the persuasive definition introducing a dichotomy that is not acceptable? If yes, then ask: Is the dichotomy used for an argumentative purpose? In this case, the speaker is committing both fallacies. An example is the following:

Not "racists"! Italians are the most helpful and welcoming people in the world. But with who is actually running away from the war - with children, families, relatives with disabilities. Not with the wise guys.

Here, the concept of "running away from the war" is defined in a very specific way, namely it needs to include families, children, etc. This persuasive definition is, however, joined with a dichotomy: the ones who are not actually running away from the war are qualified as "wise guys," which is not the contrary thereof, and involves a sharp accusation. Thus, the message involves a false dichotomy also.

A potentially confusing strategy is the following

We have fixed for Saturday December $8^{\text {th }}$ a meeting in Rome, with all the respectable Italians who support us.

Here the message is ambiguous, as it may mean either that respectable Italians support him, or that to qualify as a respectable Italian who support Salvini one needs to show up at the meeting. In any case, a dichotomy is drawn: either to be a respectable Italian (and support Salvini)/respectable supporter (and show up at the meeting) or not be respectable/a respectable supporter. Here, the dichotomy is created without any redefinition. 
A similar case is the use of "real" to refer to a state of affairs, not a meaning. For example we consider the following:

The real scandal here is that classified information is illegally given out by "intelligence" like candy. Very un-American!

Here Trump is not redefining "scandal" but rather emphasizing that the other scandals that involved him were not scandal. Here he is creating a false dilemma: if this is the real scandal, the other is not real.

\section{Slippery slope}

The slippery slope fallacy is committed when an unwarranted consequence is drawn from an alleged cause, in order to induce the hearer to avoid an action or carry it out to avoid or produce such a consequence. Thus, the reasoning is the following: if I do $x$, then the good/bad consequence $y(z, j \ldots)$ will follow (the consequence is not direct). Therefore, I will/will not do $x$. The slippery slope is a fallacious use of the argument from consequences, where the effect is not direct, but is an exaggeration resulting from other intermediate causes that are very unlikely to result in it.

Slippery slope involves thus two aspects: 1) a cause-effect chain, where the last effect is only indirectly related to the cause under discussion, and 2) an evaluative dimension - the consequence is not neutral but serves a specific purpose.

\subsection{Illustration}

An example is the following message, in which Trump argues in favor of a short-notice ban or even a ban with no notice to avoid a flow of immigrants:

If the ban were announced with a one week notice, the "bad" would rush into our country during that week. A lot of bad "dudes" out there!

Trump is presenting the consequences of not having the short notice, but such consequences are not supported by the evidence. The acceptable causation effect would be that a notice would result in more attempts to reach the United States before the ban, and more attempts would include more illegal attempts. Among such illegal attempts, some could be successful, and among the successful ones, there could be cases of "bad" immigrants. Trump is jumping to a far consequence of a decision, namely a slippery slope.

\subsection{Distinctions}

The slippery slope can involve a lack of qualifications that can characterize a causal relation, and for this reason it can be confused with the fallacy of ignoring qualifications. Moreover, it involves an extreme consequence, and thus be confused with the false dilemma.

\subsubsection{Slippery slope vs. Ignoring qualifications}


Slippery slope concerns indirect cause-effect relations - and an effect can be related to a cause only considering certain circumstances, which can be ignored. However, when the effect is used as a consequence that is subject to evaluation, the fallacy is slippery slope, as it is more complex and involves a more specific effect on the interlocutor. Thus, the questions for distinguishing the two fallacies are: Is the effect related indirectly to the cause? Is the effect evaluated in a specific way to affect a decision? If both questions are answered positively, it is a slippery slope. In case the first is not, it can be a case of ignoring qualifications.

\subsubsection{Slippery slope vs. False dilemma}

The slippery slope presents an extreme consequence of an option. However, this consequence leads to a dilemma: either we do as suggested, or consequences will follow. The line is thin, but the slippery slope involves a cause-effect relationship, while this relation is not necessary in the false dilemma. The difference lies in what is marked: Is the message presenting explicitly a dilemma (either...or)? If yes, it can be a false dilemma. Instead, is the message presenting a consequence that is unwarranted or unacceptable? If it is, then it is more than a dilemma; it is a slippery slope, as it involves a cause-effect that in the false dilemma is not involved. We consider the following case:

If the U.S. does not win this case as it so obviously should, we can never have the security and safety to which we are entitled. Politics!

In this example, Trump presents the consequence of not winning a case. It can be interpreted as a false dilemma, as there are no other options (either we win or...). But this alternative is not manifested; instead, he expresses the effects of the loss. It is, for this reason, a slippery slope. If the outcome were not relatable to a cause-effect relationship, we would have excluded the slippery slope and it would have been a false dilemma.

\section{Post hoc}

The post hoc is a fallacy of explanation: two events that have a temporal or spatial relation (they occur at the same time or at the same place) are shown to be linked by a cause-effect relation (the former causes the latter). The crucial feature of the post hoc is that the conclusion is an explicit or implicit causal relationship (generalization) of the kind " $x$ is caused by $y$. . The post hoc is frequently associated with unacceptable presuppositions, as the causal relation is taken for granted in drawing a further conclusion. This fallacy is the one commonly used by conspiracy theories.

\subsection{Illustration}

An example is the following message, in which Trump justifies his ban on some Muslim countries:

Interesting that certain Middle-Eastern countries agree with the ban. They know if certain people are allowed in it's death \& destruction! 
The fact that some Middle-Eastern countries agree with the ban does not mean that they know that the people from these countries are terrorists. A much easier explanation would be that they want to show support to these policies against some common enemies. For this reason, it is a post-hoc. This message presupposes that immigrants from these countries are terrorist, without any specific qualification.

A common use of post hoc is finding favorable associations between an event and indicators that are commonly the result of long-term policies, such as in the following case:

Stock market hits new high with longest winning streak in decades. Great level of confidence and optimism - even before tax plan rollout!

Stock market and economic indicators are frequently associated with several factors, not certainly only with incomplete policies made in the few first months of a presidency. Moreover, economic trends are the long-term result of past decisions and policies. However, the cooccurrence of these effects with Trump's office can be used to show that he is responsible for them.

Under the label of "post-hoc" we include also a deceptive move that consists in drawing a further conclusion from an unwarranted causal generalization. The "false cause" is a specific conclusion, which is, however, based on a problematic causal generalization. Thus, while the classic post hoc can be represented as " $p$ and $q$ (at the same time or place); therefore $p$ causes $q$," the false cause variant is a further step: " $q$; $p$ (somehow related to $q$ ); therefore $p$ caused $q$." An example is the following message, in which Trump responded to the women's marches around the world where millions of people, including celebrities, protested his presidency:

Watched protests yesterday but was under the impression that we just had an election! Why didn't these people vote?

Trump is not drawing a causal generalization as in the case of the classic post hoc; instead, he is drawing an explanation (a false cause). The deceptive dimension is, however, the same as the post hoc, namely the unwarranted causal relation - in this case based on the fact that the occurrence of the election preceded the protest.

\subsection{Distinctions}

The post hoc can be confused with ignoring qualifications characterizing a causal relation.

\subsubsection{Slippery slope vs. Ignoring qualifications}

Post hoc concerns cause-effect relations; however, ignoring qualification can deal with cause-effects as well (an effect can be related to a cause only considering certain circumstances, which can be ignored). The two fallacies are distinguished by two features: 1) the status of the causal generalization and 2) their conclusion. The post hoc introduces an unwarranted and unaccepted causal generalization from two distinct events; the ignoring qualifications can modify an acceptable one to draw a further conclusion. The post hoc results in a generalization (Ethiopians are black and tall; therefore, skin color influences a person's height); the ignoring qualifications uses a 
distorted version of an accepted generalization (Ethiopians are black; therefore, they have black teeth).

\section{Hasty generalization}

The hasty generalization is a fallacy of induction: from one or few events (this cat is red, this other cat is red), a generalization is drawn (cats are generally red).

\subsection{Illustration}

An example is the following tweet by Trump, who from (few) allegedly incorrect news draws the hasty generalization that they always lie.

The Fake News media is officially out of control. They will do or say anything in order to get attention - never been a time like this!

A similar example is the following, where from one specific case (related to a car manufacturer), Trump draws a generalization that applies to all.

Big announcement by Ford today. Major investment to be made in three Michigan plants. Car companies coming back to U.S. JOBS! JOBS! JOBS!

Here the case from which the generalization is drawn is Ford's decision to make investments in the US (on existing plants). This decision leads to a hasty conclusion that car companies in general are going back and creating jobs.

\subsection{Distinctions}

The hasty generalization can be confused with the post hoc, as in both cases the conclusion is a generalization.

\subsubsection{Hasty generalization vs. Post hoc}

Both post hoc and hasty generalization lead to a generalization from a case. However, post-hoc is an abductive fallacy, while the hasty is an inductive one. The difference lies in the type of generalization that is drawn: based on the complexity criterion, the most complex fallacy prevails over the less complex, as it involves more specifications. The post hoc is a causal relation that results in a generalization; hasty generalization is a simple generalization - it concerns how a property is attributed to several individuals only on the basis of observing its occurrence. In this sense, the post hoc is a more sophisticated type of generalization. In case of doubt, the criterion should be: Is the generalization based on or results in a allegedly causal relation? If the answer is positive, it is a post-hoc. Otherwise, if the generalization is based on a small number of instances, it is a hasty generalization.

An example is the following message, in which Trump responded to the women's marches around the world where millions of people, including celebrities, protested his presidency: 
Watched protests yesterday but was under the impression that we just had an

election! Why didn't these people vote? Celebs hurt cause badly.

The claim "Celebs hurt cause badly" is a generalization - which could qualify as a hasty one. However, the question is, where does this generalization come from? Trump is observing that celebrities were present, and the march for women's rights turned into a protest against him. He links these two facts as a cause-effect relationship: on his view, celebrities had an agenda that led to organizing the protests (who hurt the cause of the march).

\section{Question begging}

Question begging is the use of term, phrase, or syntactical construction that introduces unshared presuppositions (Bentham, 1824, pp. 213-220; Macagno and Walton, 2014). Every word carries a shared meaning, and its use results in specific information that is taken for granted and communicated. For example, "murderer" presupposes a human being as an agent, who killed an entity who is also a human being. When the speaker 1) uses a term carrying a specific positive or negative value judgment ("murderer", "saint”...) without providing evidence for its appropriate use, and 2) its very use can be controversial, the fallacy of question-begging epithets is committed. Thus, when someone claims that "the murderer our daughter is engaged with was happy today," and it happens that the individual is not commonly accepted to be a murderer, he is using a question-begging epithet.

\subsection{Illustration}

An example that illustrates the typical case of question begging is the following message by Trump:

The failing @nytimes has been wrong about me from the very beginning. Said I would lose the primaries, then the general election. FAKE NEWS!

In this message, we notice that Trump defends one point - the fact that the NY Times was wrong about him - but two other controversial claims are not only left unjustified, but they are taken for granted. First, the NY Times is described as "failing," which is, however, not backed by reasons or evidence - Trump takes this classification for granted. However, this epithet is not neutral: it is aimed at negatively classifying the newspaper. So, without any further reasons that justifies the epithet, the argument sounds like "the NY Times is bad because it is failing, and it is failing because it is failing." Second, the predictions made by the NY Times are classified as "fake news." However, in order to be a news, a piece of information needs to be a factual statement (and not an opinion such as a prediction); moreover, to be "fake," a piece of information needs to be false (which is quite different from "wrong," and hardly applicable to a prediction) and conveyed with malice (otherwise it would be simply false information). Trump uses the phrase without justification - in contrast, the very classification of the predictions as "news" that are intentionally false is incorrect. The phrase is again evaluative - leading to a conclusion (the NY Times is bad) based on an ungrounded epithet (it is fake because it is fake).

The second case is more complex, as it involves an unshared presupposition carried through an adverb: 
So to all Americans in every city near and far, small and large, from mountain to mountain, from ocean to ocean, hear these words: You will never be ignored again.

The adverb "again” presupposes that the event described (the Americans being ignored) occurred before. Again, the epithet used (ignored) is evaluative (leading to a negative evaluation of who failed to take into account the interlocutors), but its use to refer to the past administration is not warranted. Its justification lies only in Trump's saying it. In this sense, it is question-begging.

\subsection{Distinctions}

The question-begging can be confused with the persuasive definition, as in both cases a word is used in conflict with its commonly shared meaning.

\subsubsection{Question-begging vs. Persuasive definition}

Question-begging consists in using an expression with its ordinary meaning but taking for granted facts or classifications that are not shared nor justified. So, it is a fallacy of presupposition. In contrast, a persuasive definition consists in using a word or phrase with a meaning that is different from the one commonly accepted, so that a state of affairs can be classified in a specific way. Thus, the problem is not in the shared facts, but in the shared meaning. To explain the difference, we consider the following example:

Terrible! Just found out that Obama had my "wires tapped" in Trump Tower just before the victory. Nothing found. This is McCarthyism!

In this example, the state of affairs is not unshared; rather, Trump describes it - even though this information is false. However, it is described using a word, "McCarthyism," which has a specific meaning - "the practice of making accusations of subversion or treason, especially when related to communism.” This definition does not apply to the state of affairs described. However, Trump uses it. The explanation of this possibility lies in the fact that "McCarthyism" has for him a specific meaning - spying obsessively - which is not commonly shared. However, this neutral meaning is combined with the evaluations and emotions commonly associated with "McCarthyism" - fear, witch-hunt, etc. The meaning is bent to describe a different state of affairs, but the emotions associated remain the same.

This case can be compared with the following message:

Thank you to Prime Minister of Australia for telling the truth about our very civil conversation that FAKE NEWS media lied about. Very nice!

Here, Trump is referring to an alleged accusation by Trump against Turnbull. Trump's travel ban affected the US-Australia deal to take 1,250 refugees; the tension between the two countries rose; Trump allegedly (according to leaks) told the Australian Prime Minister of seeking to export the "next Boston bombers" to the US, and complained that the deal was going to kill him politically. The expressions "truth," "Fake News Media" 
and "lie" are not redefined here; rather, they are used in conflict with the common opinion (the leaks were published days before and were not proven false). Trump does not challenge the information that his word use contradicts; rather, he takes for granted that media lied, that the truth is different from the one that is known, and that the media that published the information about US-Australia relations disseminated false information knowingly. This amounts to using question-begging epithets, namely using words whose conditions of use depend on the very fact that the speaker said them.

\section{Persuasive definition}

Persuasive definitions consist in redefining a concept without providing any reasons for accepting the new definition, nor any ground for rejecting its old meaning. For example, one can redefined "culture" as "aesthetic sensitivity," so that people who love arts can be classified as "cultivated" individuals (Stevenson, 1944, 1938, 1937). The characteristics of this type of redefinition are two: 1 ) the new meaning is not defended, indeed most of the time it is taken for granted ("Bob is cultivated, as he likes arts"); 2) the redefined term plays an argumentative role - Stevenson called this function "emotive" as it affected value judgments and dispositions to act. Normally this strategy is amplified through an opposition between the "false" or "incorrect" meaning and the “true” one (“true migrants...”) (Halldén, 1960; Schiappa, 2003; Van Rees, 2009).

\subsection{Illustration}

An example that illustrates the typical case of persuasive definition is the following message by Trump:

If our healthcare plan is approved, you will see real healthcare and premiums will start tumbling down. ObamaCare is in a death spiral!

In this message, we notice that the concept of "healthcare" is implicitly redefined: Trump is classifying as "real" healthcare the outcome of his plan - which allegedly will lead to lower premiums - in contrast with the apparent one (to which the Medicare belongs to). He does not provide any criteria for his new concept, but simply draws a line between his concept and the old one.

This case is more complex, as it involves two different strategies of persuasive definitions:

My goal is to come back to Bolzano as a minister, to return all the neighborhoods of the city to the decent people. It is not possible to have fear to go out at night. The integrated and decent immigrants are my brothers - the false refugees who commit crimes shall be sent back to their homes.

Two expressions are particularly problematic: “decent people” and "false refugee.” The first phrase is used without any definition to refer to a specific group of citizens, namely the ones who are complaining of immigration. The loose boundaries of what constitutes a "decent" individual allows Salvini to exclude from this concept immigrants who are not integrated (which does not mean that they are not decent people) or "false refugees." In this way, the phrase is used ad hoc with a new specific meaning that is left implicit. "False refugees" is also a persuasive definition, as a refugee is not true or false, and 
committing crimes is not a sign of not being a refugee. Salvini confuses the concept of refugee with immigrant, and redefines "true refugee" distinguishing it from its ordinary meaning ("a person who has been forced to leave their country in order to escape war, persecution, or natural disaster"). The new implicit definition identifies the "true refugee" with someone who is not accused of committing crimes (different from being found guilty by a court) and preferentially is integrated.

\subsection{Distinctions}

The persuasive definition can be confused with the false dilemma, as persuasive definition can involve dichotomies between the "true" and the "false" meaning.

\subsubsection{Persuasive definition vs. false dilemma}

The persuasive definition is a modification of meaning, while a false dichotomy is an apparent incompatibility between two states of affairs or concepts. Clearly, it is possible that a persuasive definition combines with a false dilemma.

A persuasive definition often splits a concept, which can often result in an implicit redefinition (and loose boundaries), such as in the following case:

\section{Let us go ahead; the right to self-defense for the decent citizens is sacred!}

The "decent citizen" is an obscure term that is created and implicitly defined in opposition to an even more blurred category. In this case, the dichotomy is possible; but its boundaries are obscure. A decent citizen is not necessarily one who does not commit crimes (white-collar crimes do not make a citizen not decent), and being found guilty of a crime does not constitute a sufficient criterion (guilty individuals are in prison and do not constitute a danger). So one wonders what a decent citizen is - probably someone who supports the party. This is clearly a persuasive definition, as the problem is not in the opposition, but in the meaning.

Sometimes, the persuasive definition is combined with a false dilemma. We consider the following case:

True life is not the spread. The spread will adjust to an Italy that will grow again.

Here, true "life" is redefined implicitly as something that is not the spread. This implicit redefinition is extremely problematic, as: 1 ) "life" refers to tangible economy (business); 2) its boundaries are not traced, only one concept is excluded from it (spread); 3) the "false life" is used to refer to an even more blurred concept, one of whose indicators is the spread. This persuasive definition, however, introduces a false dichotomy between tangible economy and spread, which is an indicator - even if indirect - of the financial and economic stability of a country. Salvini does not argue in favor of this opposition, but takes it for granted, generating a false dichotomy.

The following message by Salvini illustrates a similar strategy:

We will support the Rumanian president of the EU in the first semester of next year on this topic and all the other matters, from security to anti-terrorism, holding always one principle: the PEOPLES are more important than the institutions. 
The problem with this message is not only the false dichotomy between peoples and institutions (as the latter were not in function of the former), but the very use of "peoples." This word refers to "the members of a particular nation, community, or ethnic group," is neither in contrast nor incompatible with the institutions. Thus, in order to account for the conflict, it is necessary to infer that Salvini had a specific meaning of "peoples" in mind - the sovranist interests as opposed to the EU interests. In this way, "peoples" are not the individuals, but the single states that challenge the communitarian policies. For this reason, this message expresses both a false dilemma and a persuasive definition - or more precisely, the false dilemma can be accounted for by assuming a persuasive definition.

\section{Quasi-definition}

Quasi-definitions consist in modifying the "emotive" meaning of a term (Stevenson, $1944,1938,1937)$, or rather the value judgment associated with the referent of an expression. It is not properly a definition; rather, it is a way to modify how the interlocutor evaluates the entities or states of affairs referred to without providing any reason. Therefore, while persuasive definition modify meaning (true crime is eluding taxes), quasi-definitions influence how we assess referents (tax eluders are shameful criminals who destroy the foundations of society).

\subsection{Illustration}

The following example illustrates this strategy:

The thought of a priest who listen to the people, against the hypocrisy of many so-called "intellectuals," also belonging to the Church, who depict me as the devil...

The message is aimed at attacking some individuals who belong to the Church and attacked Salvini's policies. The crucial strategy consists in suggesting a negative value judgment through the expression "so-called intellectuals." By claiming that these people are called by others "intellectuals" introduces a distinction between himself (and the supporters) and the opinion of the detractors. The quotation marks stress the fact that this expression is a representation of someone else's words, which are implied to be misused. Thus, Salvini is suggesting that these people of the Chuch are only apparently intellectuals, or are claimed to be intellectuals when in fact they are hypocrites and haters. By stressing that the referent of "intellectuals" is bad, Salvini is changing how people evaluate the referent of this term.

Another common strategy consists in using suffixes or composite words, relying on the negative connotations triggered by the modification of the word, such as in the following example:

According to the British newspaper "The Independent," Italy is becoming fascist... How strange, in the last few months these foreign "big journals" have become all experts in Italian politics

The evaluation triggered by the stereotypes commonly associated to a word use (in this case "international journals," commonly associated to positive evaluations based on 
their credibility) is modified through the use of a suffix (giornalone, resulting from giornale + one: the Italian "-one," translated in English as "big”). The journals have become "big journals," where the augmentative suffix adds to "big" a negative trait that triggers contempt (Lo Duca, 2004, p. 211). Thus, the "big journals” are evaluated as journals that are considered as big without reasons. The quasi-definition allows Salvini to attack the journals without any reason, taking for granted that they are contemptible.

\subsection{Distinctions}

The quasi-definition can be confused with the persuasive definition, as in both cases the evaluation of a state of affairs is modified using words, and question-begging, as in both cases a word is used to refer to a state of affairs improperly.

\subsubsection{Quasi-definition vs. Persuasive definition}

Quasi-definitions are modifications of the evaluation that we normally associate with the referents of a word. Persuasive definitions modify how we use a word. So the question is: What is modified, the evaluation or the meaning (use)? If it is the evaluation, it is a fallacy of quasi-definition. For example we consider the following:

According to the newspaper Repubblica and some left-wing big professors, I should not share with you on the social media what I do, eat or drink!!! I do not change, I was with you before being a minister, and I continue to do that today! Big kisses and Maalox to sore losers.

The "big professors" is used to refer to university professors who took a stance against Salvini. Here, the word is used according to the common usage to refer to individuals holding specific positions or (metaphorically) having a high educational or cultural level. Thus, it is not a persuasive-definition. However, the word is distorted (using the suffix “-one” in Italian) to trigger a negative judgment, when normally professors are praised and culture and education are qualities, not vices. So, Salvini is trying to modify the evaluation of the people referred to.

\subsubsection{Quasi-definition vs. Question-begging}

Quasi-definitions are modifications of the evaluation that we normally associate with the referents of a word. In contrast, question-begging epithets are misuses of a word, or the use of a word that could not be applied to the given referent. Thus, the question is:

Is the speaker modifying how we evaluate the referents of a word, or is he using a word without reasons? The difference lies in the generalization, as a quasi-definition is intended to change how all the referents are assessed, while a question-begging epithet only concerns a specific use.

To illustrate this difference, we consider the example above. Salvini is using tw problematic expressions, "big professors" and "sore losers." As seen above, "big professors" modifies the evaluation of an otherwise positive term through a distortion of the word itself. Instead, "sore losers" behaves differently. This phrase is normally perceived as offensive and Salvini uses it as such. Thus, it cannot be a quasi-definition (the "emotive meaning" remains the same). However, he is not saying why professors are sore losers. He is just calling them losers, even though it is extremely likely that 
they are not. Thus, in this case he is committing a question-begging fallacy (they are losers because they are losers).

\section{References}

Abrusán, M., 2011. Predicting the presuppositions of soft triggers. Linguist. Philos. 34, 491-535. https://doi.org/10.1007/s10988-012-9108-y

Abrusán, M., 2010. Triggering verbal presuppositions, in: Li, N., Lutz, D. (Eds.), Semantics and Linguistic Theory. CLC Publications, Ithaca, NY, pp. 684-701.

Allan, K., 2013. What is common ground?, in: Capone, A., Lo Piparo, F., Carapezza, M. (Eds.), Perspectives in Pragmatics, Philosophy \& Psychology. Volume 2. Springer, Cham, Switzerland, pp. 285-310.

Aristotle, 1991a. Topics, in: Barnes, J. (Ed.), The Complete Works of Aristotle, Vol. I. Princeton University Press, Princeton, NJ.

Aristotle, 1991b. Sophistical refutations, in: Barnes, J. (Ed.), The Complete Works of Aristotle, Vol. I. Princeton University Press, Princeton, NJ.

Atlas, J.D., 2018. 'Few', 'hardly any', and 'only' at the semantics/pragmatics boundary: Negative quantifier noun phrases and negative polarity items - conjectures and refutations in the Horn-Atlas debate (1991 - 2018). San Antonio, TX.

Atlas, J.D., 1991. Topic/comment, presupposition, logical form and focus stress implicatures: The case of focal particles only and also. J. Semant. 8, 127-147. https://doi.org/10.1093/jos/8.1-2.127

Austin, J.L., 1962. How to do things with words. Oxford University Press, Oxford, UK.

Bellack, A., 1968. Methods for observing classroom behavior of teachers and students, in: Methods of Determining Criteria for the Evaluation of Comprehensive Schools. Teachers College Press, New York, NY, pp. 1-37.

Bellack, A., Kliebard, H., Hyman, R., Smith, J.F., 1966. The language of the classroom. Teachers College Press, New York, NY.

Bentham, J., 1824. The book of fallacies. John and H.L. Hunt, London, UK.

Ducrot, O., 1980. Les mots du discours. Minuit, Paris, France.

Ducrot, O., 1972. Dire et ne pas dire. Hermann, Paris, France.

Ennis, R.H., 1982. Identifying implicit assumptions. Synthese 61-86.

Fairclough, I., Fairclough, N., 2011. Practical reasoning in political discourse: The UK government's response to the economic crisis in the 2008 Pre-Budget Report. Discourse Soc. 22, 243-268. https://doi.org/10.1177/0957926510395439

Gazdar, G., 1979. Pragmatics: Presupposition, implicature, and logical form. Academic Press, New York, NY.

Gumperz, J., 1982. Discourse strategies. Cambridge University Press, Cambridge, UK.

Halldén, S., 1960. True love, true humour and true religion: a semantic study. Gleerlup, Lund, Sweden.

Hamblin, C.L., 1971. Mathematical models of dialogue. Theoria 37, 130-155. https://doi.org/10.1111/j.1755-2567.1971.tb00065.x

Hamblin, C.L., 1970. Fallacies. Methuen, London, UK.

Hitchcock, D., 2003. Toulmin's warrants, in: Van Eemeren, F., Blair, A., Willard, C., Snoeck-Henkemans, F. (Eds.), Anyone Who Has a View: Theoretical Contributions to the Study of Argumentation. Springer Netherlands, Dordrecht, Netherlands, pp. 69-82.

Horn, L., 2011. ONLY XL: The assertoric asymmetry of exponibles, in: Cormany, E., 
Ito, S., Lutz, D. (Eds.), Proceedings of Semantics and Linguistic Theory (SALT.

CLC Publications, Ithaca, pp. 198-222.

Horn, L., 1969. A presuppositional analysis of only and even, in: Proceedings Oft He Fifth Annual Meeting of the Chicago Linguistics Society. pp. 97-108.

Hurley, P., Watson, L., 2018. A concise introduction to logic (13th edition). Cengage, Boston, MA.

Kay, P., 1992. The inheritance of presuppositions. Linguist. Philos. 15, 333-379. https://doi.org/10.1007/BF00627681

Kecskes, I., 2013. Intercultural pragmatics. Oxford University Press, Oxford, UK.

Kretzmann, N., Kenny, A., Pinborg, J., 1982. The Cambridge history of later Medieval philosophy. Cambridge University Press, New York, NY.

Levinson, S., 1983. Pragmatics. Cambridge University Press, Cambridge, UK.

Lo Duca, M., 2004. Nomi di agente, in: Grossmann, M., Rainer, F. (Eds.), La Formazione Delle Parole in Italiano. Niemeyer, Tübingen, Germany, pp. 191-217.

Macagno, F., 2019. Analizzare l'argomentazione sui social media. Il caso dei tweet di Salvini. Sist. intelligenti 601-632. https://doi.org/10.1422/95091

Macagno, F., 2018. A dialectical approach to presupposition. Intercult. Pragmat. 15, 291-313. https://doi.org/10.1515/ip-2018-0008

Macagno, F., 2015. Presupposition as argumentative reasoning, in: Capone, A., Mey, J. (Eds.), Interdisciplinary Studies in Pragmatics, Culture and Society. Springer, Cham, Switzerland, pp. 465-487.

Macagno, F., 2013. Strategies of character attack. Argumentation 27, 369-401. https://doi.org/10.1007/s10503-013-9291-1

Macagno, F., Gil, B., 2021. Análise argumentativa nas redes sociais: Bolsonaro no Twitter. Uma abordagem preliminar, in: Ferreira, I., Mateus, S. (Eds.), Retórica Mediatizada- a Comunicação Persuasiva Através Dos Media. Sistema Solar e Documenta, Lisbon, Portugal.

Macagno, F., Walton, D., 2017. Interpreting straw man argumentation. The pragmatics of quotation and reporting. Springer, Amsterdam, Netherlands.

Macagno, F., Walton, D., 2014. Emotive language in argumentation. Cambridge University Press, New York, NY.

Merin, A., 1994. Algebra of elementary social acts, in: Tsohatzidis, S. (Ed.), Foundations of Speech Act Theory. Routledge, London, UK, pp. 242-272.

Reed, C., Walton, D., 2003. Applications of Argumentation Schemes, in: Hansen, H., Tindale, C., Blair, A., Johnson, R. (Eds.), Argumentation and Its Applications: Proceedings of the 4th OSSA Conference. OSSA, Windsor, Ontario.

Schiappa, E., 2003. Defining reality. Definitions and the politics of meaning. Southern Illinois University Press, Carbondale and Edwardsville, IL.

Sinclair, J., Coulthard, M., 1992. Towards an analysis of discourse, in: Coulthard, M. (Ed.), Advances in Spoken Discourse Analysis. Routledge, London, UK, pp. 1-34.

Stalnaker, R., 2002. Common ground. Linguist. Philos. 25, 701-721. https://doi.org/10.1023/A:1020867916902

Stalnaker, R., 1974. Pragmatic presuppositions, in: Munitz, M., Unger, P. (Eds.), Semantics and Philosophy. New York University Press, New York, NY, pp. 197214.

Stevenson, C., 1944. Ethics and language. Yale University Press, New Haven, CT.

Stevenson, C., 1938. Persuasive definitions. Mind 47, 331-350. https://doi.org/10.1093/mind/xlvii.187.331.

Stevenson, C., 1937. The emotive meaning of ethical terms. Mind XLVI, 14-31. https://doi.org/10.1093/mind/XLVI.181.14 
Stubbs, M., 1983. Discourse analysis: The sociolinguistic analysis of natural language. University of Chicago Press, Chicago, IL.

Stump, E., 2004. Boethius’s “De topicis differentiis.” Cornell University Press, Ithaca, IL and London, UK.

Toulmin, S., 1958. The uses of argument. Cambridge University Press, Cambridge, UK. van Eemeren, F., Grootendorst, R., 1984. Speech acts in argumentative discussions: A theoretical model for the analysis of discussions directed towards solving conflicts of opinion. Floris Publications, Dordrecht, Netherlands.

Van Rees, A., 2009. Dissociation in argumentative discussions: A pragma-dialectical perspective. Springer, Amsterdam, Netherlands.

Walton, D., 2016. Argument evaluation and evidence. Springer, Cham, Switzerland.

Walton, D., 2010. A dialogue model of belief. Argument Comput. 1, 23-46. https://doi.org/10.1080/19462160903494576

Walton, D., 2008. Informal logic: a pragmatic approach. Cambridge University Press, New York, NY.

Walton, D., 2007. The speech act of clarification in a dialogue model. Stud. Commun. Sci. 7, 165-197.

Walton, D., 2004a. Classification of fallacies of relevance. Informal Log. 24, 183-185. https://doi.org/10.22329/il.v24i1.2133

Walton, D., 2004b. Relevance in argumentation. Routledge, Amsterdam, NetherlandsPhiladelphia, PA.

Walton, D., 2002. Legal argumentation and evidence. The Pennsylvania State University Press, University Park, PA.

Walton, D., 2001. Abductive, presumptive and plausible arguments. Informal Log. 21, 141-169. https://doi.org/10.22329/il.v21i2.2241

Walton, D., 1998a. The New Dialectic. Conversational contexts of argument. University of Toronto Press, Toronto, ON.

Walton, D., 1998b. Ad hominem arguments. University of Alabama Press, Tuscaloosa, AL.

Walton, D., 1995a. Argumentation schemes for presumptive reasoning. Routledge, Mahwah, NJ.

Walton, D., 1995b. A pragmatic theory of fallacy. University of Alabama Press, Tuscaloosa, AL.

Walton, D., 1990. What is reasoning? What is an argument? J. Philos. 87, 399-419. https://doi.org/10.2307/2026735

Walton, D., 1989. Informal logic. Cambridge University Press, New York, NY.

Walton, D., 1987. Informal fallacies. John Benjamins, Amsterdam, Netherlands.

Walton, D., Krabbe, E., 1995. Commitment in dialogue. State University of New York Press, Albany, NY.

Widdowson, H.G., 1979. Explorations in applied linguistics. Oxford University Press, Oxford, UK.

Woods, J., Irvine, A.D., Walton, D., 2000. Argument: Critical thinking, logic and the fallacies. Pearson Prentice Hall, Toronto, ON. 
